Douglas Gustavo Takashi Yuba

\title{
ANÁLISE DE SISTEMAS DE PROPULSÃO E MANOBRA ALTERNATIVOS PARA AUMENTO DA MANOBRABILIDADE DE COMBOIOS FLUVIAIS
}

São Paulo

2014 
Douglas Gustavo Takashi Yuba

\section{ANÁLISE DE SISTEMAS DE PROPULSÃO E MANOBRA ALTERNATIVOS PARA AUMENTO DA MANOBRABILIDADE DE COMBOIOS FLUVIAIS}

Dissertação apresentada à Escola Politécnica da Universidade de São Paulo para obtenção do título de Mestre em Ciências.

São Paulo

2014 


\section{Douglas Gustavo Takashi Yuba}

\section{ANÁLISE DE SISTEMAS DE PROPULSÃO E MANOBRA ALTERNATIVOS PARA AUMENTO DA MANOBRABILIDADE DE COMBOIOS FLUVIAIS}

Dissertação apresentada à Escola Politécnica da Universidade de São Paulo para obtenção do título de Mestre em Ciências.

Área de Concentração:

Engenharia de Controle e Automação Mecânica

Orientador:

Prof. Dr. Eduardo Aoun Tannuri

São Paulo 
Este exemplar foi revisado e corrigido em relação à versão original, sob responsabilidade única do autor e com a anuência de seu orientador.

São Paulo, 20 de maio de 2014.

Assinatura do autor

Assinatura do orientador

Catalogação-na-publicação

Yuba, Douglas Gustavo Takashi

Análise de sistemas de propulsão e manobra alternativos para aumento da manobrabilidade de comboios fluviais / D.G.T. Yuba. -- versão corr. -- São Paulo, 2014.

$106 \mathrm{p}$.

Dissertação (Mestrado) - Escola Politécnica da Universidade de São Paulo. Departamento de Engenharia Mecatrônica e de Sistemas Mecânicos.

1.Manobrabilidade 2.Comboio fluvial I.Universidade de São Paulo. Escola Politécnica. Departamento de Engenharia Mecatrônica e de Sistemas Mecânicos Il.t. 


\section{DEDICATÓRIA}

Aos meus pais,

André e Amélia 


\section{AGRADECIMENTOS}

Gostaria de agradecer a todos que contribuíram para realização do trabalho, especialmente:

Ao Prof. Dr. Eduardo Aoun Tannuri que me auxiliou e contribui de maneira notável no desenvolvimento do trabalho, corrigindo precisamente a ortografia e conceitos. Além disso, demonstrou seus conhecimentos com bastante humildade e paciência, muito obrigado.

Aos demais professores e colegas do TPN, pelo apoio e sugestões dadas com sabedoria. Além da infraestrutura proporcionada pelo TPN.

Ao CNPq e FINEP pela bolsa de estudos concedida.

À Petrobras, em especial ao CENPES e seu programa de pós-graduação, pela concessão de tempo para dedicar ao trabalho.

Aos colegas de Petrobras, em especial: ao Allan Carré de Oliveira, que prestou valiosa ajuda para realização do trabalho; ao Mauro Costa de Oliveira e ao Vinicius Leal Ferreira Mattos que possibilitaram as vindas ã USP, além da dedicação de tempo para o trabalho.

Aos professores do Departamento de Engenharia Naval e Oceânica da EPUSP: Prof. Dr. Kazuo Nishimoto, Prof. Dr. Cláudio Mueller Sampaio e Prof. Dr. Alexandre Nicolaos Simos.

Aos colegas e amigos de Poli: Anderson Takehiro Oshiro, Felipe Ruggeri, Michel Rejani Miyasaki, Vitor Tonacio, Rafael Watai, Rodrigo Lavieri, Guilherme Feitosa Rosetti, Daniel Prata Vieira e Asdrubal N. Queiroz Filho.

À Jacqueline Taeko de Souza Hirabae pela ajuda nas revisões e paciência nesse período.

Aos meus pais André Acachi Yuba, Amélia Kyomi Sakuma Yuba e ao meu irmão Rafael Hiroshi Yuba. 


\section{RESUMO}

O presente trabalho aborda análises de sistemas de propulsão e manobra para comboios fluviais, e seus efeitos na manobrabilidade dos comboios. Analisamse o sistema de propulsão convencional (propulsor mais leme), o sistema azimutal e o equipamento de proa auxiliar combinado com cada um destes sistemas de propulsão.

Apresenta-se a modelagem matemática dos sistemas de propulsão e manobra citados, os quais serviram de base para implementação de um simulador computacional utilizado para obtenção dos resultados desta dissertação. As forças e momentos hidrodinâmicos são obtidos através do método das derivadas hidrodinâmicas para as simulações próximas à velocidade de serviço do comboio, enquanto para simulações em baixa velocidade utilizou um método semi-empírico baseado no princípio de cross-flow.

Inicialmente, efetuou-se a validação do simulador com resultados da literatura para o caso do comboio com propulsão convencional. Em seguida, o modelo foi adaptado para os demais tipos de sistemas de propulsão e manobra propostos. Os resultados obtidos mostram que há uma maior eficiência do sistema de propulsão azimutal e do equipamento na proa para manobras em baixas velocidades, o que se torna adequado sua aplicação em comboios fluvial, pois essas embarcações navegam em velocidades menores se comparadas a outros tipos de embarcações.

Palavras chave: Sistemas de propulsão, comboio fluvial, simulações de manobras, propulsor azimutal, derivadas hidrodinâmicas. 


\begin{abstract}
The present work deal with analysis of propulsion and maneuvering systems for pusher-barge system, and results on the maneuverability of convoys. It analyzes the conventional propulsion system (rudder plus propeller), the azimuth system and combined auxiliary equipment bow with each of these propulsion systems.

Presents the mathematical modeling of propulsion and maneuvering systems mentioned, which served as the basis for implementation of a computational simulator used to obtain the results of this dissertation. The hydrodynamic forces and moments are obtained by the method of hydrodynamic derivatives for simulations about service speed, while for simulations at low speed used a semi - empirical method based on the principle of cross-flow.

Initially, performed the validation of the simulation results with the literature for the case of pusher-barge system with conventional propulsion. Then the model was adapted to other types of propulsion and maneuvering systems proposed. The results show that there is a greater efficiency of azimuth propulsion system and equipment in the bow to maneuver at low speeds, which makes it suitable for application in river transport, because these vessels navigate slower speeds compared to other types of vessels.
\end{abstract}

Keywords: Propulsion devices, pusher-barge, maneuvering simulations, azimuth thruster, hydrodynamic derivatives. 


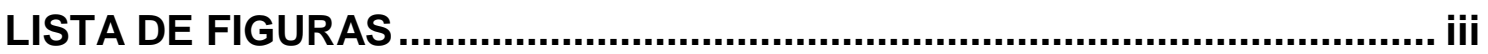

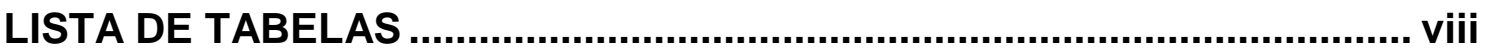

LISTA DE ABREVIAÇÕES........................................................................ ix

LISTA DE SÍMBOLOS ..................................................................................

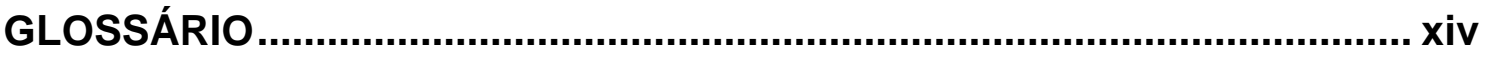

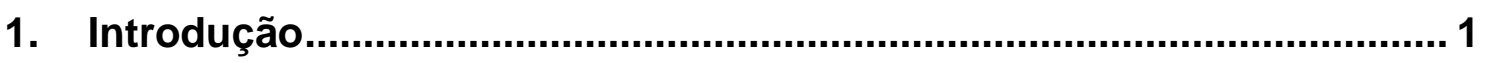

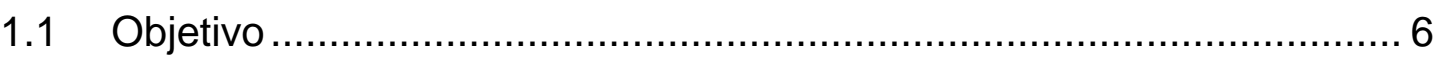

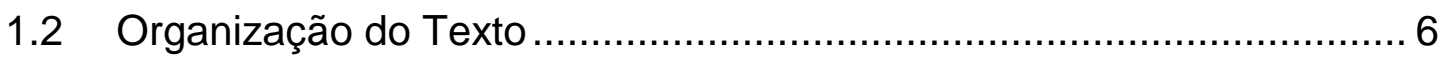

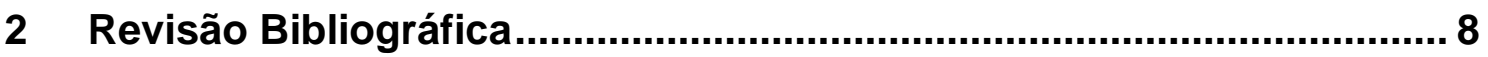

2.1 Modelos de manobra e dinâmica de comboios fluviais ......................... 8

2.2 Modelagem de esforços hidrodinâmicos ........................................... 10

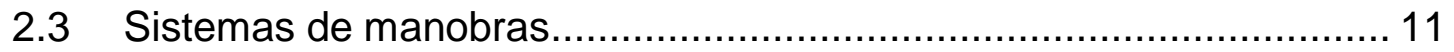

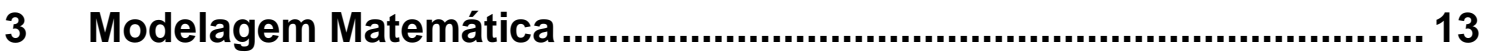

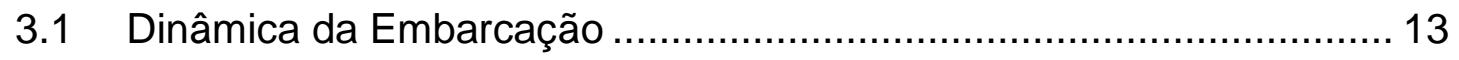

3.2 Adaptação do modelo a comboios fluviais ......................................... 21

3.2.1 Modelo dos esforços hidrodinâmicos......................................... 22

3.2.2 Modelo dos esforços hidrodinâmicos para baixas velocidades .... 23

3.2.3 Modelo dos esforços de propulsão ……………......................... 25

3.2.4 Modelo dos esforços de manobra (leme) ……............................ 26

3.3 Modelagem dos sistemas propulsores propostos ……...................... 28

3.3.1 Comboio com sistema azimutal ............................................. 29

3.3.2 Comboio com sistema convencional mais auxiliar de proa .......... 32

3.3.3 Comboio com sistema azimutal mais auxiliar de proa .................. 33

3.4 Validação do simulador desenvolvido ............................................... 34

3.4.1 Manobras simuladas................................................................... 34 


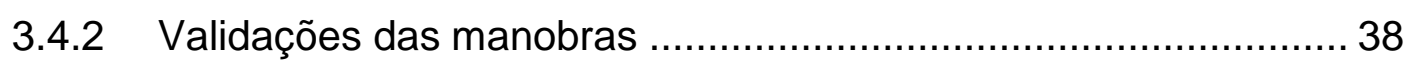

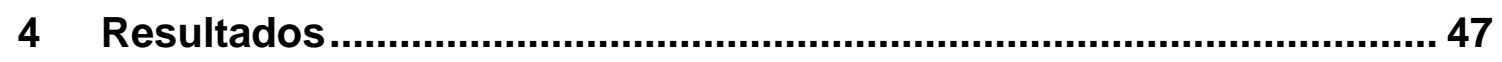

4.1 Simulações dos comboios próximas à velocidade de serviço ............ 47

4.1.2 Comparação entre sistema $\mathrm{C}$ e sistema CA ........................... 53

4.1.3 Comparação entre sistema A e sistema AA ............................ 59

4.1.4 Variação do ângulo comandado para todos os sistemas .............6 63

4.2 Simulações com as embarcações em águas rasas .........................67

4.3 Simulações com embarcações em baixa velocidade ........................ 72

4.3.1 Manobra com velocidade de 1 nó........................................... 72

4.3.2 Simulações com embarcações inicialmente paradas .................. 73

4.3.3 Análise de sensibilidade do equipamento auxiliar de proa .......... 76

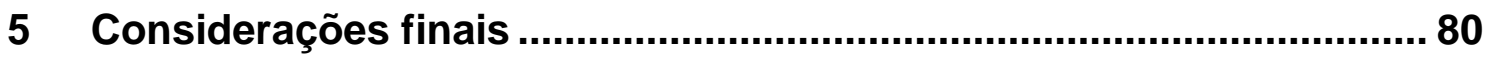

6 Referências bibliográficas........................................................ 81 


\section{LISTA DE FIGURAS}

Figura 1-1 - Eficiência energética para os diferentes modais (fonte: U.S. DOT Maritime Admin.) 1

Figura 1-2 - Comparação do custo em função da distância para os diferentes modais (extraído de AHRANA, 2010).

Figura 1-3 - Comparação na capacidade de transporte de carga para os diferentes modais (extraído de AHRANA 2010)...

Figura 1-4 - Curva do rio Parnaíba, exemplo de curva acentuada .................... 4

Figura 1-5 - Passagem de comboio fluvial por pontes................................... 5

Figura 1-6 - Passagem de comboio fluvial por eclusas ................................. 6

Figura 3-1 - Dinâmica da embarcação considerando os 6 graus de liberdade (Adaptado de Fossen, 2011) ........................................................................ 14

Figura 3-2 - Sistema de coordenadas ....................................................... 15

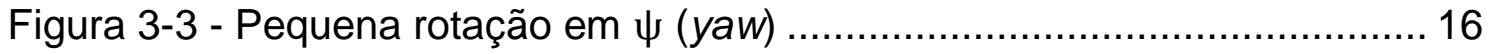

Figura 3-4 - Sistema de coordenadas para o ponto de referência $o$ …............. 17

Figura 3-5 - Sistema de coordenadas para modelo de cross-flow................... 24

Figura 3-6 - Representação do fluxo entre o propulsor e leme (adaptado de

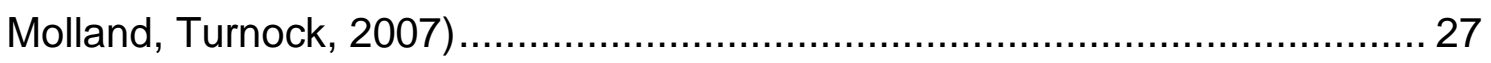

Figura 3-7 - llustração das grandezas geométricas referentes ao leme........... 28

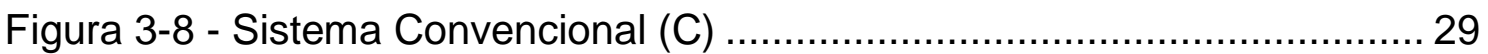

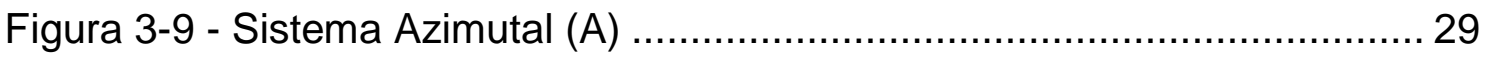

Figura 3-10 - Sistema Convencional com Equipamento Auxiliar de Proa (CA) 29

Figura 3-11 - Sistema Azimutal com Equipamento Auxiliar de Proa (AA) ........ 29

Figura 3-12 - Interação entre propulsores azimutais (extraída de Moberg;

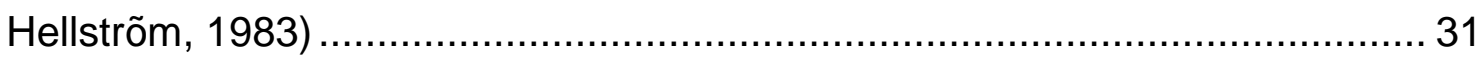

Figura 3-13 - Posição dos propulsores azimutais (extraída de Marin, 2013) ... 31 Figura 3-14 - Redução no empuxo para os propulsores azimutais (extraída de

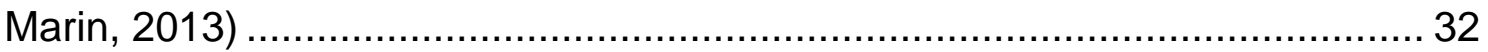

Figura 3-15 - llustração do efeito de propulsor na proa (extraída de Marin, 2013)

Figura 3-16 - Ângulo de leme e angulo do equipamento auxiliar de proa ........ 33 
Figura 3-17 - Ângulo do propulsor azimutal e do equipamento auxiliar de proa 34

Figura 3-18 - Manobra de Giro (extraída de ABS, 2006)................................. 36

Figura 3-19 - Manobra de zig-zag 10/10 (extraída de ABS, 2006) ................... 38

Figura 3-20 - Configurações de comboios propostas (adaptado de Koh et al., 2008a) 40

Figura 3-21 - Manobra de giro para $\delta=20^{\circ}$ e comboios 11BP, 12BP e 13BP: (esq.) Koh et al., (2008a); (dir.) simulador desenvolvido

Figura 3-22 - Manobra de giro para $\delta=20^{\circ}$ e comboios 21BP, 22BP e 23BP: (esq.) Koh et al., (2008a); (dir.) simulador desenvolvido

Figura 3-23 - Manobra de giro para $\delta=20^{\circ}$ e comboios 31BP, 32BP e 33BP: (esq.) Koh et al. (2008a); (dir.) simulador desenvolvido 42

Figura 3-24 - Comparação do parâmetro Avanço entre Koh et al. (2008a) e simulador desenvolvido

Figura 3-25 - Comparação do parâmetro transferência entre Koh et al. (2008a) e simulador desenvolvido

Figura 3-26 - Comparação do diâmetro tático entre Koh et al. (2008a) e

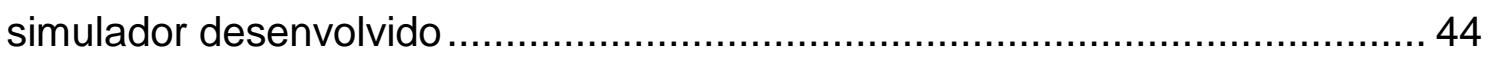

Figura 3-27 - Manobra de zig-zag 10/10 do simulador desenvolvido ............... 46

Figura 3-28 - Manobra de zig-zag 10/10 de Koh et al. (2008a) ...................... 46

Figura 4-1 - Comboios tipo Paraná e tipo Tietê (extraída de AHRANA, 2010) . 48 Figura 4-2 - Representação do empuxo total para os sistemas sem o equipamento auxiliar de proa (esq.), com equipamento auxiliar de proa com empuxo total igual a 2T (dir.) Propulsão Convencional X Propulsão Azimutal. 49 Figura 4-3 - Parâmetros da manobra de giro para sistema $C\left(\delta=20^{\circ}\right)$ e A $\left(\delta \mathrm{A}=20^{\circ}\right)$ - comboio $11 \mathrm{BP}$ 49

Figura 4-4 - Parâmetros da manobra de giro para sistema $C\left(\delta=20^{\circ}\right)$ e A $\left(\delta \mathrm{A}=20^{\circ}\right)$ - comboio 12BP 49

Figura 4-5 - Parâmetros da manobra de giro para sistema $C\left(\delta=20^{\circ}\right)$ e A $\left(\delta \mathrm{A}=20^{\circ}\right)$ - comboio 23BP 50

Figura 4-6 - Manobra de giro para sistema $C$ (esq.) e A (dir.) para U0=7nós comboio 11BP $\left(\delta=\delta \mathrm{A}=20^{\circ}\right)$ 51 
Figura 4-7 - Manobra de giro para sistema C (esq.) e A (dir.) para U0=7nós comboio 12BP $\left(\delta=\delta \mathrm{A}=20^{\circ}\right)$. 51

Figura 4-8 - Manobra de giro para sistema C (esq.) e A (dir.) para U0=7nós comboio 23BP $\left(\delta=\delta \mathrm{A}=20^{\circ}\right)$ 51

Figura 4-9 - Manobra de zig-zag 10/10 para sistema C e A - comboio 11BP .. 52 Figura 4-10 - Manobra de zig-zag 10/10 para sistema C e A - comboio 12BP 52 Figura 4-11 - Manobra de zig-zag 10/10 para sistema C e A - comboio 23BP 53 Figura 4-12 - Parâmetros da manobra de giro para sistema $C\left(\delta=20^{\circ}\right)$ e $C A$ $\left(\delta=20^{\circ} / \delta\right.$ aux $\left.=-20^{\circ}\right)$ - comboio $11 \mathrm{BP}$ 54

Figura 4-13 - Parâmetros da manobra de giro para sistema $C\left(\delta=20^{\circ}\right)$ e CA $\left(\delta=20^{\circ} /\right.$ daux $\left.=-20^{\circ}\right)$ - comboio 12BP 54

Figura 4-14 - Parâmetros da manobra de giro para sistema $C\left(\delta=20^{\circ}\right)$ e CA $\left(\delta=20^{\circ} / \delta\right.$ aux $\left.=-20^{\circ}\right)$ - comboio 23BP 55

Figura 4-15 - Manobra de giro para sistema C (esq.) e CA (dir.) para U0=7nós comboio 11BP $\left(\delta=20^{\circ} / \delta\right.$ aux $\left.=-20^{\circ}\right)$. 55

Figura 4-16 - Manobra de giro para sistema C (esq.) e CA (dir.) para U0=7nós comboio 12BP $\left(\delta=20^{\circ} / \delta\right.$ aux $\left.=-20^{\circ}\right)$. 56

Figura 4-17 - Manobra de giro para sistema C (esq.) e CA (dir.) para U0=7nós comboio 23BP $\left(\delta=20^{\circ} / \delta\right.$ aux $\left.=-20^{\circ}\right)$.. 56

Figura 4-18 - Atuação do sistema de manobra no comboio para sistema $C$ (esq.) e CA (dir.)

Figura 4-19 - Manobra de zig-zag 10/10 para sistema C e CA - comboio 11BP

Figura 4-20 - Manobra de zig-zag 10/10 para sistema C e CA - comboio 12BP

Figura 4-21 - Manobra de zig-zag 10/10 para sistema C e CA - comboio 23BP

Figura 4-22 - Parâmetros da manobra de giro para sistema $A\left(\delta A=20^{\circ}\right)$ e $A A$ $\left(\delta \mathrm{A}=20^{\circ} /\right.$ daux $\left.=-20^{\circ}\right)-$ comboio $11 \mathrm{BP}$ 59

Figura 4-23 - Parâmetros da manobra de giro para sistema $A\left(\delta A=20^{\circ}\right)$ e $A A$ $\left(\delta \mathrm{A}=20^{\circ} / \delta\right.$ aux $\left.=-20^{\circ}\right)$ - comboio 12BP 60 
Figura 4-24 - Parâmetros da manobra de giro para sistema $A\left(\delta A=20^{\circ}\right)$ e $A A$ $\left(\delta \mathrm{A}=20^{\circ} / \delta\right.$ aux $\left.=-20^{\circ}\right)$ - comboio $23 \mathrm{BP}$ 60

Figura 4-25 - Manobra de giro para sistema A (esq.) e AA (dir.) para U0=7nós comboio 11BP $\left(\delta \mathrm{A}=20^{\circ} / \delta \mathrm{aux}=-20^{\circ}\right)$

Figura 4-26 - Manobra de giro para sistema A (esq.) e AA (dir.) para U0=7nós comboio 12BP $\left(\delta \mathrm{A}=20^{\circ} / \delta \mathrm{aux}=-20^{\circ}\right)$

Figura 4-27 - Manobra de giro para sistema A (esq.) e AA (dir.) para U0=7nós comboio 23BP $\left(\delta \mathrm{A}=20^{\circ} / \delta \mathrm{aux}=-20^{\circ}\right)$

Figura 4-28 - Manobra de zig-zag 10/10 para propulsão A e AA - comboio 11BP 62

Figura 4-29 - Manobra de zig-zag 10/10 para propulsão A e AA - comboio 12BP

Figura 4-30 - Manobra de zig-zag 10/10 para propulsão A e AA - comboio 23BP

Figura 4-31 - Av para o comboio 11BP em função do ângulo comandando no sistema de manobra. 64

Figura 4-32 - DT para o comboio 11BP em função do ângulo comandando no sistema de manobra.

Figura 4-33 - Av para o comboio 12BP em função do ângulo comandando no sistema de manobra 65

Figura 4-34 - DT para o comboio 12BP em função do ângulo comandando no sistema de manobra. 65

Figura 4-35 - Av para o comboio 23BP em função do ângulo comandando no sistema de manobra 66

Figura 4-36 - DT para o comboio 23BP em função do ângulo comandando no sistema de manobra. 66

Figura 4-37 - Trajetórias das manobras de giro para os sistemas C (acima, esq.), A (acima, dir.), CA (em baixo, esq.) e AA (em baixo, dir.) em águas rasas e águas profundas - comboio 11BP 68

Figura 4-38 - Manobra de zig-zag 10/10 para propulsão C e A - comboio 11BP em águas rasas 69

Figura 4-39 - Manobra de zig-zag 10/10 para propulsão C e CA - comboio 11BP em águas rasas 
Figura 4-40 - Manobra de zig-zag 10/10 para propulsão A e AA - comboio 11BP em águas rasas 70

Figura 4-41 - Av para o comboio 11BP para águas rasas em função do ângulo comandando no sistema de manobra 71

Figura 4-42 - DT para o comboio 11BP para águas rasas em função do ângulo comandando no sistema de manobra 71

Figura 4-43 - Trajetória do comboio 12BP para os diferentes sistemas de propulsão e manobra para velocidade de 1 nó $\left(\delta=\delta \mathrm{A}=20^{\circ} / \delta\right.$ aux $\left.=-20^{\circ}\right) \ldots 72$ Figura 4-44 - Comportamento em manobra para comboio 12BP inicialmente

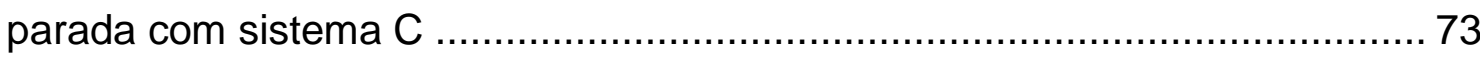

Figura 4-45 - Comportamento em manobra para comboio 12BP inicialmente

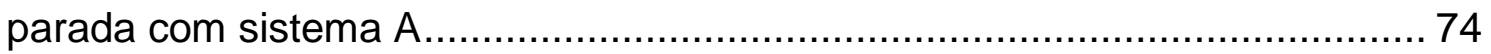
Figura 4-46 - Comportamento em manobra para comboio 12BP inicialmente

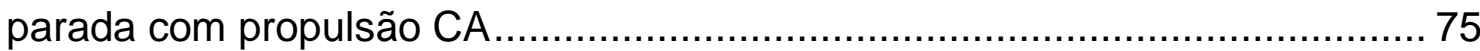

Figura 4-47 - Comportamento em manobra para comboio 12BP inicialmente

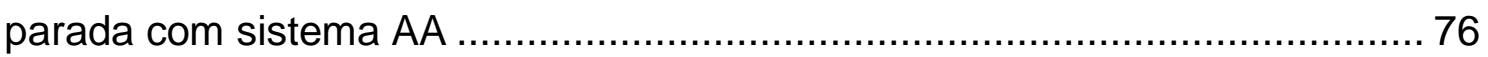

Figura 4-48 - Análise de sensibilidade do avanço para o sistema CA.............. 77

Figura 4-49 - Análise de sensibilidade do diâmetro tático para o sistema CA.. 78 Figura 4-50 - Análise de sensibilidade do avanço para o sistema AA .............. 78 Figura 4-51 - Análise de sensibilidade do diâmetro tático para o sistema AA.. 79 


\section{LISTA DE TABELAS}

Tabela 1.1- Quantidade de poluentes emitidos por km para diferentes modais (fonte: Jake Haulk, 1998) ..................................................................... 2

Tabela 3.1 - Características do empurrador (extraído de Koh et al., 2008a).... 39

Tabela 3.2 - Dados da barcaça (extraído de Koh et al., 2008a) ...................... 39

Tabela 3.3 - Dados dos comboios propostos ...................................... 40

Tabela 3.4 - Dados dos comboios propostos (continuação) .......................... 41

Tabela 3.5 - Comparação entre parâmetros da manobra de giro entre Koh et al. (2008a) e simulador desenvolvido.................................................... 43 


\section{LISTA DE ABREVIAÇÕES}

ABS

American Bureau of Shipping

AFC

Active Force Control

AHRANA

Administração da Hidrovia Tietê-Paraná

MMG

Manoeuvring Mathematical Modeling Group

PID

Proportional Integral Derivative plus

PMM

Planar Motion Mechanism 


\section{LISTA DE SÍMBOLOS}

A

AA

$A_{R}$

$A v$

$a_{H}$

C

$C A$

$C_{B}$

$C G$

$C_{1}$

$C_{x}, C_{y}, C_{n}$

$D_{P}$

$D T$

$F_{G}$

F

$F_{N}$

$f_{\alpha}$

$h$

I

$I_{Z}$

$\hat{\imath}$

$J$

$\hat{k}$

$K_{T}$

$L$

$L C B$

$l$
Sistema de propulsão e manobra azimutal

Sistema de propulsão e manobra azimutal associado ao equipamento auxiliar de proa

Área do leme

Avanço

Parâmetro de interação entre leme e casco

Sistema de propulsão e manobra Azimutal

Sistema de propulsão e manobra convencional associado ao equipamento auxiliar de proa

Coeficiente de bloco

Centro de gravidade

Fator de correção do coeficiente de esteira

Coeficientes de arrasto

Diâmetro do propulsor

Diâmetro Tático

Força no CG do navio

Força

Força normal ao leme

Gradiente do coeficiente de sustentação

Profundidade (lâmina d'água)

Inércia

Inércia no eixo $\mathrm{oz}$

Versor na direção $o x$

Coeficiente de avanço

Versor na direção oy

Versor na direção $o z$

Coeficiente de empuxo

Comprimento

Centro de carena

Distância da secção no eixo $o x$ 
$l_{P}^{\prime}$

m

$n_{P}$

$o$

$p$

$r, \dot{r}$

$R G$

$R_{G}$

$T$

$T_{A}$

$T_{P}$

$\operatorname{Tr}$

$t$

$t_{A}$

$t_{R}$

$U_{0}$

$U_{G}$

$U_{R}$

$u, \dot{u}$

$u_{R}$

$u_{p}$

$v, \dot{v}$

$v_{m}$

$v_{x}$

$X, Y, N$

$X_{A}, Y_{A}, N_{A}$

$X_{\text {aux }}, Y_{\text {aux }}, N_{\text {aux }}$
Posição efetiva entre leme e o centro de gravidade do comboio

Massa

Rotação do propulsor

Ponto de referência qualquer no navio

Passo/Diâmetro

Velocidade e aceleração de rotação do corpo em relação ao eixo $o z$

Raio de giro

Distância entre $o$ e $C G$

Calado

Empuxo do propulsor azimutal

Empuxo do propulsor convencional

Transferência

Coeficiente de redução da força propulsora ou tempo

Coeficiente de redução da força propulsora do propulsor azimutal

Fator de redução do empuxo devido ao leme

Velocidade resultante inicial antes da execução de manobra

Velocidade no $C G$ do navio

Velocidade resultante do leme

Velocidade e aceleração no eixo $o x$

Velocidade no leme no eixo ox

Velocidade no propulsor no eixo $o x$

Velocidade e aceleração no eixo $o y$

Velocidade na seção mestra no eixo $o y$

Velocidade da secção em função de $l$ no eixo $o y$

Forças e momentos externos aplicados ao $C G$ da embarcação

Forças e momentos externos aplicados ao $C G$ da embarcação devido ao propulsor azimutal

Forças e momentos externos aplicados ao $C G$ da 
embarcação devido ao equipamento auxiliar de proa

$X_{\text {ext }}, Y_{\text {ext }}, N_{\text {ext }}$

$X_{H}^{\prime}, Y_{H}^{\prime}, N_{H}^{\prime}$

$X_{\text {Hidro }}, Y_{\text {Hidro }}$,

$N_{\text {Hidro }}$

$X_{\text {Hidro_cf }}, Y_{\text {Hidro_cf }}$,

$N_{\text {Hidro_cf }}$

$X_{\text {Manob }}, Y_{\text {Manob }}$,

$N_{\text {Manob }}$

$X_{\text {Prop }}, Y_{\text {Prop }}, N_{\text {Prop }}$

$X_{\dot{u}}, Y_{\dot{v}}, N_{\dot{r}}, Y_{\dot{r}}, N_{\dot{v}}$

$X_{0}^{\prime}, X_{\beta \beta}^{\prime}, X_{\beta r}^{\prime}, X_{r r}^{\prime}, Y_{\beta}^{\prime}$,

$Y_{r}^{\prime}, Y_{\beta \beta \beta}^{\prime}, Y_{\beta \beta r}^{\prime}, N_{\beta}^{\prime}$,

$N_{r}^{\prime}, N_{\beta \beta \beta}^{\prime}, N_{\beta \beta r}^{\prime}$

w

$w_{0}$

$x_{g}$

$x_{P}$

$y_{g}$

$\alpha_{R}$

$\beta$

$\beta_{m}$

$\beta_{P}$

$\beta_{R}$

$\beta_{x}$

$\wedge$

$\vec{\Omega}$

$\vec{\mu}$

$\gamma$

$\gamma_{R}$

$\psi$
Esforços devido aos agentes ambientais externos

Coeficientes hidrodinâmicos adimensionais

Esforços devido à interação do casco com o fluido

Forças e momento calculado pelo modelo de cross-flow

Esforços devido ao sistema de manobra

Esforços devido sistema propulsivo

Massas adicionais

Derivadas hidrodinâmicas

Coeficiente de esteira

Coeficiente de esteira para o movimento de avanço

Posição de $C G$ em relação à $o$ na direção $o x$

Distância entre o leme e o propulsor

Posição de $C G$ em relação à $o$ na direção $o x$

Ângulo efetivo entre o fluxo e o leme

Ângulo de deriva

Ângulo de deriva na seção mestra

Ângulo de deriva do propulsor

Ângulo de deriva na posição do leme

Ângulo de incidência seccional relativo da corrente

Razão de aspecto

Vetor de rotação no plano horizontal

Momento da embarcação

Fator relativo à interferência casco equipamento auxiliar de proa

Coeficiente de ajuste do escoamento no leme

Ângulo de rotação do corpo em relação ao eixo $o z$ 
$\delta$

$\delta_{A}$

$\delta_{\text {aux }}$

$\nabla$

Ângulo de leme

Ângulo do propulsor azimutal

Ângulo do equipamento auxiliar de proa

Volume deslocado 


\section{GLOSSÁRIO}

$\begin{array}{ll}\text { Movimento de surge } & \text { Translação longitudinal (avanço) } \\ \text { Movimento de sway } & \text { Translação lateral (deriva) } \\ \text { Movimento de heave } & \text { Translação vertical (arfagem) } \\ \text { Movimento de pitch } & \text { Rotação (no plano vertical) em torno do eixo } \\ & \text { transversal (caturro) } \\ \text { Movimento de roll } & \text { Rotação (no plano vertical) em torno do eixo } \\ & \text { longitudinal (balaço ou jogo) } \\ \text { Movimento de yaw } & \text { Rotação no plano horizontal (guinada) }\end{array}$




\section{Introdução}

O Brasil possui mais de vinte e seis mil quilômetros de vias navegáveis, porém o transporte hidroviário ainda é pouco utilizado. Um dos motivos para esta baixa utilização é a falta de investimentos nas hidrovias, pois embora aparentem que o transporte fluvial não necessite de manutenção, as hidrovias necessitam de constante manutenção devido ao assoreamento e manutenção das eclusas, por exemplo.

Estudos mostram que o transporte por comboio fluvial apresenta menor custo por tonelagens para transporte de produtos de baixo valor agregado se comparado ao transporte terrestre como caminhões e trens para uma mesma quantidade de carga num determinado tempo.

Um fator que contribui para o alto custo no transporte dos meios terrestres é o gasto de uma quantidade maior de energia se comparado ao transporte fluvial, como mostra a Figura 1-1. Verifica-se que o transporte fluvial possui uma eficiência energética superior a $250 \%$ em relação ao transporte ferroviário e de quase $900 \%$ se comparada ao transporte rodoviário.

\section{Eficiência Energética}

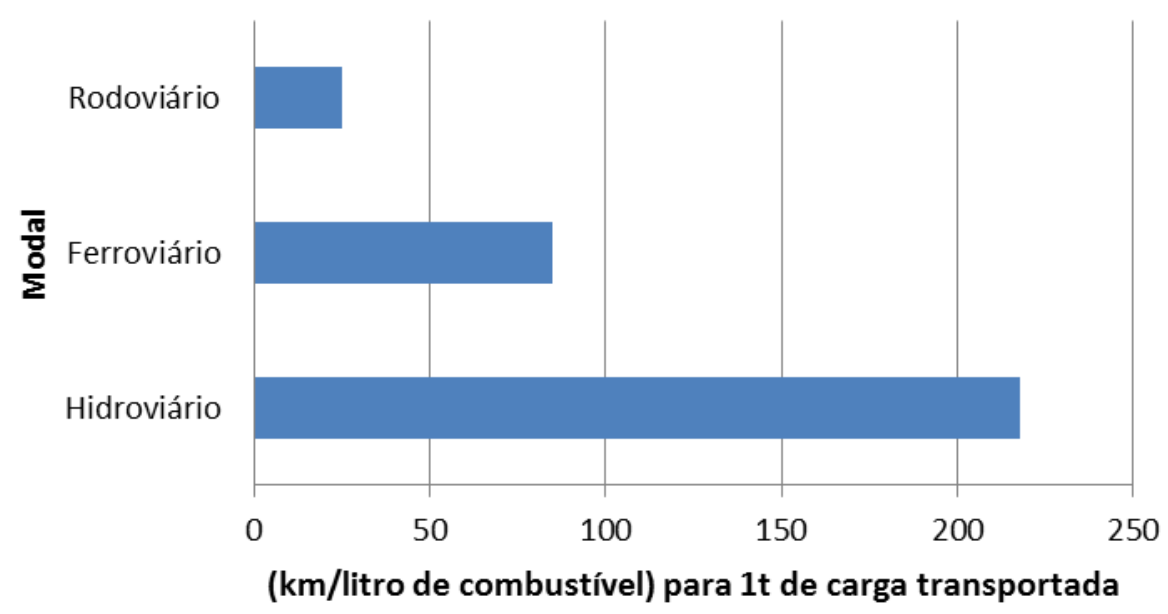

Figura 1-1 - Eficiência energética para os diferentes modais (fonte: U.S. DOT Maritime Admin.) 
Destaca-se que um maior gasto energético acarreta, além das desvantagens econômicas, uma maior emissão de poluentes ao meio ambiente. A Tabela 1.1 mostra a quantidade de poluentes emitidas ao meio ambiente para cada modal. Observa-se que o transporte rodoviário emite seis vezes mais Hidrocarbono, nove vezes mais Monóxido de Carbono e quase vinte vezes mais Óxido de Nitrogênio se comparado ao transporte rodoviário.

Tabela 1.1- Quantidade de poluentes emitidos por km para diferentes modais (fonte: Jake Haulk, 1998)

\begin{tabular}{|c|c|c|c|}
\hline \multirow{2}{*}{ Modal } & \multicolumn{3}{|c|}{ Poluente (kg de emissão por t x km) } \\
\cline { 2 - 4 } & Hidrocarbono & $\begin{array}{c}\text { Monóxido de } \\
\text { Carbono }\end{array}$ & $\begin{array}{c}\text { Oxido de } \\
\text { Nitrogênio }\end{array}$ \\
\hline Rodoviário & 0.0018 & 0.0054 & 0.0287 \\
\hline Ferroviário & 0.0013 & 0.0018 & 0.0052 \\
\hline Hidroviário & 0.0003 & 0.0006 & 0.0015 \\
\hline
\end{tabular}

A Figura 1-2 mostra o custo do transporte em função da distância para uma mesma quantidade de carga. Observa-se que o transporte rodoviário é vantajoso para distâncias de até $100 \mathrm{~km}$, a partir dessa distância até $450 \mathrm{~km}$ o transporte ferroviário tem o custo menor. Por fim, o transporte de cargas superiores a $450 \mathrm{~km}$ por meio de comboio fluviais se torna menos custoso.

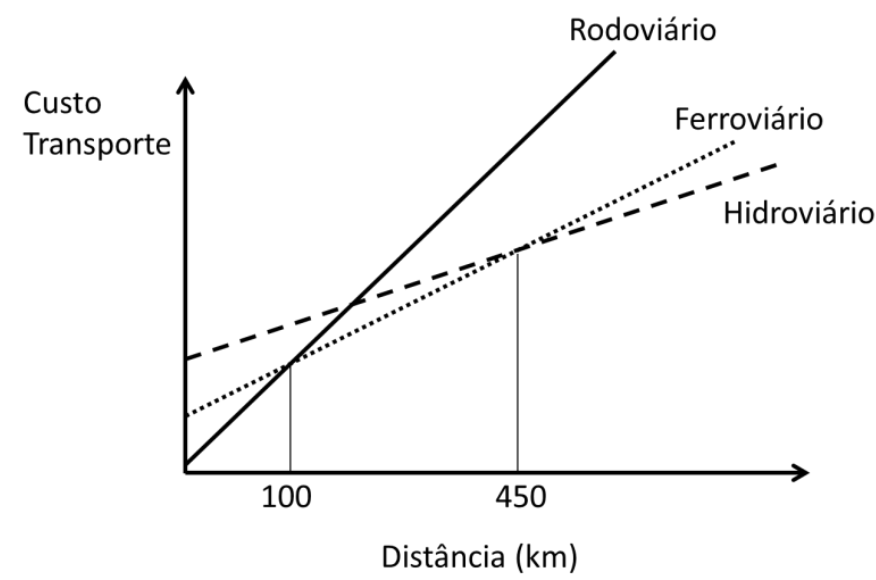

Figura 1-2 - Comparação do custo em função da distância para os diferentes modais (extraído de AHRANA, 2010) 
A Figura 1-3 faz uma comparação da capacidade de carga entre os diferentes modais, na qual se verifica que uma única barcaça transporta o equivalente a 12 vagões ou a 60 caminhões com capacidade de carga de 20 toneladas.

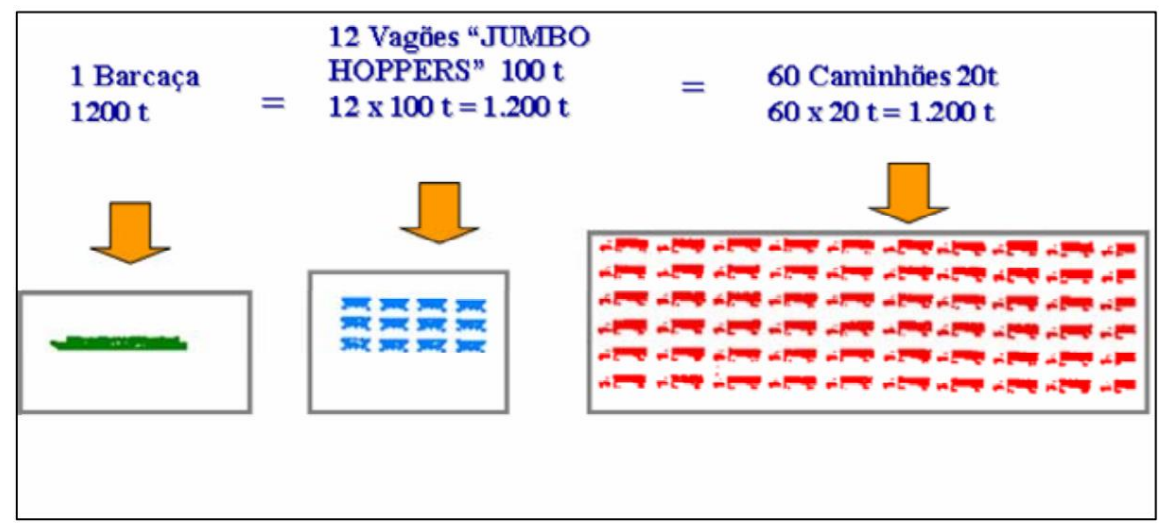

Figura 1-3 - Comparação na capacidade de transporte de carga para os diferentes modais (extraído de AHRANA 2010)

Embora os dados citados anteriormente mostrem uma ampla vantagem de transporte hidroviário em relação ao terrestre para grandes distâncias, é importante ressaltar que essas considerações são válidas para regiões nas quais a logística está adequadamente resolvida, pois o transporte hidroviário, em sua maioria, depende de uma integração eficiente com outros modais (Padovezi, 2003).

Embora haja vantagens econômicas e ambientais em favor dos comboios, ressalva-se que essas comparações seriam válidas para uma comparação perfeita onde os modais pudessem concorrer no mesmo percurso com a mesma carga transportada, fato que dificilmente ocorre.

O aumento na exportação de álcool para o mercado externo tem demandado um maior transporte desse tipo de carga, sendo o transporte hidroviário bastante requisitado, através da utilização da hidrovia Tietê-Paraná. Ressaltase que o transporte de álcool também demanda um transporte mais seguro, visto a periculosidade dessa carga (Pereira, 2007). 
Assim devido às vantagens do transporte hidroviário citadas, a tendência é uma crescente utilização desse modal e cada vez mais o comboio fluvial seja usado no transporte de cargas pelas hidrovias brasileiras. Com o intuito de torná-lo mais competitivo, há o interesse no aumento do tamanho dos comboios, com a utilização de mais barcaças por comboio, devido ao ganho em escala. Desse modo, tanto o transporte de cargas perigosas como a necessidade do aumento de barcaças por comboio são fatores que demandam a necessidade por uma navegação mais segura.

O aumento na eficiência de manobra dos comboios fluviais aumenta a segurança da navegação, principalmente no transporte de cargas de alta periculosidade. Destaca-se que os comboios são sujeitos às restrições impostas pelas hidrovias, incluindo-se curvas acentuadas (Figura 1-1), passagens por pontes com vãos estreitos (Figura 1-5) e eclusagens (Figura 1-6).

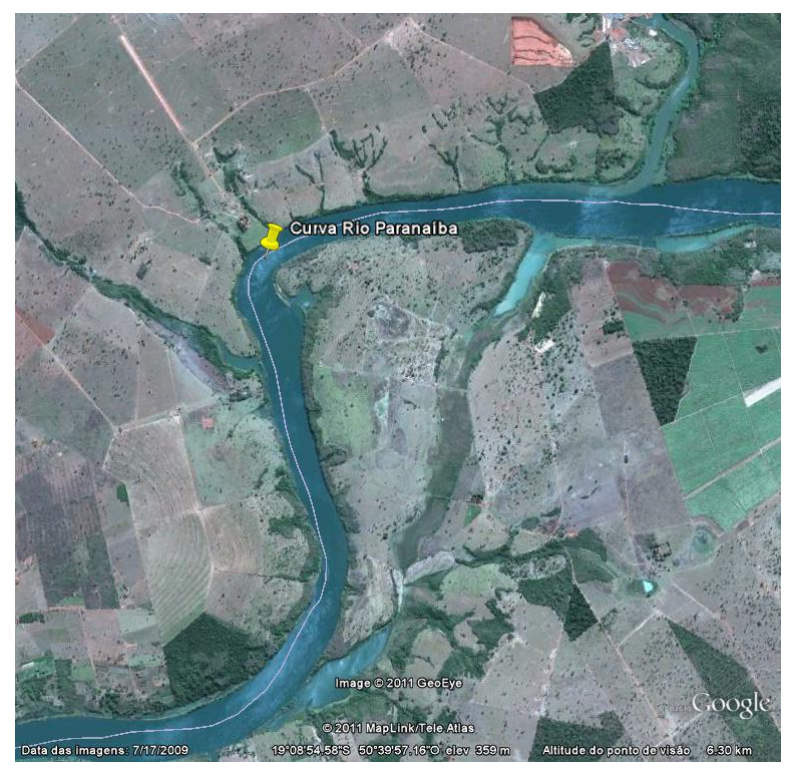

Figura 1-4 - Curva do rio Parnaíba, exemplo de curva acentuada

Assim, melhores sistemas de propulsão e manobra propiciariam ao capitão fluvial recursos para a realização de manobras em trechos curvos e sinuosos com maior segurança, diminuindo, deste modo, a ocorrência de colisões dos 
comboios fluviais com as margens do canal e com outras embarcações presentes na hidrovia.

Ademais, melhores características de manobrabilidade, como maior capacidade de execução de manobras de giro e zig-zag podem viabilizar 0 aumento do tamanho dos comboios sem comprometer a segurança da navegação.

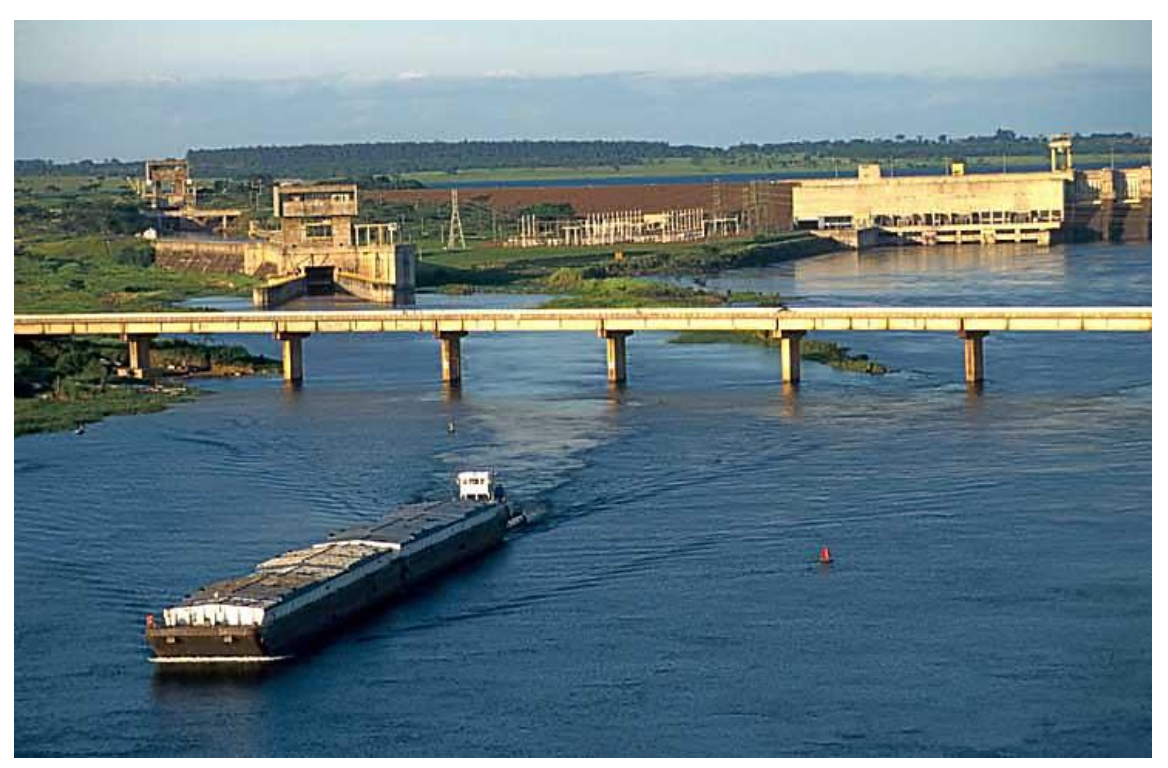

Figura 1-5 - Passagem de comboio fluvial por pontes 


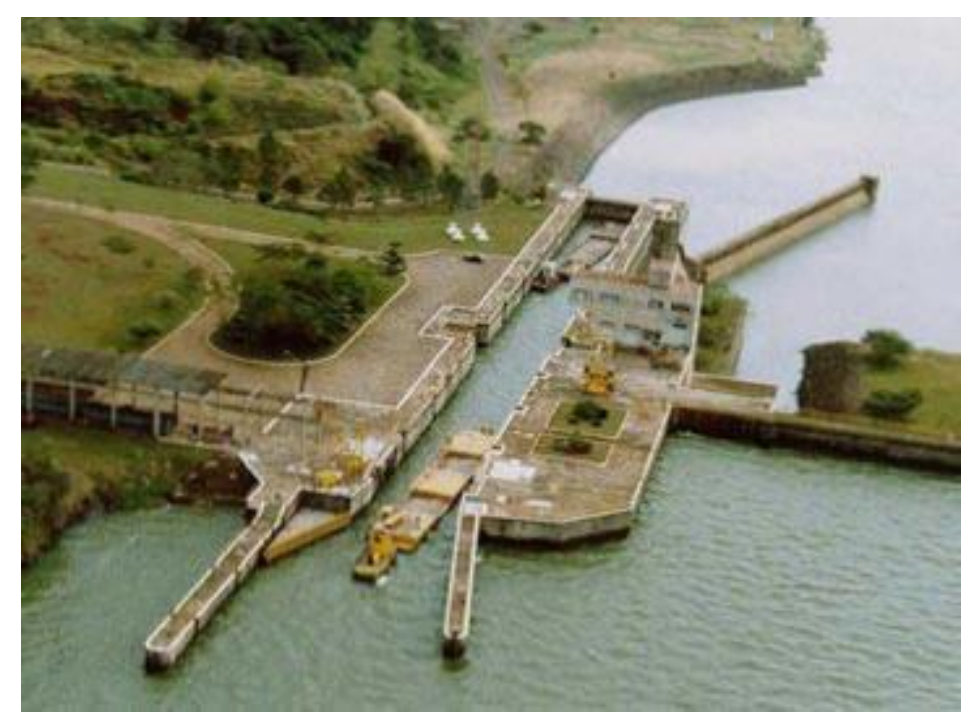

Figura 1-6 - Passagem de comboio fluvial por eclusas

\subsection{Objetivo}

Este trabalho tem como objetivo analisar o desempenho de sistemas alternativos integrados de propulsão e manobra para comboios fluviais de modo a aumentar a manobrabilidade, destacando-se o propulsor azimutal e o equipamento auxiliar de proa azimutal. $O$ trabalho se baseia em modelos da literatura adaptados aos sistemas propostos de propulsão e manobra. $O$ estudo contempla também o desenvolvimento de um simulador computacional a fim de se obterem os parâmetros de manobrabilidade dos comboios nas diversas configurações para que sejam efetuadas as comparações entre as alternativas. Destaca-se que, devido às restrições impostas pela navegação em hidrovias, a manobrabilidade de comboios fluviais costuma a ser mais crítica em relação a outros tipos de embarcações.

\subsection{Organização do Texto}

O capítulo 2 apresenta uma revisão bibliográfica de trabalhos referentes aos modelos de manobra, discutindo inicialmente a abordagem dos modelos matemáticos. Na seção 2.2 são discutidos os métodos de cálculo das forças e 
momentos hidrodinâmicos proveniente da interação casco-fluido, em seguida, analisam-se trabalhos referentes aos modelos de sistemas de propulsão e manobras na seção 2.3.

A modelagem matemática do problema é apresentada no capítulo 3 . Inicialmente é apresentada a modelagem para embarcações em geral. $\mathrm{Na}$ seção 3.2 são feitas as adaptações necessárias do modelo para comboios fluviais. A seção 3.3 apresenta os modelos dos sistemas de propulsão e manobras, iniciando pelo sistema convencional composto por propulsor mais leme, sistema com propulsor azimutal e combinações desses sistemas com 0 equipamento auxiliar de proa. Em seguida, na seção 3.4, inicia-se com uma breve explicação sobre as manobras de giro e manobras de zig-zag que foram utilizadas para comparar os sistemas, sendo então apresentadas validações do simulador computacional desenvolvido com os resultados apresentados por Koh et al. (2008a).

Após as modelagens e validações, no capítulo 4 são apresentados os resultados dos modelos comparando os sistemas de propulsão e manobra propostos: o sistema convencional (propulsor e leme), o sistema com propulsão azimutal, o sistema com propulsão convencional associado ao equipamento auxiliar de proa, e por fim o sistema com propulsão azimutal associado ao equipamento auxiliar de proa.

Por fim, o capítulo 5 apresenta as conclusões do trabalho. 


\section{Revisão Bibliográfica}

Neste capítulo são discutidos alguns trabalhos sobre manobrabilidade de embarcações, focando na área fluvial. Inicialmente, na seção 2.1 , são analisados trabalhos relacionados aos modelos de manobras e dinâmica de comboios fluviais. Na seção 2.2 são abordados trabalhos que tratam sobre métodos para cálculo das forças hidrodinâmicas que atuam sobre o casco e, por fim, na seção 2.3 são tratados os trabalhos relacionados à modelagem de sistemas de manobra e propulsão e como esses são introduzidos nos modelos de embarcação.

\subsection{Modelos de manobra e dinâmica de comboios fluviais}

Os trabalhos do grupo da Universidade de Hiroshima apresentam importantes contribuições ao estudo numérico e experimental de manobras de comboios fluviais. Yasukawa et al. (2007) realizaram ensaios cativos com 9 diferentes arranjos de comboios fluviais e obtiveram um conjunto de derivadas hidrodinâmicas para caracterizar suas forças hidrodinâmicas. Realizaram a comparação com formulações semi-empíricas para obtenção das derivadas hidrodinâmicas e verificaram que são inadequadas para o caso de comboios. Em Koh et al. (2008a) utilizam-se essas derivadas hidrodinâmicas para a realização de um estudo de simulação numérica de manobrabilidade dos comboios fluviais, através de simulações de manobras de zig-zag, giro e parada. Considerações relevantes sobre a o efeito do arranjo do comboio em sua manobrabilidade (arranjos em linhas ou colunas) são realizadas como conclusão dos resultados de simulação, como menor necessidade de potência para comboios com arranjo em linha em relação aos comboios com arranjo em coluna, enquanto que em termos de manobrabilidade os comboios com arranjos em coluna obtêm melhor desempenho. Em seguida, Koh et al. (2008b) realizaram ensaios cativos com comboios de até 8 barcaças em configurações não convencionais (arranjos não simétricos), bem como simulações de manobras. Neste trabalho, em função da assimetria do comboio bombordo- 
boreste, incluíram-se termos nas expansões das forças para obter melhor aproximação das curvas medidas, bem como termos na equação dinâmica para considerar o acoplamento entre os movimentos devido à assimetria. Finalmente, Koh e Yasukawa (2012) realizaram um estudo de um comboio com uma única barcaça sob condições de águas rasas. Realizou-se ensaio cativo (braço rotativo) com este comboio, e as derivadas obtidas em diversas condições de folga sob a quilha foram comparadas com resultados de literatura. Análises de simulação e estudo dos coeficientes de estabilidade sob condições de águas profundas e rasas também foram realizadas.

O trabalho de Maimum et al. (2011) utiliza o mesmo modelo de Koh et al. (2008a), e realiza uma análise comparativa entre a manobrabilidade prevista de comboios fluviais considerando-se a obtenção das derivadas hidrodinâmicas por métodos empíricos e experimentais, para um comboio com uma única barcaça. O método empírico consiste em fórmulas aproximadas (Kijima et al., 1990) baseada em teoria de asa corrigida por resultados de testes em condição carregada. Estas fórmulas possuem também coeficientes de correção para águas rasas. O método experimental consiste no tradicional ensaio de Mecanismo de Movimentação Planar (Planar Motion Mechanism - PMM) realizado para o comboio em análise. $O$ trabalho concluiu que há diferença significativa entre as características de manobrabilidade estimadas com cada um dos conjuntos de derivadas (empíricas e experimentais). A manobrabilidade foi analisada por simulações de manobra de zig-zag e de giro. Esse resultado reforça a necessidade de um estudo experimental específico para cada comboio para uma estimativa acurada da sua manobrabilidade.

Em Saad (2007), projeta-se um controle PID (Proportional Integral Derivative plus) mais AFC (Active Force Control) para controlar trajetórias de comboios fluviais. O autor utiliza a mesma modelagem de Maimum et al. (2011) e Koh et al.(2008a), além de apresentar o cálculo de diversos coeficientes empíricos para o cálculo das massas adicionais propostas por Hooft e Pieffers (1988). 


\subsection{Modelagem de esforços hidrodinâmicos}

As forças hidrodinâmicas atuantes sobre o casco de uma embarcação são separadas em componentes inerciais e componentes de origem viscosa. As forças de origem inerciais podem ser obtidas através da solução do problema potencial. Porém, a obtenção das forças viscosas requer a solução exata das equações de Navier-Stokes, o que é bastante custoso em termos computacionais.

Assim, como descrito em Bernitsas et al. (1999), existem dois grupos de modelos utilizados para a estimativa numérica dos componentes das forças viscosas: os modelos heurísticos e os modelos de derivadas hidrodinâmicas.

O modelo heurístico se baseia em aproximações do problema físico completo. Um exemplo é modelo de cross-flow apresentado por Obokata (1981). Nele, a força e o momento de cross-flow são estimados através da integração ao longo do comprimento do casco das forças de arrasto seccionais, considerando-se, o coeficiente de arrasto bidimensional e a velocidade lateral relativo a cada secção transversal. A estimativa do momento de yaw incorpora os efeitos de origem potencial (momento de Munk).

Outro exemplo de modelo heurístico é apresentado em Leite et al. (1998), denominado Asa Curta Estático. Neste modelo, é feita uma analogia entre uma embarcação e uma asa de pequena razão de aspecto, denominada de asa curta. Originalmente, esse modelo tratava apenas das interações relativas aos movimentos de surge e sway da embarcação, não considerando os efeitos devido ao movimento de rotação yaw. Em Simos et al. (2001) é proposta uma extensão do modelo proposto por Leite et al. (1998), no qual é utilizada a mesma base teórica do modelo estático para o cálculo das forças e momentos provenientes do movimento de rotação.

Já os modelos de derivadas hidrodinâmicas baseiam-se em resultados experimentais de ensaios de manobra de cascos, e em aproximações das forças medidas por funções dependentes de potências das variáveis de 
interesse (normalmente velocidades e acelerações). Um dos primeiros modelos desta categoria foi proposto por Abkowitz (1964), em que as forças de surge, sway e o momento de yaw são representados por uma expansão em série de Taylor de até $3^{\mathrm{a}}$ ordem. Outros modelos de manobra se basearam nesse segundo grupo como Crane (1973), Eda (1974) e Takashina (1986).

Como mencionado, os coeficientes das funções são obtidos, em geral, a partir de ensaios cativos de modelos em escala reduzida ou através de provas de mar em escala real com posterior aplicação de técnicas de identificação de sistemas. Esses coeficientes são obtidos a partir de uma faixa de velocidade, normalmente para a velocidade de serviço da embarcação, pois os coeficientes obtidos são dependentes da velocidade em que são obtidos.

No caso dos ensaios cativos, utiliza-se a imposição de movimento conhecido sobre o casco e a medição da força vincular entre o equipamento e o casco. Os ensaios mais comuns para este fim utilizam o já mencionado PMM ou o Braço Rotativo (Rotating Arm). Em ambos os casos, da força medida deve ser descontada a parcela inercial, e um tratamento matemático é feito sobre as séries temporais para a obtenção das derivadas hidrodinâmicas. Um exemplo completo deste tratamento é apresentado por Yoon (2009). Para o caso da identificação por meio de provas de mar, destaca-se o trabalho de Yoon e Rhee (2003). Este apresenta um método para obtenção das derivadas hidrodinâmicas através da aplicação de filtro de Kalman estendido, com o qual se estimam os movimentos, forças hidrodinâmicas e correnteza. Em seguida, aplica-se uma regressão para a estimativa das derivadas hidrodinâmicas. $O$ método foi validado por meio de estimativas de manobrabilidade e comparação com ensaios em escala real.

\subsection{Sistemas de manobras}

A modelagem matemática do sistema de manobras pode ser dividida em duas classes distintas. A modelagem por modelos de regressão pura e a modelagem modular (MMG - Manoeuvring Mathematical Modeling Group). Na primeira 
classe, os esforços do elemento de comando (leme e propulsor) podem ser incorporados na própria função aproximada, que passa a conter termos dependentes do ângulo de leme e suas potências, como o modelo original proposto por Abkowitz (1964) e Moolgard (2003). Esta abordagem requer, entretanto, um maior número de ensaios experimentais, pois além das velocidades do casco, há a necessidade de se variar o ângulo de leme e rotação do propulsor nos ensaios.

Na segunda classe, como a abordagem usada no caso de comboios fluviais por Koh et al. (2008a) e Saad (2007), utiliza-se a modelagem MMG, proposta por um grupo de pesquisa japonês (Ogawa, 1978 e Kose et al., 1981). Nesta abordagem, as forças hidrodinâmicas sobre o casco, o propulsor, o leme e as forças de interação são representadas por diferentes termos no modelo matemático. A vantagem desta abordagem é que permite a realização de desenvolvimentos separados para os modelos de cada componente, bem como a utilização de modelos fenomenológicos para os mesmos.

Em Tannuri et al. (2009), a modelagem dos efeitos hidrodinâmicos foram calculados pelo modelo de Asa Curta, enquanto o leme é tratado como um fólio, calculando as forças de arrasto e sustentação através dos coeficientes adimensionais de lift e drag obtidos de comboios reais e em semi escala (IPT, 2004 e 2008), além do estudo de leme de alto desempenho (leme com flap). Em Tannuri et al. (2011) é feito uma comparação de desempenho entre propulsores convencionais e azimutais, apresentando a vantagem da última em relação ao sistema convencional. 


\section{Modelagem Matemática}

Este capítulo trata sobre a modelagem matemática dos movimentos de uma embarcação, incluindo-se os esforços sofridos durante a execução de manobras.

No item 3.1 são apresentadas as equações gerais de movimento de uma embarcação, tendo como base a segunda lei de Newton para o corpo rígido sendo feita a dedução do equacionamento para o movimento do navio no plano horizontal (surge, sway e heave). Na seção 3.2, a modelagem geral da dinâmica da embarcação é então adaptada a comboios fluviais, baseando-se em Koh et al. (2008a). Mostra-se a modelagem referente aos esforços hidrodinâmicos e ao sistema de manobra e propulsão convencional.

As modelagens dos sistemas de propulsão e manobra alternativos para os comboios fluviais, a saber: propulsão azimutal, sistema de propulsão convencional com equipamento auxiliar de proa e sistema de propulsão azimutal com equipamento auxiliar de proa são esclarecidas no item 3.3 .

$\mathrm{Na}$ seção 3.4, encontram-se as validações do simulador desenvolvido para o modelo proposto por Koh et al. (2008a). Iniciando-se com uma breve descrição das manobras típicas e finalizando com os resultados e as diferenças obtidas entre os simuladores.

\subsection{Dinâmica da Embarcação}

O estudo dos movimentos de uma embarcação é divida em dois grupos (Abkowitz, 1964). O primeiro deles estuda a manobrabilidade das embarcações, em águas restritas e sua hidrodinâmica é independente das excitações de ondas. O outro grupo estuda o seakeeping, no qual a embarcação é considerada com velocidade nula ou constante, sendo necessária a incorporação das forças de onda. O foco do trabalho se concentra 
em dispositivos de propulsão e manobra, sendo assim adota-se o primeiro grupo descrito.

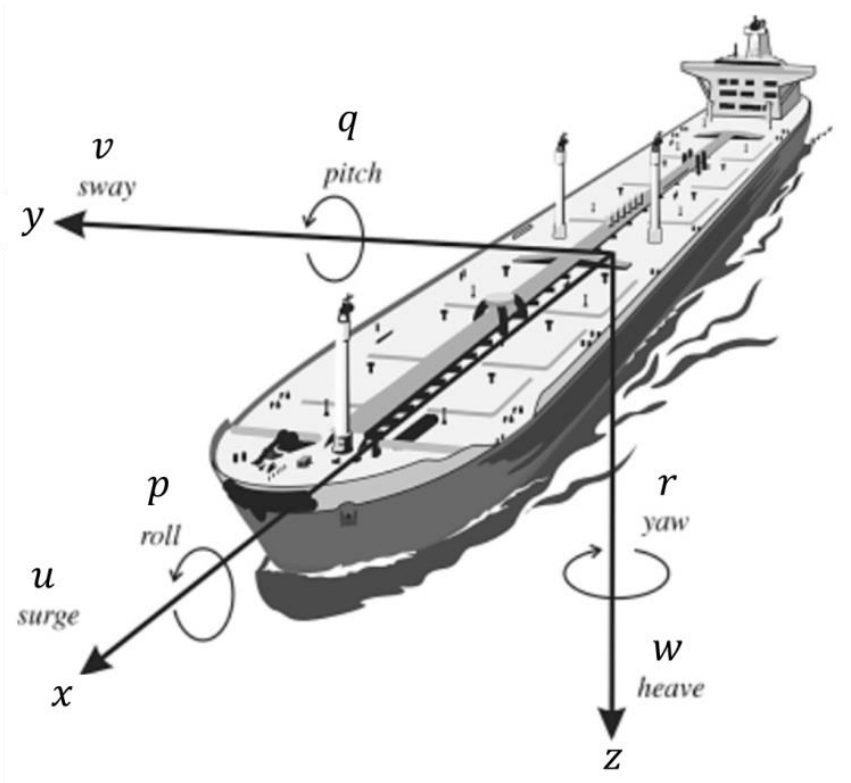

Figura 3-1 - Dinâmica da embarcação considerando os 6 graus de liberdade (Adaptado de Fossen, 2011)

Uma embarcação nas condições reais de navegação, exposta aos agentes ambientais como vento, onda e corrente, possui movimentos nos 6 graus de liberdade (Figura 3-1). Sua dinâmica pode ser obtida através das equações de Newton-Euler ou das equações de Lagrange para o corpo rígido. Adapta-se a equação do corpo rígido geral para a dinâmica de uma embarcação em manobra, considerando os graus de liberdade relacionados aos movimentos horizontais apenas: translação sobre o eixo ox (surge), translação sobre o eixo oy (sway) e rotação em torno do eixo oz (yaw). Os movimentos verticais (heave, roll, pitch) tem menor influência na análise de movimento da embarcação em manobra, desse modo não serão considerados no presente trabalho.

A Figura 3-2 mostra o sistema de coordenadas utilizado na modelagem em 3 graus de liberdade dos movimentos horizontais da embarcação, na qual são considerados dois sistemas de referências distintos. O sistema inercial $O X Y Z$ fixo à Terra, e o sistema oxyz solidário ao corpo com origem num ponto $o$ de 
referência da embarcação. As equações de movimento para o plano horizontal ${ }^{1}$ são deduzidas para ponto de referência $o$, ao invés do centro de gravidade (CG). Essa adoção do sistema de referência num ponto $o$ fornece vantagens, pois o CG no navio pode mudar de acordo com seu carregamento e, principalmente, devido a maior facilidade de obtenção das derivadas hidrodinâmicas para a seção mestra.

Considerando a mesma Figura 3-2, $u, v$ são as velocidades de translação do ponto $o$ na direção dos eixos locais, $\psi$ e $r$ são o ângulo e a velocidade de rotação do corpo em relação ao eixo $o z$ respectivamente, sendo $\psi$ usualmente conhecido como aproamento. A variável $\delta$ denota o ângulo de leme e a variável $\beta$ representa o ângulo de deriva (drift), definido como $\circ$ ângulo entre 0 aproamento da embarcação e a direção do movimento de seu ponto de interesse.

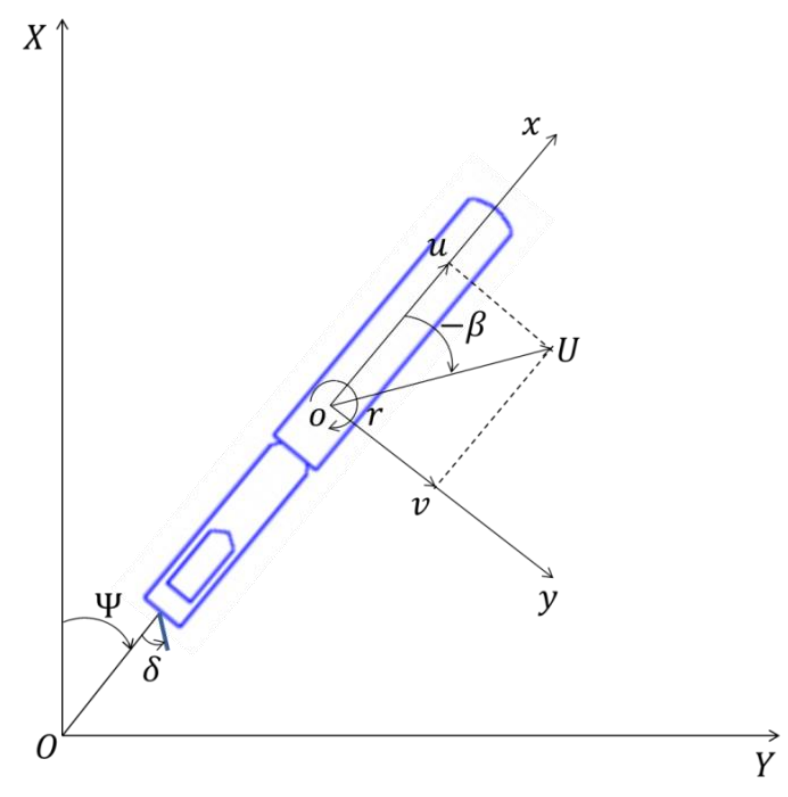

Figura 3-2 - Sistema de coordenadas

Admitindo-se a origem no $C G$ da embarcação é possível escrever a segunda lei de Newton separando as equações de força e momento. Considerando,

\footnotetext{
${ }_{1}^{1}$ Para dedução da equação de movimento para os 6 graus de liberdade, ler Abkowitz (1964)
} 
adicionalmente, que os eixos principais de inércia passam pelo CG, é possível escrever a equação das forças, como:

$\overrightarrow{F_{G}}=\frac{d}{d t}\left(m \overrightarrow{U_{G}}\right)=m \frac{d \overrightarrow{U_{G}}}{d t}+\overrightarrow{U_{G}} \frac{d m}{d t}$

onde, $\overrightarrow{U_{G}}$ é a velocidade no $\mathrm{CG}$ do navio. Como a variação de massa da embarcação decorre, principalmente, do consumo de combustível, ela pode ser considerada desprezível em relação à massa total da embarcação $\left(\frac{d m}{d t}=0\right)$, assim:

$\overrightarrow{F_{G}}=m \frac{d \overrightarrow{U_{G}}}{d t}$

Como a velocidade da embarcação em relação ao referencial inercial fixo $O X Y Z$ é:

$\overrightarrow{U_{G}}=u \hat{\imath}+v \hat{\jmath}$

A equação (3.2) pode ser escrita como:

$\overrightarrow{F_{G}}=m \frac{d}{d t}(u \hat{\imath}+v \hat{\jmath})=m\left(\frac{d u}{d t} \hat{\imath}+u \frac{d \hat{\imath}}{d t}+\frac{d v}{d t} \hat{\jmath}+v \frac{d \hat{\jmath}}{d t}\right)$

Para dedução dos termos $d \hat{\imath}$ e $d \hat{\jmath}$. Considera-se uma pequena rotação em $\psi$ (Figura 3-3), assim:

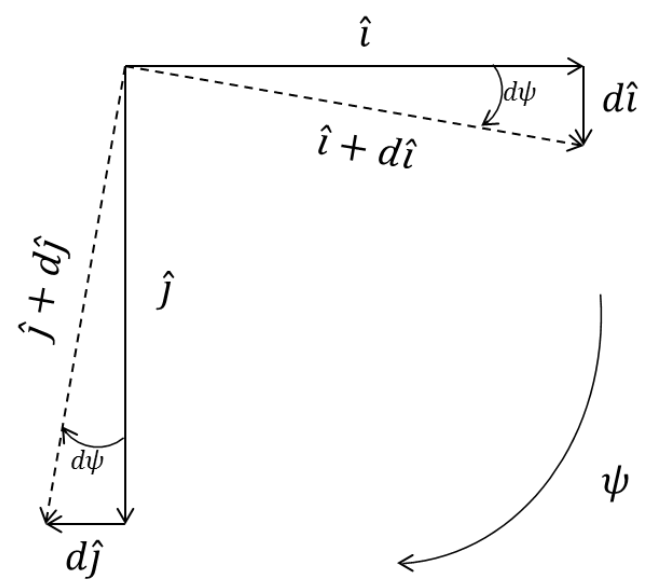

Figura 3-3 - Pequena rotação em $\psi$ (yaw) 


$$
\begin{aligned}
& d \hat{\imath}=d \psi \hat{\jmath} \rightarrow \frac{d \hat{\imath}}{d t}=\frac{d \psi}{d t} \hat{\jmath} \\
& d \hat{\jmath}=-d \psi \hat{\imath} \rightarrow \frac{d \hat{\jmath}}{d t}=-\frac{d \psi}{d t} \hat{\imath}
\end{aligned}
$$

Como $\frac{d \psi}{d t}=r$ e aplicando a relação (3.5) em (3.4):

$\overrightarrow{F_{G}}=m\left(\frac{d u}{d t} \hat{\imath}+u \frac{d \psi}{d t} \hat{\jmath}+\frac{d v}{d t} \hat{\jmath}+v \frac{d \psi}{d t} \hat{\imath}\right)=m[(\dot{u}+v r) \hat{\imath}+(u r+\dot{v}) \hat{\jmath}]$

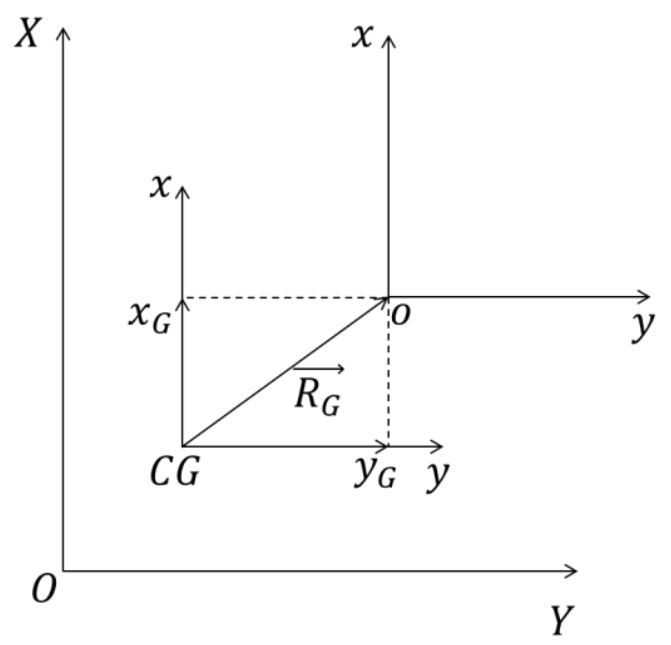

Figura 3-4 - Sistema de coordenadas para o ponto de referência $o$

Considerando um ponto de referência o qualquer no navio, com eixos de coordenadas paralelos aos eixos principais de inércia (Figura 3-4), onde o vetor distância entre o CG e o ponto de referência $o\left(\overrightarrow{R_{G}}\right)$ é representado por:

$\overrightarrow{R_{G}}=x_{g} \hat{\imath}+y_{g} \hat{\jmath}$

Onde $x_{g}$ e $y_{g}$ são posições do CG em relação a $o$ nas direções $o x$ e oy, respectivamente.

Reescreve-se a velocidade da embarcação para o ponto de referência $o$ como:

$\vec{U}=\overrightarrow{U_{G}}+\overrightarrow{R_{G}}$

onde a velocidade do vetor da distância entre o ponto de referência $o$ para 0 CG da embarcação é escrita por: 
$\dot{\overrightarrow{R_{G}}}=\frac{d \overrightarrow{R_{G}}}{d t}=\frac{d}{d t}\left(x_{g} \hat{\imath}+y_{g} \hat{\jmath}\right)=\dot{x_{g} \hat{\imath}}+x_{g} \frac{d \hat{\imath}}{d t}+\dot{y}_{g} \hat{\jmath}+y_{g} \frac{d \hat{\jmath}}{d t}$

Como $\overrightarrow{R_{G}}$ é fixo ao corpo $\left(\dot{x_{g}}=\dot{y}_{g}=0\right)$ e aplicando as relações de (3.5) em (3.9):

$\dot{\overrightarrow{R_{G}}}=y_{g} r \hat{\imath}-x_{g} r \hat{\jmath}$

Substituindo (3.8) em (3.1) tem-se:

$\vec{F}=\frac{d}{d t}\left[m\left(\overrightarrow{U_{G}}+\dot{\overrightarrow{R_{G}}}\right)\right]=m\left(\frac{d \overrightarrow{U_{G}}}{d t}+\frac{d \dot{\overrightarrow{R_{G}}}}{d t}\right)$

Onde a aceleração do vetor da distância entre o ponto de referência $o$ para 0 CG do navio é:

$\frac{d \dot{R_{G}}}{d t}=\frac{d}{d t}\left(y_{g} r \hat{\imath}-x_{g} r \hat{\jmath}\right)=y_{g}\left(\dot{r} \hat{\imath}+r \frac{d \hat{\imath}}{d t}\right)-x_{g}\left(\dot{r} \hat{\jmath}+r \frac{d \hat{\jmath}}{d t}\right)$

Assim, aplicam-se as relações (3.5) em (3.12):

$\frac{d \dot{\overrightarrow{R_{G}}}}{d t}=-\left(\dot{r} y_{g}+x_{g} r^{2}\right) \hat{\imath}+\left(\dot{r} x_{g}-y_{g} r^{2}\right) \hat{\jmath}$

Combinando (3.6), (3.11) e (3.13), tem-se a equação de força para um ponto de referência $o$ na embarcação no plano horizontal:

$\vec{F}=m\left[\left(\dot{u}-v r-\dot{r} y_{g}-x_{g} r^{2}\right) \hat{\imath}+\left(\dot{v}+u r+\dot{r} x_{g}-y_{g} r^{2}\right) \hat{\jmath}\right]$

Para demonstrar o momento no eixo oz, inicia-se com o vetor de rotação no plano horizontal (yaw):

$\vec{\Omega}=r \hat{k}$

Assumindo as mesmas hipóteses de (3.1), a equação do momento pode ser escrita como:

$\vec{\mu}=\frac{d}{d t}(I \vec{\Omega})=I \frac{d \vec{\Omega}}{d t}+\vec{\Omega} \frac{d I}{d t}$ 
Como a massa da embarcação é considerada constante no tempo, adicionalmente, assumindo o navio como corpo rígido, a distribuição de massa também pode ser considerada constante no tempo $\left(\frac{d I}{d t}=0\right)$, assim:

$\vec{\mu}=I \frac{d \vec{\Omega}}{d t}=I_{Z} \dot{r} \hat{k}$

O momento para um ponto de referência $o$ na embarcação no plano horizontal é:

$\vec{\mu}=\overrightarrow{\mu_{G}}+\overrightarrow{R_{G}} \times \vec{F}$

onde, o momento para o CG é:

$\overrightarrow{\mu_{G}}=I_{Z} \dot{r}^{\prime} \hat{k}^{\prime}$

Como os eixos coordenados são paralelos aos eixos principais de inércia $\left(\hat{k}^{\prime}=\hat{k}\right)$, permite-se o uso do teorema dos eixos paralelos para determinar $I_{Z}{ }^{\prime}$, inércia do navio no eixo oz:

$I_{Z}{ }^{\prime}=I_{Z}-m\left(x_{G}^{2}+y_{G}^{2}\right)$

E como o ponto de interesse se encontra sobre a embarcação, $\dot{r}^{\prime}=\dot{r}$. Assim:

$\overrightarrow{\mu_{G}}=I_{Z} \dot{r}-m\left(x_{G}^{2} \dot{r}+y_{G}^{2} \dot{r}\right) \hat{k}$

A segunda parcela do momento para o ponto de referência $o$ da equação (3.18) é:

$\overrightarrow{R_{G}} \times \vec{F}=$

$=\left(x_{g} \hat{\imath}+y_{g} \hat{\jmath}\right) \times m\left[\left(\dot{u}-v r-\dot{r} y_{g}-x_{g} r^{2}\right) \hat{\imath}+\left(\dot{v}+u r+\dot{r} x_{g}-y_{g} r^{2}\right) \hat{\jmath}\right]$

$\left.=m\left[x_{g} \dot{v}+x_{g} u r+\dot{r} x_{g}{ }^{2}-x_{g} y_{g} r^{2}-y_{g} \dot{u}+y_{g} v r+\dot{r} y_{g}{ }^{2}+x_{g} y_{g} r^{2}\right)\right] \hat{k}$

$=m\left[x_{g} \dot{v}+x_{g} u r+\dot{r} x_{g}{ }^{2}-y_{g} \dot{u}+y_{g} v r+\dot{r} y_{g}{ }^{2}\right] \hat{k}$

Substituindo (3.21) e (3.22) em (3.18), tem-se a equação de momento para um ponto de referência $o$ na embarcação no plano horizontal: 
$\vec{\mu}=\left[I_{z} \dot{r}+m\left(x_{g} \dot{v}+x_{g} u r-y_{g} \dot{u}+y_{g} v r\right)\right] \hat{k}$

Assim, considerando-se apenas os movimentos horizontais, deduzidos anteriormente, têm-se as equações do movimento como:

$$
\begin{aligned}
& m\left[\dot{u}-v r-x_{g} r^{2}+y_{g} \dot{r}\right]=X \\
& m\left[\dot{v}+u r-y_{g} r^{2}+x_{g} \dot{r}\right]=Y \\
& I_{z} \dot{r}+m\left[x_{g}(\dot{v}+u r)-y_{g}(\dot{u}-v r)\right]=N
\end{aligned}
$$

Incorporando as forças inerciais da água em volta do casco proporcionais à aceleração da superfície do navio (Kat, Wichers, 1991), ou seja, as massas adicionais à equação (3.24), tem-se:

$$
\begin{aligned}
& \left(m-X_{\dot{u}}\right) \dot{u}-\left(m-Y_{\dot{v}}\right) v r-\left(m-\frac{Y_{\dot{r}}+N_{\dot{v}}}{2}\right) x_{G} r^{2}-\left(m y_{G}\right) \dot{r}=X \\
& \left(m-Y_{\dot{v}}\right) \dot{v}+\left(m x_{G}-Y_{\dot{r}}\right) \dot{r}-\left(m y_{G}\right) r^{2}+\left(m-X_{\dot{u}}\right) u r=Y \\
& \left(I_{Z}-N_{\dot{r}}\right) \dot{r}-\left(m y_{G}\right) \dot{u}+\left(m x_{G}-N_{\dot{v}}\right) \dot{v}+\left(m y_{G}\right) v r+\left(Y_{\dot{v}}-X_{\dot{u}}\right) u v+ \\
& \left(m x_{G}-\frac{Y_{\dot{r}}+N_{\dot{v}}}{2}\right) u r=N \\
& \text { onde, } X_{\dot{u}}, Y_{\dot{v}}, N_{\dot{r}}, Y_{\dot{r}}, N_{\dot{v}} \text { são as massas adicionais. }
\end{aligned}
$$

Observa-se da equação (3.25) que em embarcações em movimento de manobra, a matriz de massas adicionais não pode ser considerada simétrica, pois $Y_{\dot{r}}$ e $N_{\dot{v}}$ não possuem o mesmo valor, assim Fossen (1994) propõe que os termos das massas adicionais cruzados entre $Y_{\dot{r}}$ e $N_{\dot{v}}$ seja calculada pela média dos termos.

A embarcação pode ser considerada simétrica em relação ao eixo $o x$, ou seja, $y_{G}=0$, assim a equação (3.25) simplifica para:

$$
\begin{aligned}
& \left(m-X_{\dot{u}}\right) \dot{u}-\left(m-Y_{\dot{v}}\right) v r-\left(m-\frac{Y_{\dot{r}}+N_{\dot{v}}}{2}\right) x_{G} r^{2}=X \\
& \left(m-Y_{\dot{v}}\right) \dot{v}+\left(m x_{G}-Y_{\dot{r}}\right) \dot{r}+\left(m-X_{\dot{u}}\right) u r=Y \\
& \left(I_{Z}-N_{\dot{r}}\right) \dot{r}+\left(m x_{G}-N_{\dot{v}}\right) \dot{v}+\left(Y_{\dot{v}}-X_{\dot{u}}\right) u v+\left(m x_{G}-\frac{Y_{\dot{r}}+N_{\dot{v}}}{2}\right) u r=N
\end{aligned}
$$


As forças e momentos resultantes da equação (3.26) são gerados por diferentes fenômenos e podem ser decompostos de forma genérica por (Pérez e Blanke, 2002):

$X=X_{\text {Hidro }}+X_{\text {Prop }}+X_{\text {Manob }}+X_{\text {ext }}$

$Y=Y_{\text {Hidro }}+Y_{\text {Prop }}+Y_{\text {Manob }}+Y_{\text {ext }}$

$N=N_{\text {Hidro }}+N_{\text {Prop }}+N_{\text {Manob }}+N_{\text {ext }}$

na qual o subscrito Hidro refere-se aos esforços devido à interação do casco com o fluido, Prop ao sistema propulsivo da embarcação, Manob ao sistema de manobra da embarcação e ext aos agentes ambientais externos como vento, correnteza e onda. No presente trabalho, apesar da relevância da correnteza para a navegação do comboio fluvial, os agentes ambientais não foram considerados com objetivo de simplificar a modelagem e focar nos sistemas de propulsão e manobra das embarcações. Assim $X_{\text {ext }}=Y_{\text {ext }}=N_{\text {ext }}=0$ e não são considerados nas modelagens dos demais sistemas.

\subsection{Adaptação do modelo a comboios fluviais}

Os trabalhos de Koh et al. (2008a) e Maimum et al. (2011) baseiam-se num modelo semelhante ao apresentado na seção anterior, com simplificações devido às particularidades inerentes de uma embarcação com quase-simetria proa-popa, como é o caso de comboios fluviais. Nestes trabalhos, os esforços hidrodinâmicos $\left(X_{\text {Hidro }}, Y_{\text {Hidro }}, N_{\text {Hidro }}\right)$ são calculados pelo método das derivadas hidrodinâmicas.

Os referidos trabalhos consideram o ponto de referência coincidente como CG da embarcação, ou seja, $x_{G}=0$. Neste caso, a equação do movimento é simplificada para:

$$
\begin{aligned}
& \left(m-X_{\dot{u}}\right) \dot{u}-\left(m-Y_{\dot{v}}\right) v r=X \\
& \left(m-Y_{\dot{v}}\right) \dot{v}+\left(-Y_{\dot{r}}\right) \dot{r}+\left(m-X_{\dot{u}}\right) u r=Y
\end{aligned}
$$




$$
\left(I_{Z}-N_{\dot{r}}\right) \dot{r}+\left(-N_{\dot{v}}\right) \dot{v}+\left(Y_{\dot{v}}-X_{\dot{u}}\right) u v+\left(-\frac{Y_{\dot{r}}+N_{\dot{v}}}{2}\right) u r=N
$$

Levando-se em conta que o comboio fluvial possui quase simetria proa-popa em função da pequena dimensão do empurrador comparado às chatas, podese considerar $Y_{\dot{r}}=N_{\dot{v}}=0$. Além disso, o momento de Munk $\left(Y_{\dot{v}}-X_{\dot{u}}\right) u v$ é, no modelo de King et al. (2008) é incorporado diretamente na parcela hidrodinâmica $N_{\text {Hidro }}$, resultando, portanto:

$$
\begin{aligned}
& \left(m-X_{\dot{u}}\right) \dot{u}-\left(m-Y_{\dot{v}}\right) v r=X \\
& \left(m-Y_{\dot{v}}\right) \dot{v}+\left(m-X_{\dot{u}}\right) u r=Y \\
& \left(I_{z}-N_{\dot{r}}\right) \dot{r}=N
\end{aligned}
$$

\subsubsection{Modelo dos esforços hidrodinâmicos}

As forças e momento hidrodinâmicos são calculados por:

$$
\begin{aligned}
& X_{\text {Hidro }}=\frac{1}{2} \rho L T U^{2} X_{H}^{\prime}\left(\beta_{m}, r^{\prime}\right) \\
& Y_{\text {Hidro }}=\frac{1}{2} \rho L T U^{2} Y_{H}^{\prime}\left(\beta_{m}, r^{\prime}\right) \\
& N_{\text {Hidro }}=\frac{1}{2} \rho L^{2} T U^{2} N_{H}^{\prime}\left(\beta_{m}, r^{\prime}\right)
\end{aligned}
$$

sendo $\rho$ a densidade da água, $L$ e $T$ o comprimento e calado da embarcação, respectivamente, $r^{\prime}$ a velocidade angular referente ao eixo $o z$ na forma adimensional $\left(r^{\prime}=r \frac{L}{U}\right)$ e $U$ a velocidade resultante. Esta velocidade pode ser calculada pela norma de suas componentes de seus eixos no plano horizontal:

$U=\sqrt{u^{2}+v^{2}}$

As resultantes hidrodinâmicas foram calculadas em função de coeficientes adimensionais $X_{H}^{\prime}, Y_{H}^{\prime}$ e $N_{H}^{\prime}$. Esses coeficientes normalmente são obtidos a partir de ensaios do tipo PMM ou Rotating Arm. Nestes, o modelo do navio é fixado num ponto em geral coincidente com o ponto central da seção mestra. 
Assim nas equações (3.32) e (3.33) são apresentadas as adaptações para o ângulo de deriva $(\beta)$ e para velocidade de deriva $(v)$, necessárias para 0 deslocamento do centro de massa para a seção mestra da embarcação. $O$ ângulo de deriva $\beta_{m}$ referente à meia nau da embarcação é dado por:

$\beta_{m}=\operatorname{arctg}\left(\frac{-v_{m}}{u}\right)$

sendo $v_{m}$ a velocidade referente ao eixo oy na meia nau da embarcação, que pode ser calculada por:

$v_{m}=v-x_{G} r$

Os coeficientes hidrodinâmicos adimensionais para o cálculo das forças hidrodinâmicas na embarcação foram calculados através de uma expansão de Taylor até terceira ordem para uma determinada condição nominal de velocidade de serviço, através do modelo de derivadas hidrodinâmicas modelo MMG (Kobayashi et al., 1995):

$X_{H}^{\prime}=X_{0}^{\prime} \cos ^{2} \beta_{m}+X_{\beta \beta}^{\prime} \beta_{m}^{2}+X_{\beta r}^{\prime} \beta_{m} r^{\prime}+X_{r r}^{\prime} r^{\prime 2}$

$Y_{H}^{\prime}=Y_{\beta}^{\prime} \beta_{m}+Y_{r}^{\prime} r^{\prime}+Y_{\beta \beta \beta}^{\prime} \beta_{m}^{3}+Y_{\beta \beta r}^{\prime} \beta_{m}^{2} r^{\prime}$

$N_{H}^{\prime}=N_{\beta}^{\prime} \beta_{m}+N_{r}^{\prime} r^{\prime}+N_{\beta \beta \beta}^{\prime} \beta_{m}^{3}+N_{\beta \beta r}^{\prime} \beta_{m}^{2} r^{\prime}$

Observa-se da equação (3.34) que as forças e momentos através das derivadas hidrodinâmicas foram calculadas em termos do ângulo de deriva $\left(\beta_{m}\right)$, diferente da maioria dos autores, como Fossen (1994), em que essas derivadas são calculadas em função de velocidade lateral $v$. Deve-se destacar, entretanto, que o ângulo $\beta_{m}$ é diretamente relacionado a $v_{m}$ como apresentado na expressão (3.32).

\subsubsection{Modelo dos esforços hidrodinâmicos para baixas velocidades}

Para as simulações de baixa velocidade, as derivadas hidrodinâmicas obtidas por Yasukawa et al. (2007) não são válidas, pois as derivadas são válidas para uma faixa de velocidade próxima a velocidade de serviço em que foram 
obtidas. Deste modo foi necessária a utilização do modelo de cross-flow apresentado por Obokata (1981) para o cálculo dos esforços hidrodinâmicos dessas simulações.

Neste modelo, as forças hidrodinâmicas devido à rotação em yaw do navio são calculadas integrando-se a contribuição da força de arraste de cada seção do navio, considerando-se a velocidade e o ângulo de ataque relativo de cada seção ao longo do navio (Figura 3-5).

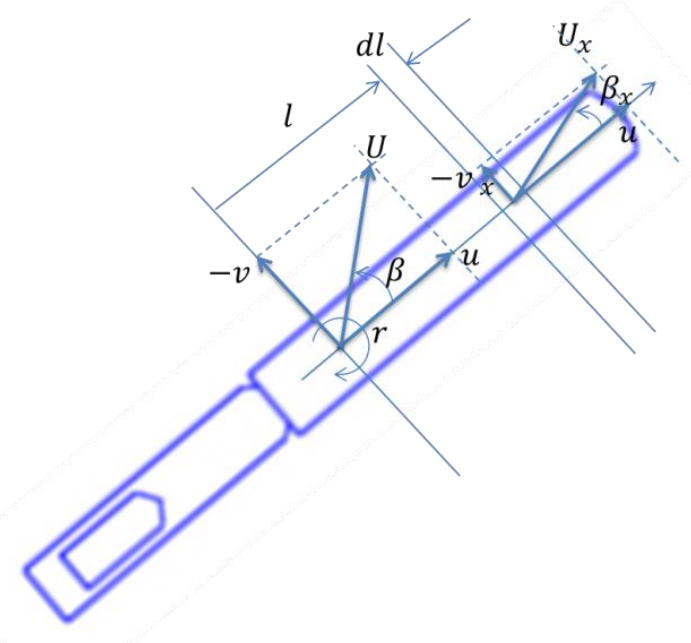

Figura 3-5 - Sistema de coordenadas para modelo de cross-flow

$$
\begin{aligned}
& X_{\text {Hidro_cf }}=\frac{1}{2} \rho L T \int_{-\frac{L}{2}}^{\frac{L}{2}}\left[C_{x}\left(\beta_{x}\right) U_{x}^{2}\right] d l \\
& Y_{\text {Hidro_cf }}=\frac{1}{2} \rho L T \int_{-\frac{L}{2}}^{\frac{L}{2}}\left[C_{y}\left(\beta_{x}\right) U_{x}^{2}\right] d l \\
& N_{\text {Hidro_cf }}=\frac{1}{2} \rho L^{2} T C_{n}(\beta) U^{2}+\frac{1}{2} \rho T \int_{-\frac{L}{2}}^{\frac{L}{2}}\left[C_{y}\left(\beta_{x}\right) U_{x}^{2}-C_{y}(\beta) U^{2}\right] l d l
\end{aligned}
$$

Onde $l$ é distância da secção no eixo ox; o subscrito Hidro_cf refere se às forças e momento calculado pelo modelo de cross-flow, $C_{x}, C_{y}$ e $C_{n}$ são os coeficientes de arrasto em função do ângulo de ataque para as forças em $o x$, 
oy e momento em $o z$, respectivamente; $\beta_{x}$ é o ângulo de incidência seccional relativo da corrente e pode ser calculado por:

$\beta_{x}=\operatorname{arctg} \frac{\left(-v_{x}\right)}{u}$

sendo $v_{x}$ a velocidade da secção em função de $l$ no eixo oy:

$-v_{x}(l)=U+r l$

Assim $U_{x}$ é a resultante da velocidade da secção:

$U_{x}=\sqrt{u^{2}+v_{x}^{2}}$

\subsubsection{Modelo dos esforços de propulsão}

A força exercida pelo propulsor pode ser representada por:

$X_{\text {Prop }}=(1-t) \sum T_{P}$

Como o propulsor, nesse caso, está fixo ao eixo longitudinal da embarcação, há apenas empuxo devido ao sistema propulsivo no eixo $O x$, de modo que não há componentes na direção lateral e nem momento de guinada resultante $\left(Y_{\text {Prop }}=N_{\text {Prop }}=0\right)$. O sinal de somatória foi incluído na expressão anterior, caso a embarcação possua mais de um propulsor (embarcações com dois eixos, por exemplo). A resistência à propulsão da embarcação é medida quando o casco é rebocado, ou seja, sem considerar a resistência ao avanço adicional causada pela operação do hélice. Na navegação com propulsão na popa, forma-se uma região de baixa pressão próxima à popa devida à ação do propulsor, aumentando a resistência do casco em relação ao valor rebocado. Esta diferença é representada pelo coeficiente de redução da força propulsora $(t)$.

O empuxo de cada propulsor representado por $T_{P}$ pode ser calculado por:

$$
T_{P}=\rho n_{P}^{2} D_{P}^{4} K_{T}(J, p)
$$


na qual $n_{P}$ representa da rotação do propulsor (em rotações por segundo), $D_{P} 0$ diâmetro do propulsor, $K_{T}$ o coeficiente de empuxo, $p$ a relação entre o passo e o diâmetro do hélice (3.41) e $J$ o coeficiente de avanço (3.42).

$p=\frac{\text { Passo }}{D_{P}}$

O coeficiente de avanço é dado por:

$J=\frac{u(1-w)}{n_{P} D_{P}}$

sendo $w$ o coeficiente de esteira. Este coeficiente representa a redução da velocidade na esteira da popa do navio, onde se localiza o propulsor, e depende do formato do casco.

\subsubsection{Modelo dos esforços de manobra (leme)}

As forças e momento devidos ao sistema de manobras, que nesse caso é o leme, podem ser calculados por:

$$
\begin{aligned}
& X_{\text {Manob }}=-\left(1-t_{R}\right) \sum F_{N} \operatorname{sen} \delta \\
& Y_{\text {Manob }}=-\left(1-a_{H}\right) \sum F_{N} \cos \delta \\
& N_{\text {Manob }}=-\left(x_{R}-a_{H} x_{H}\right) \sum F_{N} \cos \delta
\end{aligned}
$$

em que $t_{R}$ é um coeficiente experimental que incorpora a redução na resistência comparada com a componente longitudinal da força sobre o leme; $a_{H}$ é o coeficiente de força no eixo oy decorrente da perturbação do fluxo ao redor do casco sendo proporcional a força $Y_{\text {Manob }}$ do leme; $x_{H}$ denota a posição longitudinal do ponto de aplicação da força adicional devido ao casco e $x_{R}$ é a posição do leme no eixo ox. A força normal ao leme $\left(F_{N}\right)$ pode ser calculada por:

$F_{N}=\frac{1}{2} \rho A_{R} f_{\alpha} U_{R}^{2} \operatorname{sen} \alpha_{R}$ 
onde $A_{R}$ é a área do leme e $f_{\alpha}$ é o gradiente do coeficiente de sustentação (lift) do leme e é calculado em função da razão de aspecto do leme $(\Lambda)$ através da fórmula de Fujii (1961):

$f_{\alpha}(\Lambda)=\frac{6,13 \wedge}{\Lambda+2,25}$

Na equação (3.44), $U_{R}$ é a velocidade resultante no leme e pode ser calculada a partir da norma de suas componentes nas direções $O x$ e $O y$ :

$U_{R}=\sqrt{\overline{u_{R}^{2}+v_{R}^{2}}}$

A componente da velocidade sobre o leme na direção $O x$ depende do jato de água gerado pelo propulsor à montante. Pode ser obtida a partir de uma aproximação aplicando-se a conservação do momento na direção axial (Molland, Turnock, 2007), resultando na expressão abaixo:

$u_{R}=u_{p}\left[1+K_{R}\left\{\left(1+\frac{8 K_{T}}{\pi J^{2}}\right)-1\right\}\right]$

sendo $u_{p}$ a velocidade relativa na direção longitudinal na posição do propulsor e $K_{R}$ um fator de correção devido à distância entre o propulsor e o leme, dado por:

$K_{R}=0,5+0,5 /\left(1+0,15 / \frac{x_{P}}{D_{P}}\right)$

onde $x_{P}$ (Figura 3-6) é a distância entre o leme e o propulsor. Assim quando $\frac{x_{P}}{D_{P}} \cong 0, K_{R} \cong 0,5$ e quando $\frac{x_{P}}{D_{P}} \cong \infty, K_{R} \cong 1,0$.

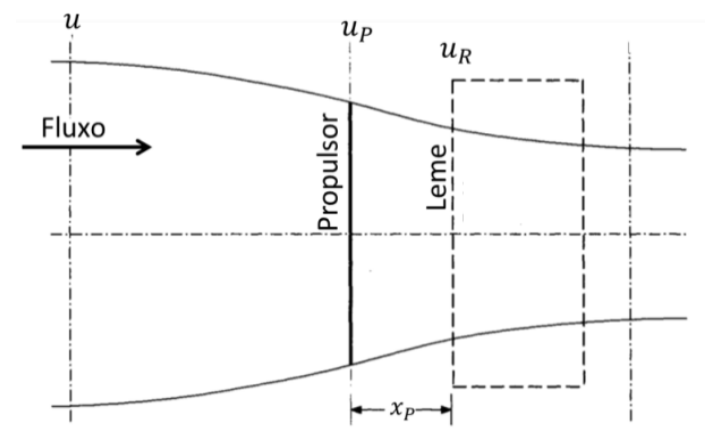

Figura 3-6 - Representação do fluxo entre o propulsor e leme (adaptado de Molland, Turnock, 2007) 
A componente da velocidade do leme na direção oy é dada por:

$v_{R}=U \gamma_{R} \beta_{R}$

onde $\beta_{R}=\beta-x_{r}$.r é o ângulo de deriva na posição do leme e $\gamma_{R}$ é o coeficiente de ajuste do escoamento no leme (flow straightening).

Finalmente, $\alpha_{R}$ é o ângulo efetivo entre o fluxo e o leme (ângulo de ataque - ver Figura 3-7), dado por:

$$
\alpha_{R}=\delta-\operatorname{arctg}\left(\frac{v_{R}}{u_{R}}\right)
$$

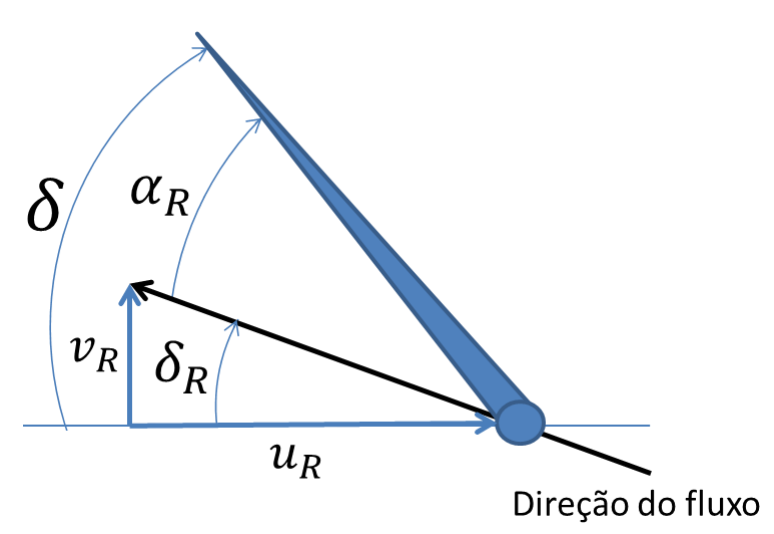

Figura 3-7 - Ilustração das grandezas geométricas referentes ao leme

\subsection{Modelagem dos sistemas propulsores propostos}

$\mathrm{Na}$ seção anterior, apresentou-se a modelagem do sistema de propulsão mais utilizado em comboios fluviais (sistema convencional, Figura 3-8), composto por propulsor e leme. Neste item são apresentados os modelos dos sistemas de propulsão alternativos propostos de serem analisados, incluindo-se 0 sistema de propulsão azimutal (Figura 3-9), sistema de propulsão convencional associado a equipamento auxiliar de proa (Figura 3-10) e sistema de propulsão azimutal associado a equipamento auxiliar de proa (Figura 3-11).

Com o objetivo de tornar melhor a leitura, os sistemas de manobras foram abreviados da seguinte maneira:

- sistema de propulsão e manobra convencional (C); 
- $\quad$ sistema de propulsão e manobra azimutal (A);

- sistema de propulsão e manobra convencional com equipamento auxiliar de proa (CA);

- sistema de propulsão e manobra azimutal com equipamento auxiliar de proa (AA).

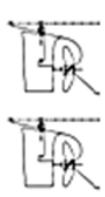

Figura 3-8 - Sistema Convencional (C)

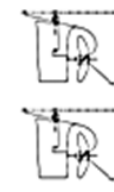

Figura 3-10 - Sistema Convencional com Equipamento Auxiliar de Proa (CA)

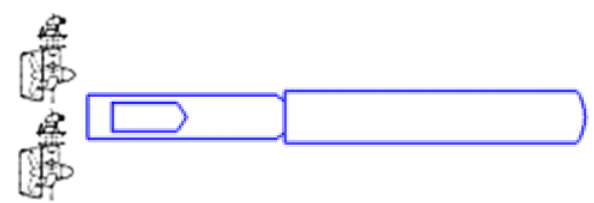

Figura 3-9 - Sistema Azimutal (A)

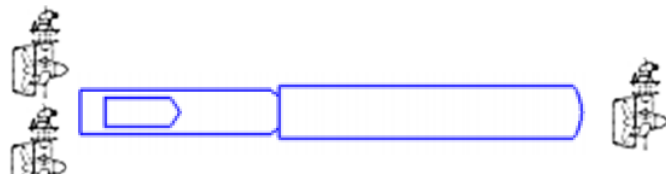

Figura 3-11 - Sistema Azimutal com Equipamento Auxiliar de Proa (AA)

\subsubsection{Comboio com sistema azimutal}

Em substituição às forças atuantes sobre o casco (3.27), para o caso de comboio com sistema de propulsão azimutal considera-se:

$X=X_{\text {Hidro }}+X_{A}$

$Y=Y_{\text {Hidro }}+Y_{A}$

$N=N_{\text {Hidro }}+N_{A}$

o subscrito $A$ relaciona-se ao propulsor azimutal, que passa tanto a realizar a ação de propelir a embarcação como gerar os esforços necessários para a execução das manobras. As forças e momento devidos ao casco ( $X_{\text {Hidro }}, Y_{\text {Hidro }}$ e $N_{\text {Hidro }}$ ) do comboio foram considerados iguais ao modelo com sistema de propulsão convencional com o objetivo de simplificar as simulações, apesar de algumas diferenças que o formato da popa do casco possuiria devido à mudança no sistema de propulsão. 
As forças e momento exercidos pelo propulsor azimutal em suas respectivas coordenadas podem ser representados por:

$X_{A}=\left(1-t_{A}\right) \sum T_{A} \cos \delta_{A}$

$Y_{A}=-\left(1-t_{A}\right) \sum T_{A} \operatorname{sen} \delta_{A}$

$N_{A}=Y_{A} x_{A}-X_{A} y_{A}$

onde $\delta_{A}$ é o ângulo comandado ao propulsor azimutal $x_{A}$ e $y_{A}$ são as posições do propulsor na coordenada $x$ e $y$, respectivamente e $t_{A}$ é o coeficiente de redução da força propulsora do propulsor azimutal.

O empuxo gerado pelo propulsor azimutal $\left(T_{A}\right)$ pode ser representado por:

$T_{A}=\rho n_{P}^{2} D_{P}^{4} K_{T}\left(J_{A}, p\right)$

Seu coeficiente de avanço $\left(J_{A}\right)$ necessita que o fluxo de entrada no propulsor azimutal seja corrigido pelo fluxo efetivo:

$J_{A}=J * \cos \alpha_{R}$

Por simplificação e com o propósito de comparação mais coerente aos sistemas de propulsão e manobras, utilizou-se o mesmo coeficiente de empuxo $\left(K_{T}\right)$ da propulsão convencional. O símbolo de somatória na expressão (3.52) considera a possibilidade da utilização de mais de um propulsor azimutal.

Considerou-se a interferência entre os propulsores azimutais para sistemas com mais de um propulsor azimutal, pois há perda de eficiência em função da distância entre eles e em função do ângulo relativo entre eles (Moberg; Hellstrõm, 1983). A Figura 3-12 mostra essa interferência em função da distância entre os propulsores e de seu ângulo relativo. Essa perda de eficiência foi considerada para os casos de manobras inicialmente paradas (item 4.3.2), em que o ângulo dos propulsores azimutais traseiros foi de $90^{\circ}$, no qual o ângulo relativo entre os propulsores $(\varphi)$ é igual a $0^{\circ} \mathrm{e}$ a distância relativa entre eles é de 3 diâmetros. Em Marin (2013) também foram calculados através de CFD a perda de eficiência causada pela interferência entre propulsores 
azimutais próximos posicionados conforme Figura 3-13. A redução no empuxo em função do ângulo relativo entre esses propulsores considerada no presente modelo é mostrada conforme Figura 3-14.

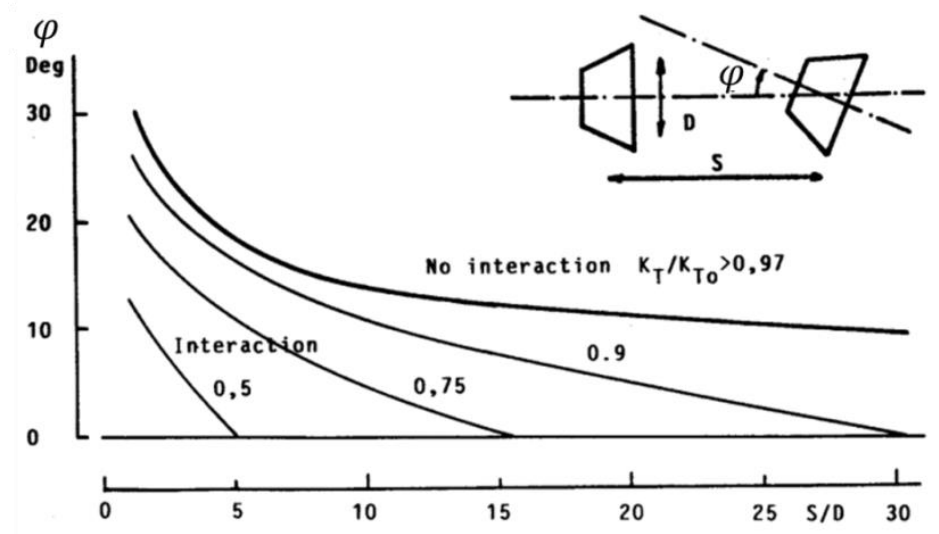

Figura 3-12 - Interação entre propulsores azimutais (extraída de Moberg; Hellstrõm, 1983)

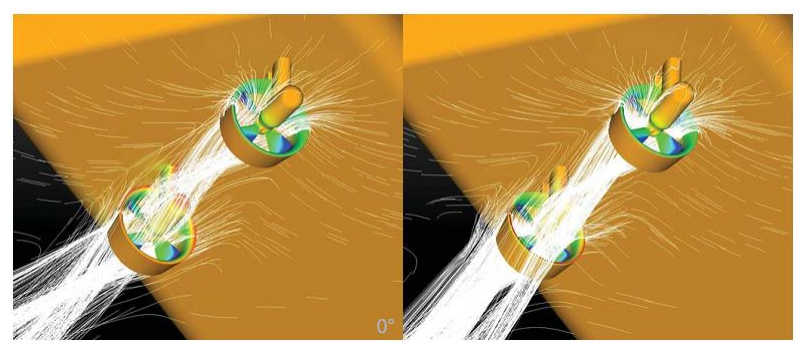

Figura 3-13 - Posição dos propulsores azimutais (extraída de Marin, 2013) 


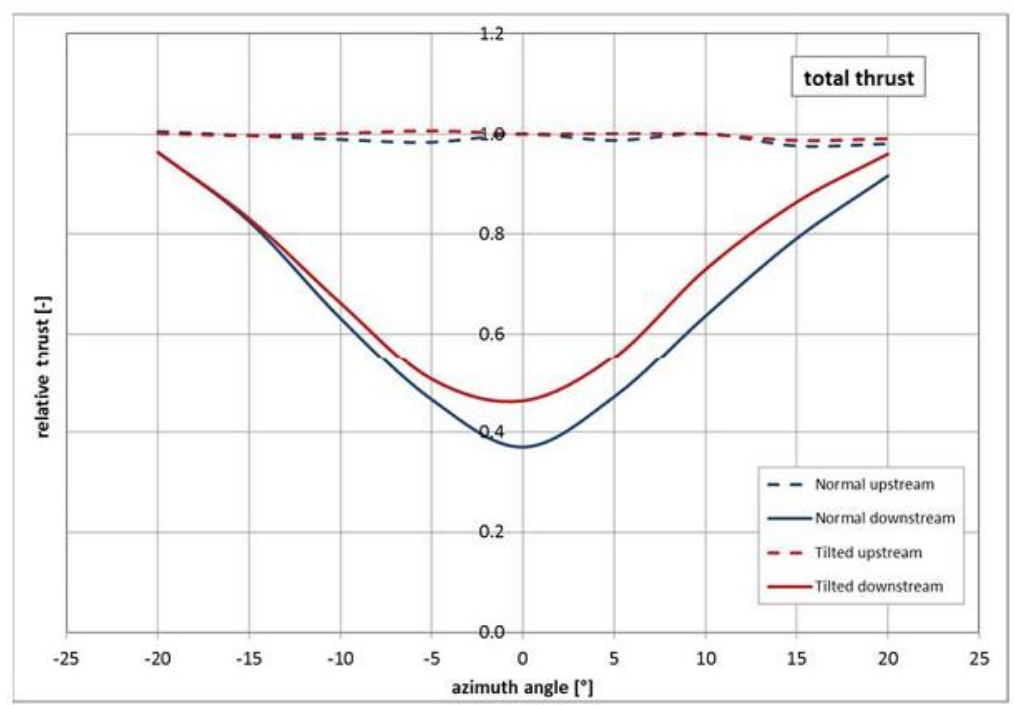

Figura 3-14 - Redução no empuxo para os propulsores azimutais (extraída de Marin, 2013)

\subsubsection{Comboio com sistema convencional mais auxiliar de proa}

As forças e momento resultantes para o comboio com sistema de propulsão convencional com equipamento auxiliar de proa podem ser representados por:

$X=X_{\text {Hidro }}+X_{\text {Prop }}+X_{\text {Manob }}+X_{\text {aux }}$

$Y=Y_{\text {Hidro }}+Y_{\text {Prop }}+Y_{\text {Manob }}+Y_{\text {aux }}$

$N=N_{\text {Hidro }}+N_{\text {Prop }}+N_{\text {Manob }}+N_{\text {aux }}$

Nas quais as forças e momentos devido ao sistema auxiliar (subscrito aux) são representados por:

$X_{\text {aux }}=\gamma T_{\text {aux }} \cos \delta_{\text {aux }}$

$Y_{\text {aux }}=-\gamma T_{\text {aux }} \operatorname{sen} \delta_{\text {aux }}$

$N_{\text {aux }}=Y_{\text {aux }} x_{\text {aux }}-X_{\text {aux }} y_{\text {aux }}$

onde $\delta_{a u x}$ é o ângulo do propulsor azimutal instalado na proa do comboio, $T_{a u x}$ é o empuxo fornecido pelo propulsor e modelou-se como o sistema azimutal. Foi utilizada a mesma curva de $K_{T}$ da propulsão convencional. $O$ fator $\gamma$ é relativo à interferência casco propulsor e foi adotado no presente trabalho 0 valor de 0,85 , baseado em medições de um caso similar apresentado em 
Marin, 2013. Este propulsor está localizado na proa da embarcação, e em grande parte do tempo o jato de água gerado pelo mesmo será direcionado ao plano da quilha da embarcação, percorrendo toda a mesma (como ilustra a Figura 3-15). A fricção deste jato de água com o casco gera uma força no sentido contrário à do propulsor, reduzindo, portanto, o empuxo líquido gerado. A resistência adicional gerada pela presença do propulsor auxiliar ao casco não foi considerada de modo a simplificar a modelagem.

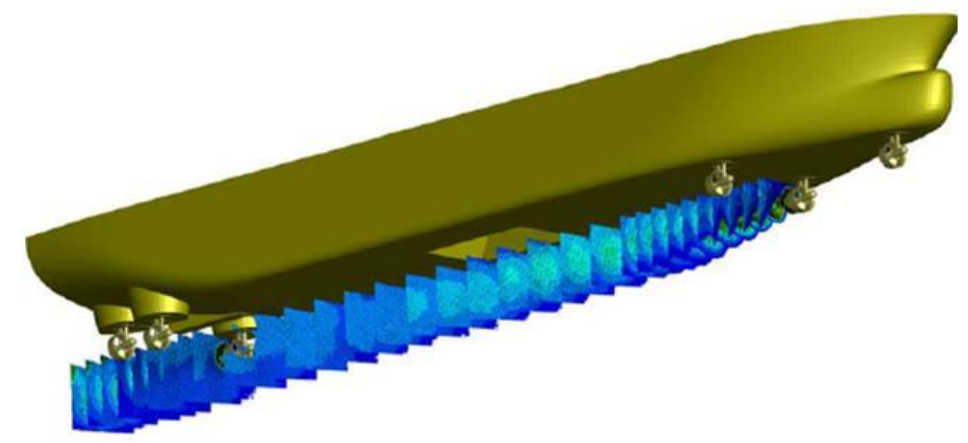

Figura 3-15 - Ilustração do efeito de propulsor na proa (extraída de Marin, 2013)

O sinal do ângulo do sistema de propulsão auxiliar foi definido como sendo contrário ao ângulo de leme, de modo a não gerar um momento contrário às manobras (Figura 3-16):

sinal de $\delta_{\text {aux }}=-$ sinal de $\delta$

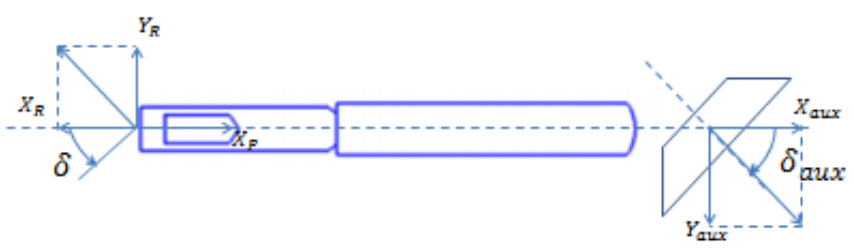

Figura 3-16 - Ângulo de leme e angulo do equipamento auxiliar de proa

\subsubsection{Comboio com sistema azimutal mais auxiliar de proa}

As forças e momento resultantes para o comboio com o sistema azimutal mais o equipamento auxiliar de proa são representados por: 
$X=X_{\text {Hidro }}+X_{A}+X_{\text {aux }}$

$Y=Y_{\text {Hidro }}+Y_{A}+Y_{\text {aux }}$

$N=N_{\text {Hidro }}+N_{A}+N_{\text {aux }}$

A expressão para o cálculo dos esforços dos propulsores azimutais de popa é dada por (3.52) e do propulsor auxiliar é dada em (3.56).

Da mesma forma que o caso anterior, o sinal do ângulo do sistema de propulsão auxiliar foi definido como sendo o contrário do ângulo do sistema de propulsão azimutal, de modo a ajudar nas manobras (Figura 3-17):

sinal de $\delta_{a u x}=-$ sinal de $\delta_{A}$

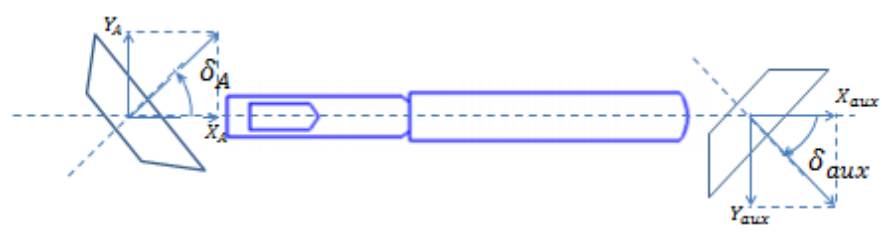

Figura 3-17 - Ângulo do propulsor azimutal e do equipamento auxiliar de proa

\subsection{Validação do simulador desenvolvido}

Nesta seção será apresentada a validação do simulador desenvolvido pela modelagem proposta no item 3.2, comparando-se com os resultados obtidos com o trabalho de Koh et al. (2008a), também oriundos de simulação numérica, permitindo assim a implementação dos sistemas alternativos propostos no simulador.

Inicialmente é apresentada uma breve descrição das manobras utilizadas na validação baseadas em ABS (2006), em seguida, no item 3.4.2 são apresentados os resultados da comparação e suas respectivas discussões.

\subsubsection{Manobras simuladas}




\subsubsection{Manobra de giro}

A manobra de giro avalia a capacidade de uma embarcação executar uma curva numa velocidade previamente estabelecida, avaliando, desse modo, a eficiência de seu sistema de manobra. Na manobra, parte-se do navio em velocidade constante, em linha reta, e com ângulo de leme nulo $\left(\delta=0^{\circ}\right)$. Em seguida, comanda-se, geralmente, o maior ângulo de leme que a embarcação consegue executar e são medidos os seguintes parâmetros (Figura 3-18):

- Avanço: distância longitudinal para uma mudança de aproamento de $90^{\circ}$.

- Transferência: distância transversal para uma mudança de aproamento de $90^{\circ}$.

- Diâmetro tático: distância transversal para uma mudança de aproamento de $180^{\circ}$.

- Raio de giro: a partir do momento que o ângulo de leme atinge o ângulo comandado, é calculada a distância ao centro de rotação da manobra de giro. 


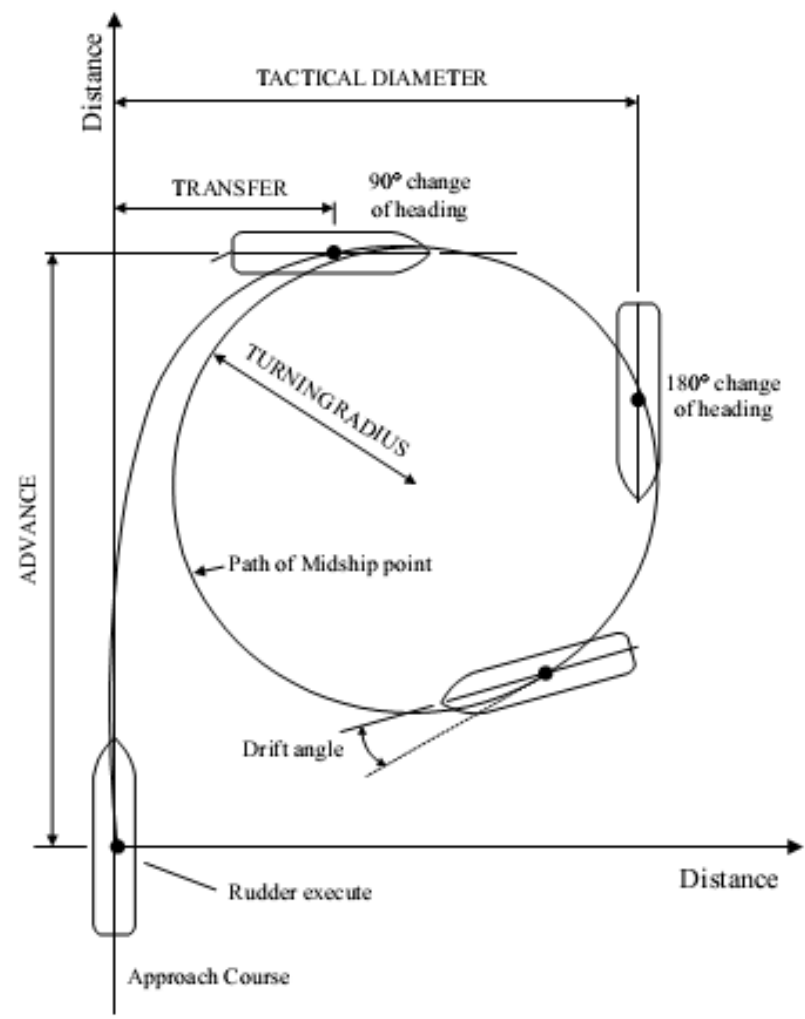

Figura 3-18 - Manobra de Giro (extraída de ABS, 2006)

Utilizam-se abreviações referentes aos parâmetros das manobras de giro de modo a facilitar a leitura do presente trabalho:

- $\operatorname{avanço~}(\mathrm{Av})$;

- transferência (Tr);

- diâmetro tático (DT);

- raio de giro $(R G)$.

\subsubsection{Manobra de zig-zag}

Outra manobra importante para medição do sistema de manobra de uma embarcação é a manobra de zig-zag, pois raramente o navio executa mudanças de direção da ordem de $90^{\circ}$ ou $180^{\circ}$. Mudanças mais frequentes são da ordem de $10^{\circ}, 20^{\circ}$ ou $30^{\circ}$. Por outro lado, numa emergência, por exemplo, quando uma colisão é iminente, o fator crítico é a resposta inicial do navio ao 
momento do leme. Infelizmente, o procedimento da curva de giro não define adequadamente essa resposta inicial, e os valores do avanço e da transferência para mudanças de direção de 90 graus, e o diâmetro tático, normalmente, são pouco afetados por fatores que tem influência significativa na resposta inicial do leme.

A manobra de zig-zag consiste em medir a capacidade de uma embarcação mudar seu aproamento a partir de um aproamento inicial inverso. Ela é executada da seguinte forma (Figura 3-19):

- inicia-se com uma velocidade previamente estabelecida e movimento apenas de avanço;

- comanda-se certo ângulo de leme;

- quando o aproamento da embarcação alcança o mesmo ângulo de leme é comandado um ângulo de leme inverso ao ângulo inicial;

- quando o aproamento da embarcação atinge este novo ângulo inverso é comandado novamente o ângulo de leme inicial.

Nesta manobra é calculado o parâmetro de sobressinal ou sobretiro (overshoot), correspondente a quantos graus o aproamento ultrapassa após 0 comando do ângulo de leme ter sido invertido. São medidos os sobressinais na primeira (first overshoot angle) e na segunda (second overshoot angle) inversão de leme. O tempo para inverter a taxa de guinada (Time to check yaw) também é medido. A Figura 3-19 mostra um exemplo da manobra de zig-zag $10 / 10$. 


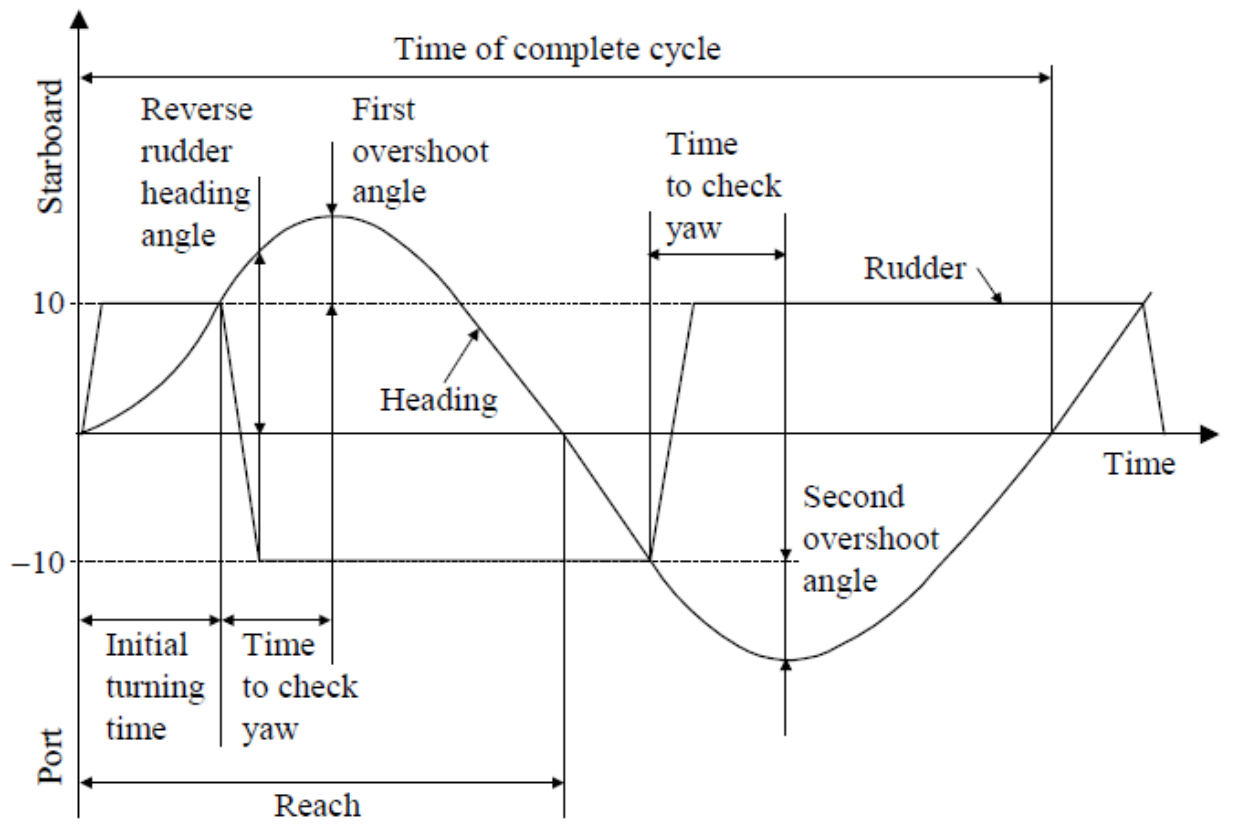

Figura 3-19 - Manobra de zig-zag 10/10 (extraída de ABS, 2006)

\subsubsection{Validações das manobras}

As características gerais do empurrador e das barcaças são apresentadas nas Tabela 3.1 e Tabela 3.2, respectivamente.

No presente trabalho, adotou-se o coeficiente de empuxo dado pela expressão polinomial abaixo, extraída de (Koh et al., 2008a). Este representa um hélice de diâmetro pequeno, típico de propulsores para navegação fluvial, pois devido à baixa profundidade dos rios há necessidade da utilização de um hélice com essa característica.

$K_{T}(J, p)=-0.3260 p J-0.2005 J+0.5234 p-0.0398$

Koh et al. (2008a) calcula o coeficiente de esteira $(w)$ por Hirano (1980):

$w=\frac{w_{0} e^{C_{1} \beta_{P}^{2}}}{n_{P} D_{P}}$ 
onde, $w_{0}$ é coeficiente de esteira para o movimento de avanço, $C_{1}$, o fator de correção e $\beta_{P}$ é o ângulo de deriva do propulsor, calculador por:

$\beta_{P}=\beta-l^{\prime} r^{\prime}$

sendo $l_{P}^{\prime}$ a distância entre o propulsor e o CG do comboio adimensionalisada pelo seu comprimento.

Tabela 3.1 - Características do empurrador (extraído de Koh et al., 2008a)

\begin{tabular}{|l|c|}
\hline Comprimento $(L)$ & $40,00 \mathrm{~m}$ \\
\hline Boca $(B)$ & $9,00 \mathrm{~m}$ \\
\hline Calado $(T)$ & $2,20 \mathrm{~m}$ \\
\hline Volume $(\nabla)$ & $494,70 \mathrm{~m}^{3}$ \\
\hline Centro de carena $(L C B)$ & $21,98 \mathrm{~m}$ \\
\hline Coeficiente de bloco $\left(C_{B}\right)$ & 0,63 \\
\hline Diâmetro do propulsor $\left(D_{P}\right)$ & $1,8 \mathrm{~m}$ \\
\hline Área do leme $\left(A_{R}\right)$ & $4 \mathrm{~m}^{2}$ \\
\hline Passo/Diâmetro $(p)$ & 0.8 \\
\hline Coeficiente de redução da força propulsora $(t)$ & 0,164 \\
\hline Fator de redução do empuxo devido ao leme $\left(t_{R}\right)$ & 0,055 \\
\hline Parâmetro de interação entre leme e casco $\left(a_{H}\right)$ & 0,194 \\
\hline Razão de aspecto $(\Lambda)$ & $-0,427$ \\
\hline $\begin{array}{l}\text { Razão da posição efetiva entre leme e CG do } \\
\text { comboio }\left(l^{\prime}{ }_{P}\right)\end{array}$ & $-1,033$ \\
\hline Coeficiente de ajuste do escoamento no leme $\left(\gamma_{R}\right)$ & 0,23 \\
\hline $\begin{array}{l}\text { Coeficiente de esteira para o movimento de } \\
\text { avanço }\left(w_{0}\right)\end{array}$ & 0,34 \\
\hline Fator de correção do coeficiente de esteira $\left(C_{1}\right)^{*}$ & 0,2 \\
\hline
\end{tabular}

$\left.{ }^{*}{ }^{*}\right)$ dado não fornecido no trabalho de Koh et al. (2008a), estimado para as presentes simulações.

Tabela 3.2 - Dados da barcaça (extraído de Koh et al., 2008a)

\begin{tabular}{|l|c|}
\hline Comprimento $(L)$ & $60,96 \mathrm{~m}$ \\
\hline Boca $(B)$ & $10,67 \mathrm{~m}$ \\
\hline Calado $(T)$ & $2,74 \mathrm{~m}$ \\
\hline Volume $(\nabla)$ & $1707,60 \mathrm{~m}^{3}$ \\
\hline Centro de carena $(L C B)$ & $30,48 \mathrm{~m}$ \\
\hline Coeficiente de bloco $\left(C_{\mathrm{B}}\right)$ & 0,96 \\
\hline
\end{tabular}

$\mathrm{Na}$ Figura 3-20 são apresentadas as configurações de comboios fluviais propostas em Koh et al. (2008a). Utilizaram-se as mesmas configurações nas simulações com o propósito dos resultados obtidos fossem passíveis de 
comparação. Manteve-se, também, a mesma nomenclatura "ijBP”, onde $i$ indica a quantidade de barcaças paralelas e $j$ indica a quantidade de barcaças em fila. "BP" são abreviações da língua inglesa Barge de barcaça e Pusher de empurrador.

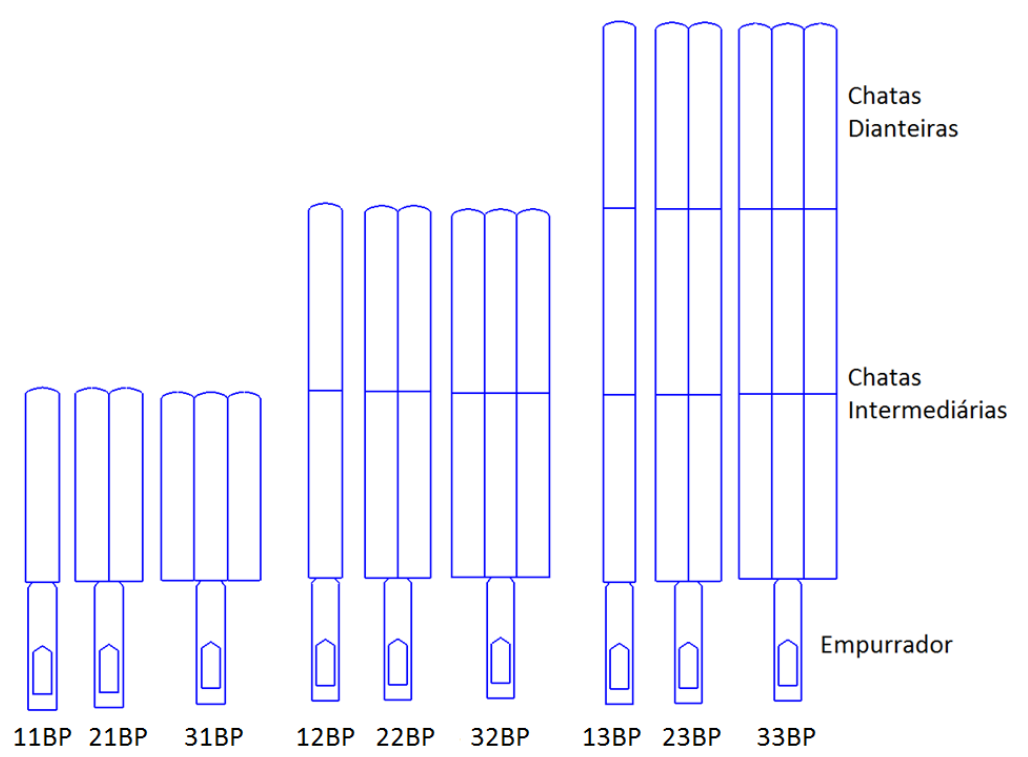

Figura 3-20 - Configurações de comboios propostas (adaptado de Koh et al., 2008a)

A Tabela 3.3 e a Tabela 3.4 apresentam as características gerais do comboio, nos quais são combinadas as configurações das barcaças com seus respectivos empurradores.

Tabela 3.3 - Dados dos comboios propostos

\begin{tabular}{|l|l|l|l|l|l|l|}
\hline & 11BP & 12BP & 13BP & 21BP & 22BP & 23BP \\
\hline $\mathbf{L}(\mathbf{m})$ & 100,96 & 161,92 & 222,88 & 100,96 & 161,92 & 222,88 \\
\hline $\mathbf{B}(\mathbf{m})$ & 10,67 & 10,67 & 10,67 & 21,34 & 21,34 & 21,34 \\
\hline $\mathbf{d}(\mathbf{m})$ & 2,74 & 2,74 & 2,74 & 2,74 & 2,74 & 2,74 \\
\hline $\boldsymbol{\nabla}(\mathbf{m} 3)$ & 2140,9 & 3848,5 & 5556,1 & 3787,1 & 7202,3 & 10618 \\
\hline $\mathbf{L C B}(\mathbf{m})$ & 58,47 & 89,88 & 120,7 & 63,24 & 94,54 & 125,3 \\
\hline $\mathbf{C}_{\mathbf{B}}$ & 0,725 & 0,813 & 0,853 & 0,642 & 0,761 & 0,815 \\
\hline
\end{tabular}


Tabela 3.4 - Dados dos comboios propostos (continuação)

\begin{tabular}{|l|l|l|l|l|l|l|}
\hline & 21BP & 22BP & 31BP & 32BP & 33BP & 23BP \\
\hline $\mathbf{L}(\mathbf{m})$ & 100,96 & 161,92 & 100,96 & 161,92 & 222,88 & 222,88 \\
\hline $\mathbf{B}(\mathbf{m})$ & 21,34 & 21,34 & 32,01 & 32,01 & 32,01 & 21,34 \\
\hline $\mathbf{d}(\mathbf{m})$ & 2,74 & 2,74 & 2,74 & 2,74 & 2,74 & 2,74 \\
\hline $\boldsymbol{\nabla}(\mathbf{m} 3)$ & 3787,1 & 7202,3 & 5433,3 & 10556 & 15679 & 10618 \\
\hline $\mathbf{L C B}(\mathbf{m})$ & 63,24 & 94,54 & 65,12 & 96,24 & 126,9 & 125,3 \\
\hline $\mathbf{C}_{\mathbf{B}}$ & 0,642 & 0,761 & 0,614 & 0,743 & 0,802 & 0,815 \\
\hline
\end{tabular}

\subsubsection{Manobra de giro}

A Figura 3-21 mostra a comparação da manobra de giro para as configurações do comboio 11BP, 12BP e 13BP. A Figura 3-22, mostra a comparação para 21BP, 22BP e 23BP. Finalmente, a Figura 3-23 apresenta os resultados de comparação para 31BP, 32BP e 33BP. As manobras foram executas com uma rotação do propulsor, $n_{P}=300 \mathrm{rpm}$ e ângulo de leme, $\delta=20^{\circ}$ e velocidade de serviço igual a 7 nós.
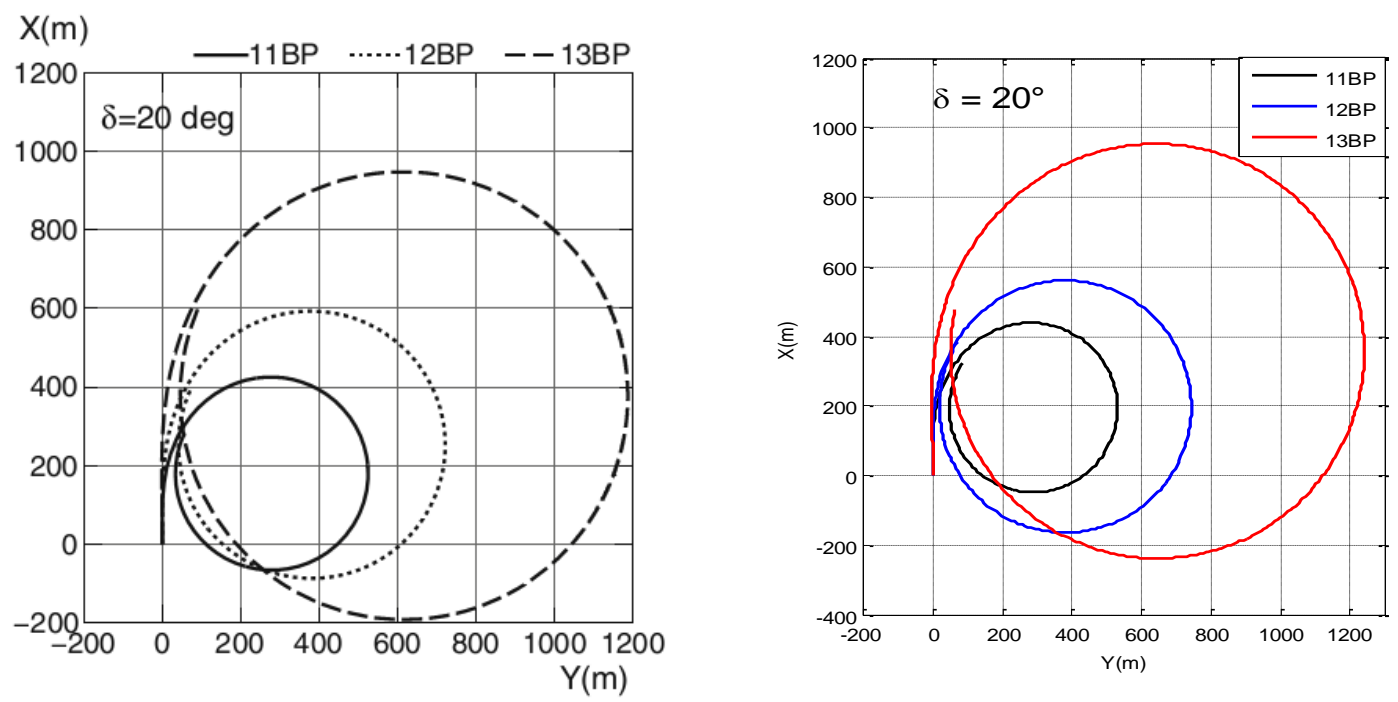

Figura 3-21 - Manobra de giro para $\delta=20^{\circ}$ e comboios 11BP, 12BP e 13BP: (esq.) Koh et al., (2008a); (dir.) simulador desenvolvido 

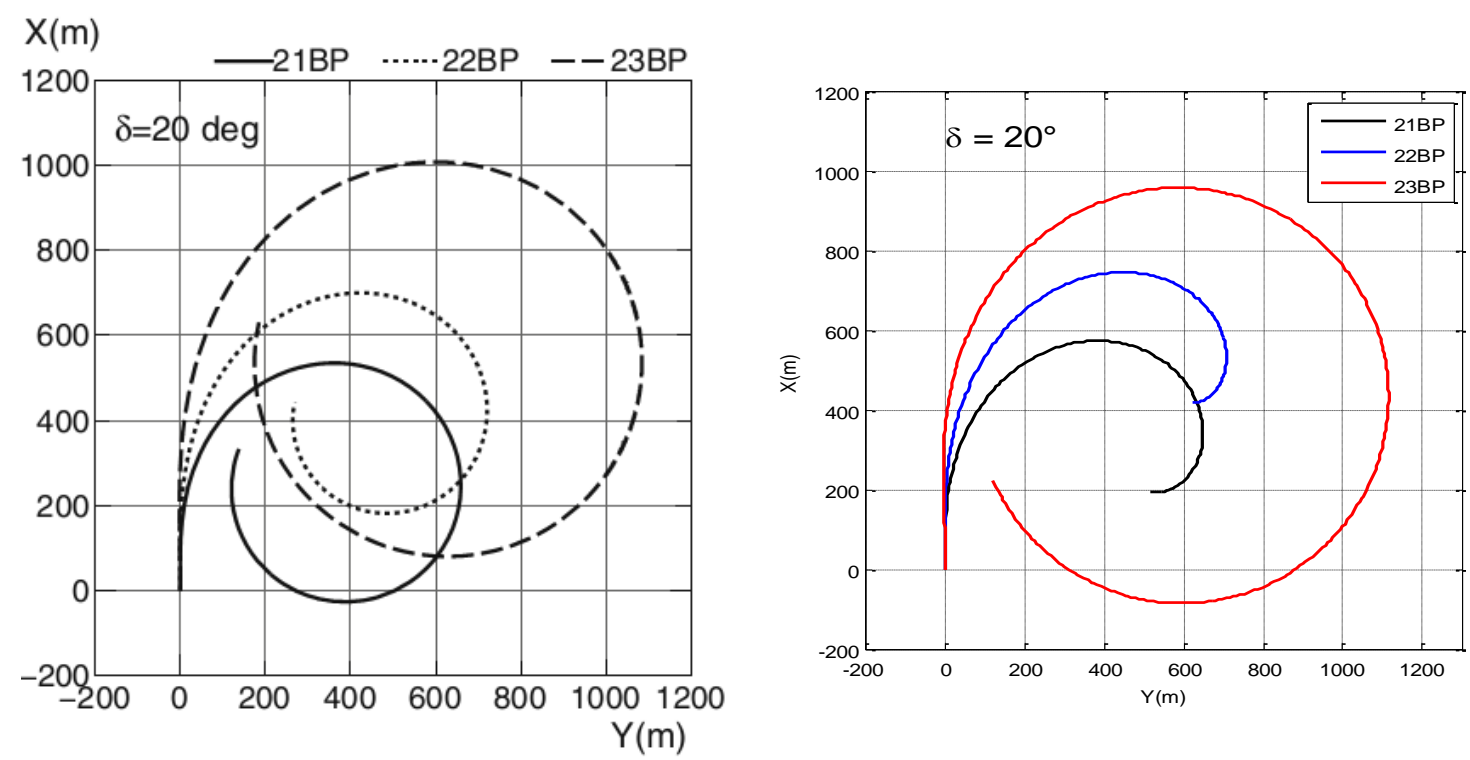

Figura 3-22 - Manobra de giro para $\delta=20^{\circ}$ e comboios 21BP, 22BP e 23BP: (esq.) Koh et al., (2008a); (dir.) simulador desenvolvido
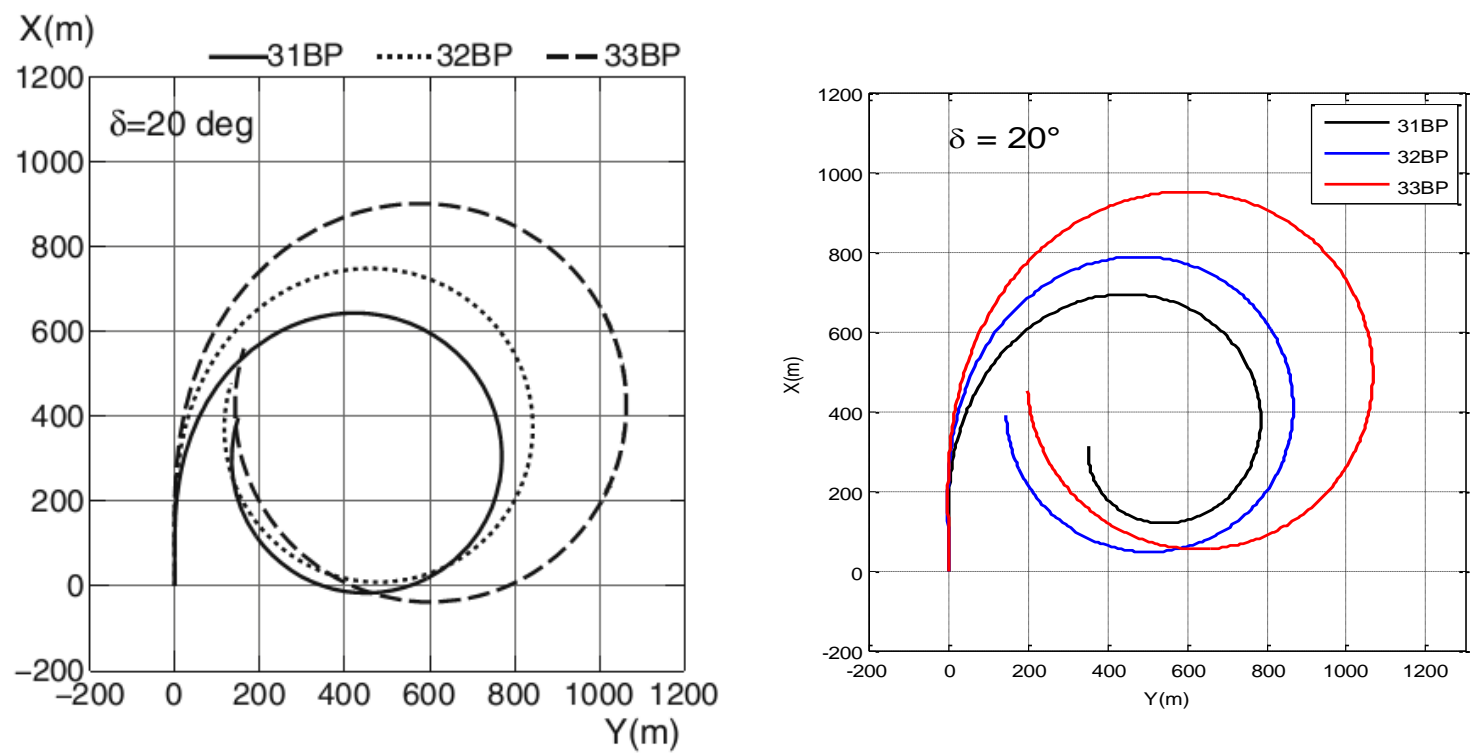

Figura 3-23 - Manobra de giro para $\delta=20^{\circ}$ e comboios 31BP, 32BP e 33BP: (esq.) Koh et al. (2008a); (dir.) simulador desenvolvido

Observa-se dos resultados das manobras de giro que, para as configurações de comboio com 1 fila de barcaça (11BP, 12BP, 13BP), as simulações foram satisfatórias, sendo as trajetórias das manobras de giro semelhantes às simuladas por Koh et al. (2008a). Para as configurações com 2 filas de barcaças (21BP, 22BP, 23BP) os resultados não foram muito satisfatórios, pois houve uma diferença considerável na trajetória, embora os parâmetros das 
manobras tenham sido satisfatórios. Nas simulações com 3 filas de barcaças (31BP, 32BP, 33BP) os resultados foram satisfatórios exceto para a configuração 31BP, no qual a manobra simulada teve uma trajetória menor.

A Tabela 3.5 mostra a comparação entre os parâmetros da manobra de giro para as trajetórias representadas. Os parâmetros comparados são avanço, transferência e diâmetro tático. Apresenta-se também a diferença percentual entre os resultados (dif.).

Tabela 3.5 - Comparação entre parâmetros da manobra de giro entre Koh et al. (2008a) e simulador desenvolvido

\begin{tabular}{|c|c|c|c|c|c|c|c|c|c|}
\hline \multirow{2}{*}{ Comboio } & \multicolumn{2}{|c|}{ Koh et al. (2008a) } & \multicolumn{6}{|c|}{ Simulador desenvolvido } \\
\cline { 2 - 11 } & Av $(\mathbf{m})$ & $\operatorname{Tr}(\mathbf{m})$ & DT $(\mathbf{m})$ & Av $(\mathbf{m})$ & dif. & $\operatorname{Tr}(\mathbf{m})$ & dif. & DT $(\mathbf{m})$ & dif. \\
\hline 11BP & 418 & 212 & 516 & 439 & $5 \%$ & 201 & $-5 \%$ & 519 & $1 \%$ \\
\hline 12BP & 583 & 290 & 709 & 564 & $-3 \%$ & 297 & $2 \%$ & 732 & $3 \%$ \\
\hline 13BP & 927 & 455 & 1160 & 933 & $1 \%$ & 441 & $-3 \%$ & 1210 & $4 \%$ \\
\hline 21BP & 523 & 272 & 644 & 565 & $8 \%$ & 263 & $-3 \%$ & 623 & $-3 \%$ \\
\hline 22BP & 679 & 302 & 695 & 724 & $7 \%$ & 297 & $-2 \%$ & 669 & $-4 \%$ \\
\hline 23BP & 961 & 382 & 1030 & 929 & $-3 \%$ & 370 & $-3 \%$ & 1070 & $4 \%$ \\
\hline 31BP & 623 & 299 & 747 & 680 & $9 \%$ & 298 & $0 \%$ & 754 & $1 \%$ \\
\hline 32BP & 720 & 311 & 813 & 767 & $7 \%$ & 307 & $-1 \%$ & 828 & $2 \%$ \\
\hline 33BP & 867 & 391 & 1030 & 917 & $6 \%$ & 381 & $-3 \%$ & 1020 & $-1 \%$ \\
\hline
\end{tabular}

Observa-se que os resultados referentes aos parâmetros de manobras medidos foram próximos, sendo a maior diferença de $9 \%$, relativo à configuração 31BP no parâmetro de avanço. A Figura 3-24, Figura 3-25 e Figura 3-26 mostram a comparação através de gráficos de coluna para os parâmetros da manobra de giro. 


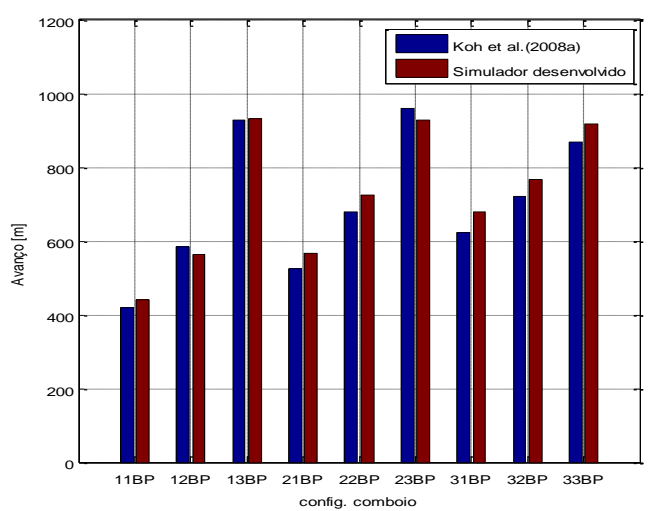

Figura 3-24 - Comparação do parâmetro Avanço entre Koh et al. (2008a) e simulador desenvolvido

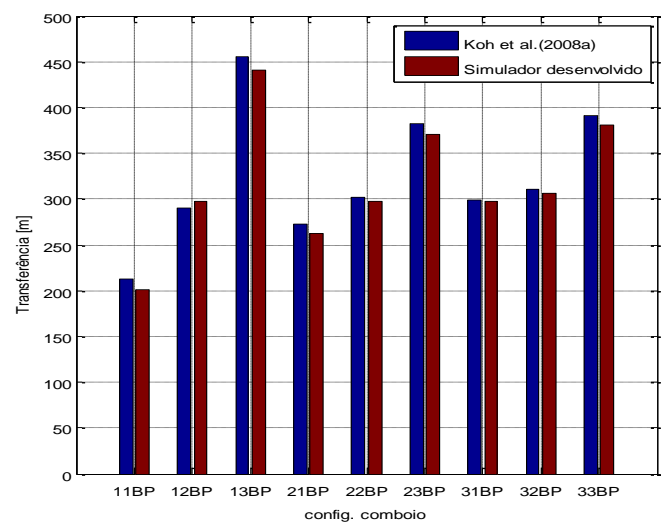

Figura 3-25 - Comparação do parâmetro transferência entre Koh et al. (2008a) e simulador desenvolvido

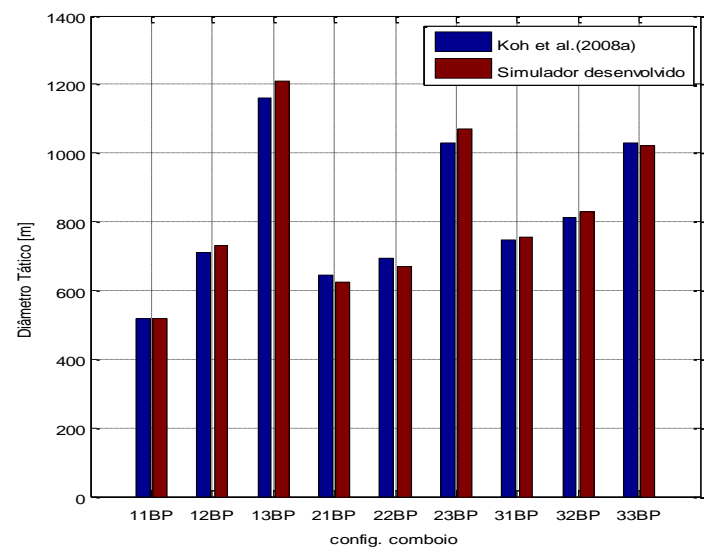

Figura 3-26 - Comparação do diâmetro tático entre Koh et al. (2008a) e simulador desenvolvido 
Apreende-se dos resultados que a modelagem está satisfatória, permitindo que sejam empregadas no modelo, as novas propostas de sistemas de propulsão e manobra modelados no item 3.3 para as configurações com 1 e 3 filas de barcaças, exceto para a configuração 31BP. A principal causa da diferença entre os resultados é a modelagem das forças do leme, em que se empregou o modelo de Molland e Turnock (2007) enquanto de Koh et al. (2008a) utilizou a fórmula de Yoshimura (1978). Outras possíveis causas relacionadas às diferenças nos resultados verificadas:

- diferenças numéricas na integração,

- diferença entre a razão passo/diâmetro do hélice utilizado pelo autor, no qual não foram apresentados os valores,

- não fornecimento na taxa de mudança no ângulo do leme, no trabalho foi utilizado uma taxa de $2 \% \mathrm{~s}$,

- fator de correção no coeficiente de esteira não fornecido por Koh et al. (2008a), e que foi estimado segundo a Tabela 3.1,

- não exatidão em como foram feitas as simulações realizadas por Koh et al. (2008a), como velocidade inicial da embarcação e valor de $p$ para cada configuração de comboio simulada.

\subsubsection{Manobra de zig-zag}

Neste presente item é apresentada a validação para a manobra de zig-zag entre o simulador desenvolvido e os resultados obtidos por Koh et al. (2008a).

A Figura 3-27 e Figura 3-28 apresentam os resultados obtidos para os comboios 11BP, 12BP e 13BP no simulador desenvolvido e resultados de Koh et al. (2008a), respectivamente. 


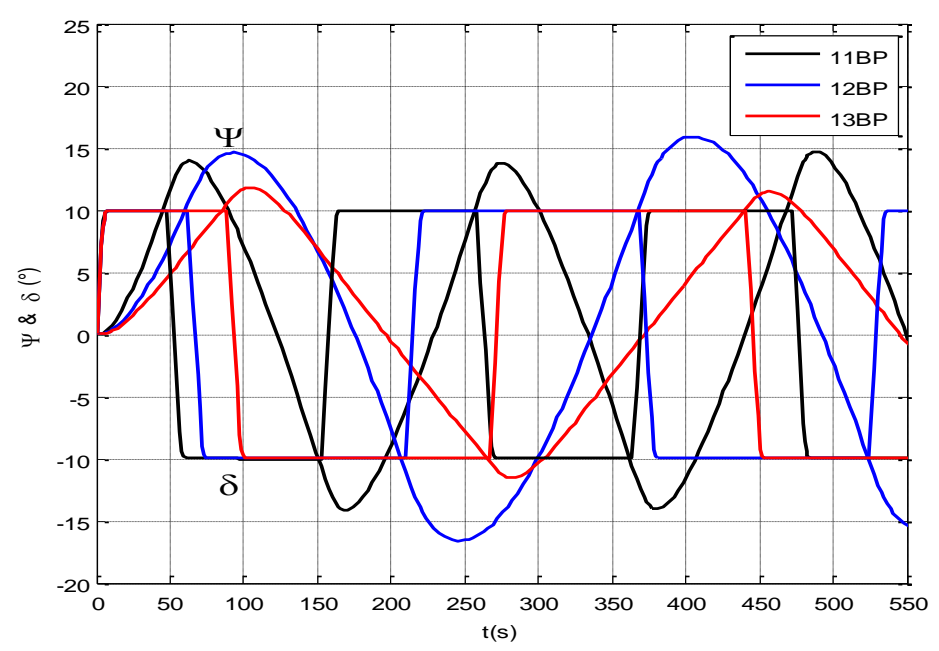

Figura 3-27 - Manobra de zig-zag 10/10 do simulador desenvolvido

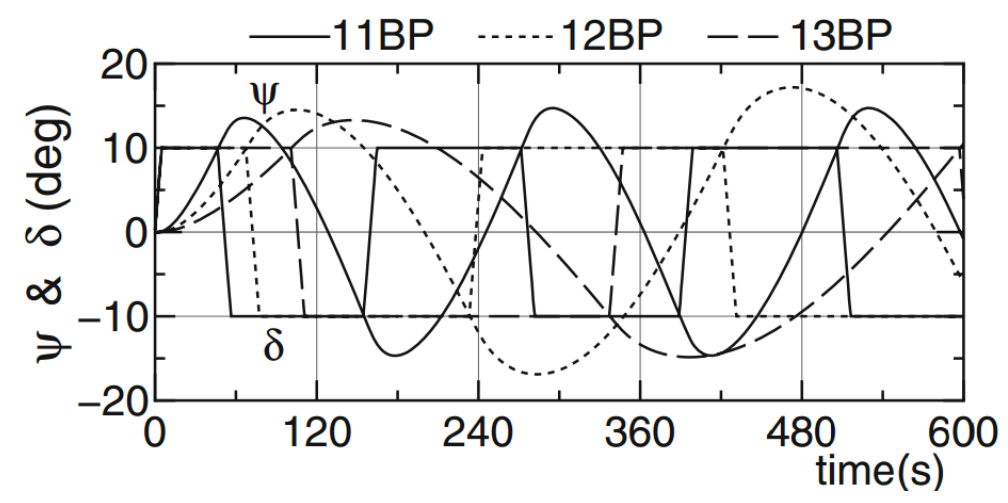

Figura 3-28 - Manobra de zig-zag 10/10 de Koh et al. (2008a)

Observa-se das figuras que os valores do primeiro e segundo sobressinais obtidos pelo simulador estão em torno de $5^{\circ}$ para os comboios 11BP e 12BP, valores próximos aos obtidos por Koh et al. (2008a). Porém para a embarcação 13BP na simulação houve um sobressinal de aproximadamente $2^{\circ}$, enquanto 0 resultado obtido por Koh et al. (2008a) fica em torno de $5^{\circ}$. Verifica-se uma diferença no tempo de resposta para o terceiro sobressinal de aproximadamente $8 \%$. Essas diferenças entre os resultados podem ser atribuída às mesmas causas apontadas para a manobra de giro no item 3.4.2.1. 


\section{Resultados}

Neste capítulo são apresentados os resultados das simulações realizadas de acordo com a modelagem apresentada no item 3.3. Foram utilizados, também, os mesmos parâmetros citados na validação do modelo (item 3.4.2) para realizações das simulações.

Inicialmente, no item 4.1, são apresentados os resultados referentes às embarcações em movimento na execução da manobra de giro. Obtiveram-se os parâmetros de Av e DT em função da velocidade da embarcação antes do início do comando no leme, a fim de analisar o desempenho dos diferentes sistemas de propulsão e manobra propostos. Em seguida foram realizadas as manobras de zig-zag 10/10 com o objetivo de analisar tanto os sobressinais obtidos quanto seus respectivos tempos de resposta.

As manobras simuladas foram realizadas para uma faixa de velocidades próximas a 7 nós, velocidade em que foram obtidas as derivadas hidrodinâmicas por Yasukawa et al. (2007). Utilizaram-se as configurações de comboio 11BP, 12BP e 23BP nessas simulações.

$\mathrm{Na}$ seção 4.3.2 são apresentados os resultados de manobra dos comboios fluviais em baixa velocidade, no qual a embarcação se encontra inicialmente parada, simulando, assim, as manobras necessárias para atracação, desatracação, passagem de trechos extremamente sinuosos, entre outros. Nas simulações de baixa velocidade utilizou o modelo de cross-flow (Obokata, 1981), pois as derivadas hidrodinâmicas de Yasukawa et al. (2007) são válidas apenas para a faixa de velocidade de 7 nós. Os coeficientes de arrasto utilizados no modelo de cross-flow foram obtidos de Grassi et al. (2013).

\subsection{Simulações dos comboios próximas à velocidade de serviço}

Nesta seção são apresentados os resultados referentes às simulações do comboio próximo à velocidade de serviço (7 nós) no instante anterior ao 
comando para a manobra. Selecionam-se as configurações de comboio 11BP, 12BP e 23BP. A primeira foi escolhida por causa das simulações em águas rasas, em que apenas nessa configuração tiveram as derivadas hidrodinâmicas calculadas por Koh e Yasukawa (2012). As duas últimas foram escolhidas, por serem as configurações mais apropriadas para hidrovia Tietê-Paraná (AHRANA, 2010), sendo a configuração tipo Paraná, equivalente a configuração 23BP e a configuração tipo Tietê, equivalente à configuração 12BP (Figura 4-1), as mais adequadas para navegação nas hidrovias de mesmos nomes.

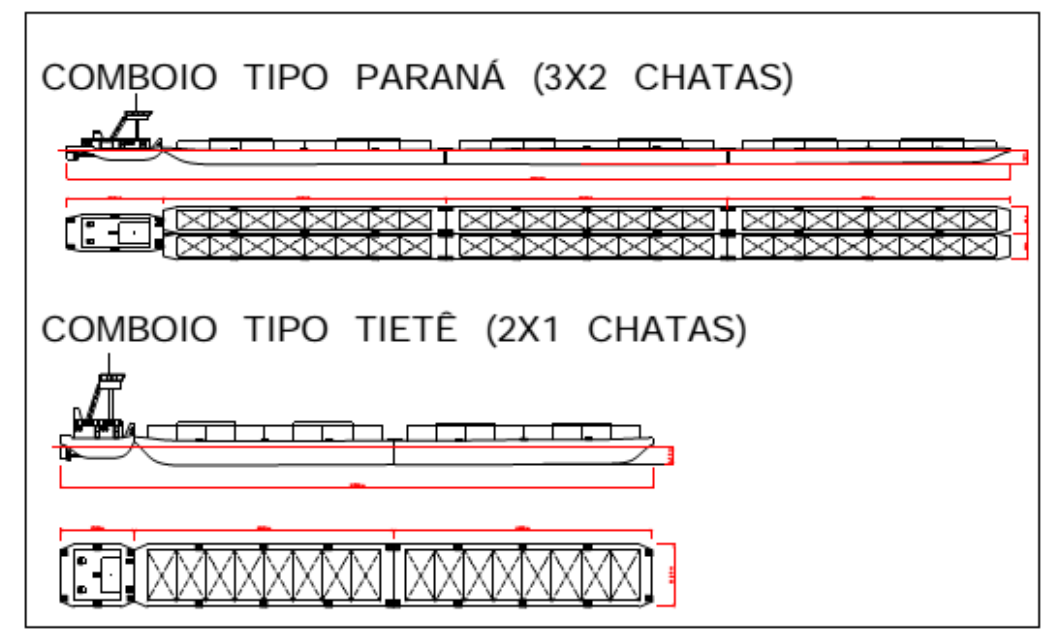

Figura 4-1 - Comboios tipo Paraná e tipo Tietê (extraída de AHRANA, 2010)

Considerou-se o propulsor com rotação de 300 RPM, com passo variável e ajustado de forma a obter velocidade entre 6 e 8 nós. $O$ ângulo do sistema de manobra (leme ou propulsor azimutal) foi de $20^{\circ}$, enquanto do equipamento de proa auxiliar foi de $-20^{\circ}$. Nas simulações com o equipamento auxiliar de proa, os comboios utilizaram o mesmo empuxo total resultante do sistema sem equipamento auxiliar, alocando-se $2 / 3$ T para cada propulsor proporcionando 0 total de 2T para a embarcação (Figura 4-2). Deste modo, permite-se uma melhor comparação entre os sistemas modelados, pois o empuxo total em todos os casos é o mesmo. 

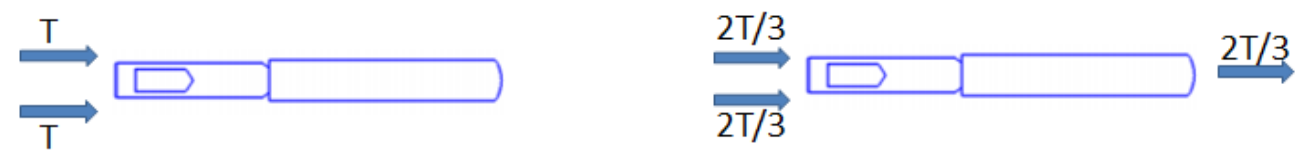

Figura 4-2 - Representação do empuxo total para os sistemas sem o equipamento auxiliar de proa (esq.), com equipamento auxiliar de proa com empuxo total igual a 2T (dir.) Propulsão

Convencional X Propulsão Azimutal

\subsubsection{Manobra de giro para sistema C e A}

Na comparação entre o sistema C e A, utilizou-se ângulo de leme ou ângulo do azimutal em $\delta=\delta_{A}=20^{\circ}$. A Figura 4-3, Figura 4-4 e Figura 4-5 mostram os parâmetros avanço e diâmetro tático da manobra de giro para as configurações de comboio 11BP, 12 BP e 23BP, respectivamente, variando-se a velocidade inicial.
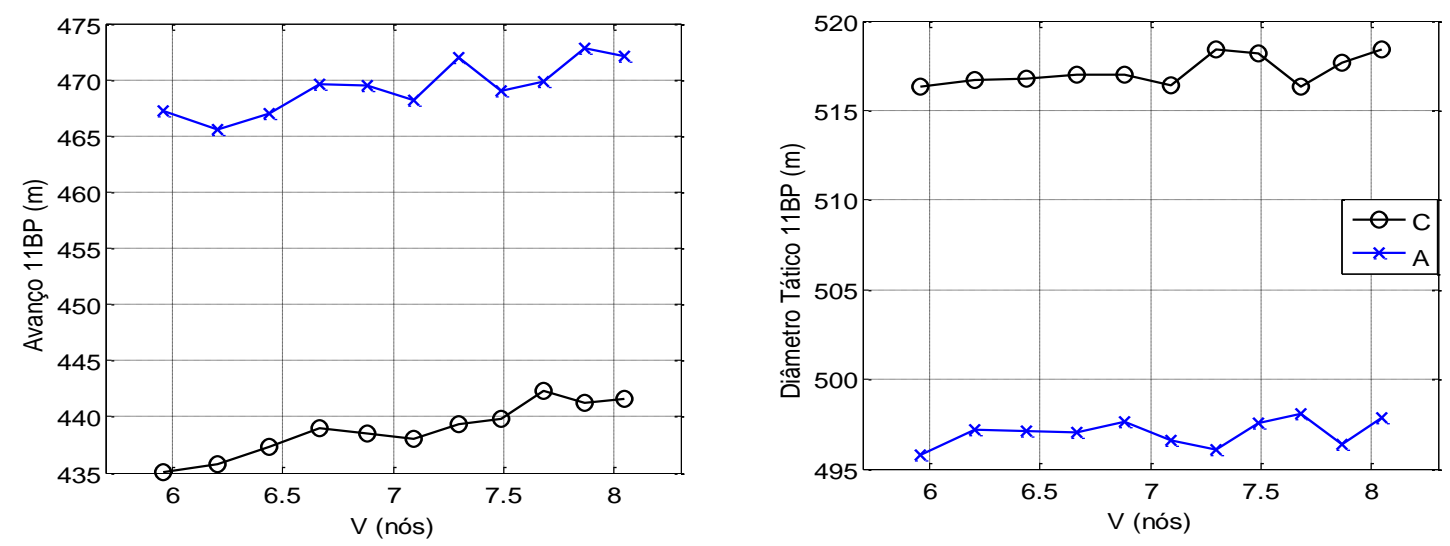

Figura 4-3 - Parâmetros da manobra de giro para sistema C $\left(\delta=20^{\circ}\right)$ e $\mathrm{A}\left(\delta_{A}=20^{\circ}\right)$ - comboio 11BP
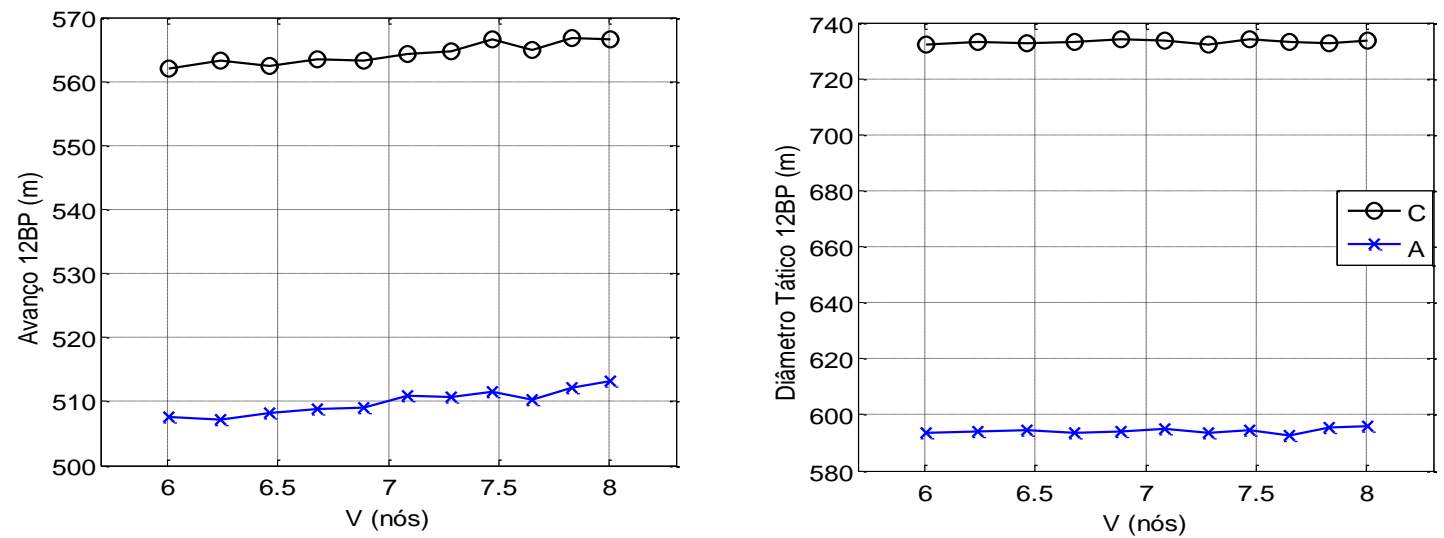

Figura 4-4 - Parâmetros da manobra de giro para sistema $\mathrm{C}\left(\delta=20^{\circ}\right)$ e $\mathrm{A}\left(\delta_{A}=20^{\circ}\right)$ - comboio $12 \mathrm{BP}$ 

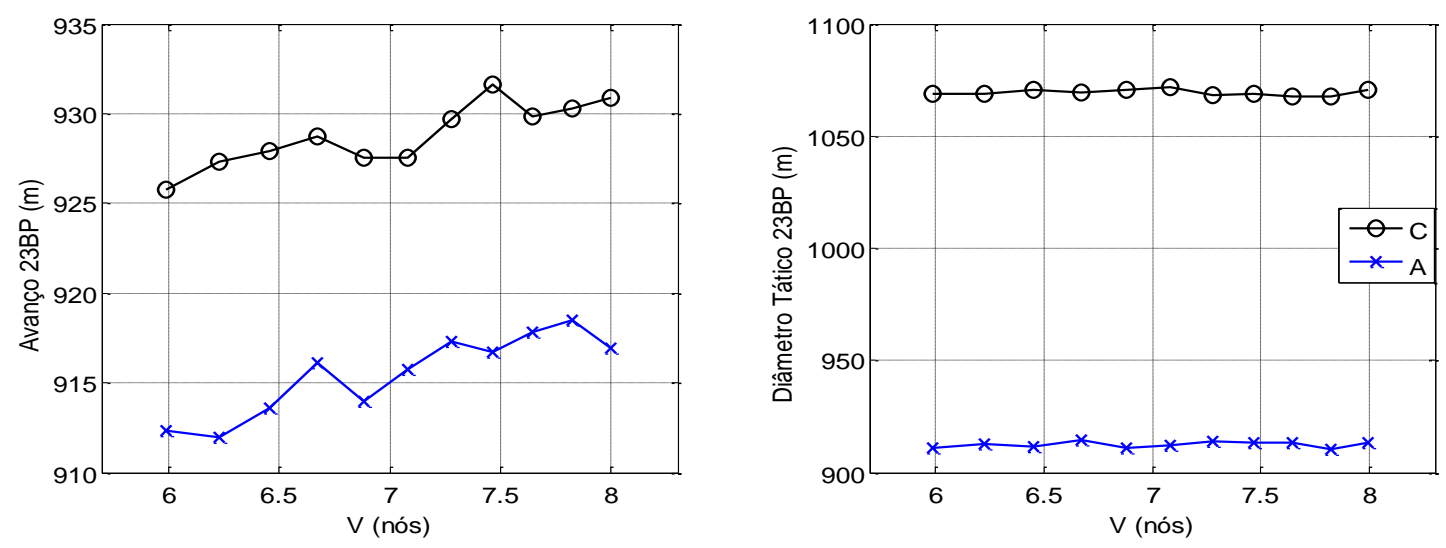

Figura 4-5 - Parâmetros da manobra de giro para sistema $\mathrm{C}\left(\delta=20^{\circ}\right)$ e $\mathrm{A}\left(\delta_{A}=20^{\circ}\right)$ - comboio 23BP

Observa-se das manobras de giro, para as configurações selecionadas, que o sistema azimutal melhora as características de manobrabilidade dos comboios em relação ao sistema convencional, tendo o maior ganho nos comboios com mais barcaças enfileiradas (12BP e 23BP), em que o Av teve uma redução em torno de $10 \%$ e o DT em torno de $20 \%$. A única exceção verificada foi para o comboio $11 \mathrm{BP}$, caso em que o sistema $\mathrm{A}$ se mostrou menos eficiente que $\mathrm{o}$ sistema C.

A Figura 4-6, Figura 4-7 e Figura 4-8 mostram as manobra de giro para os sistemas $\mathrm{C}$ e A com velocidade inicial de 7 nós. Nessas figuras são mostradas, também, as velocidades instantâneas para o aproamento de $90^{\circ}, 180^{\circ}, 270^{\circ} \mathrm{e}$ $360^{\circ}$ e os parâmetros para o avanço, transferência, diâmetro tático e raio de giro. 

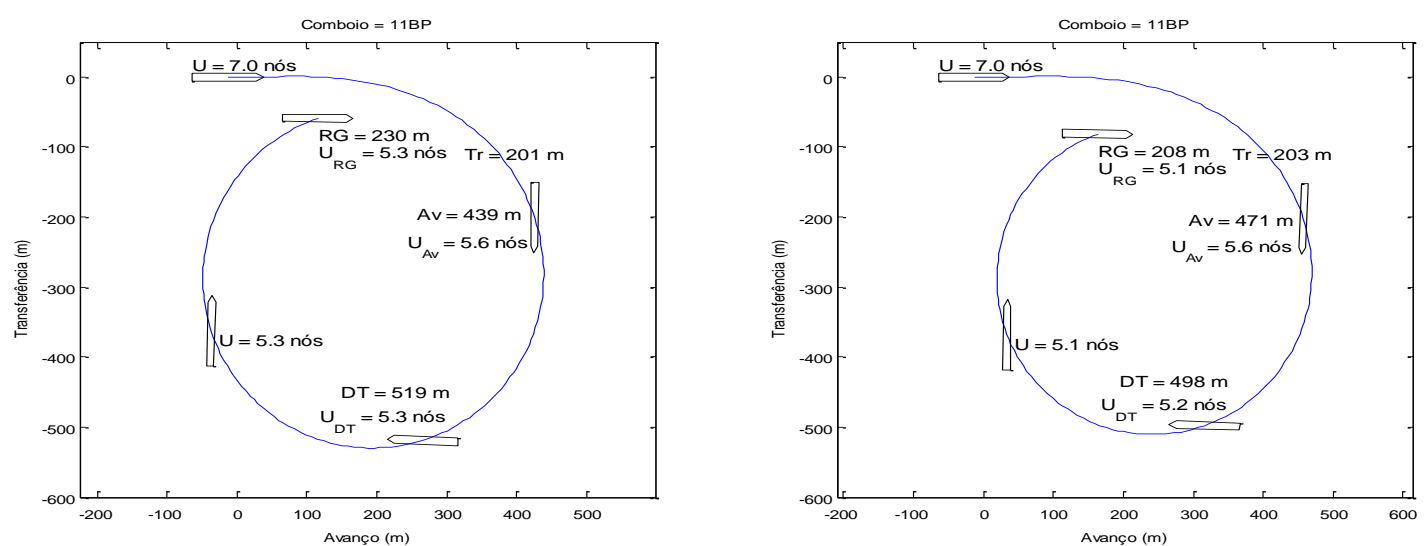

Figura 4-6 - Manobra de giro para sistema C (esq.) e A (dir.) para $U_{0}=7$ nós - comboio $11 \mathrm{BP}$ $\left(\delta=\delta_{A}=20^{\circ}\right)$
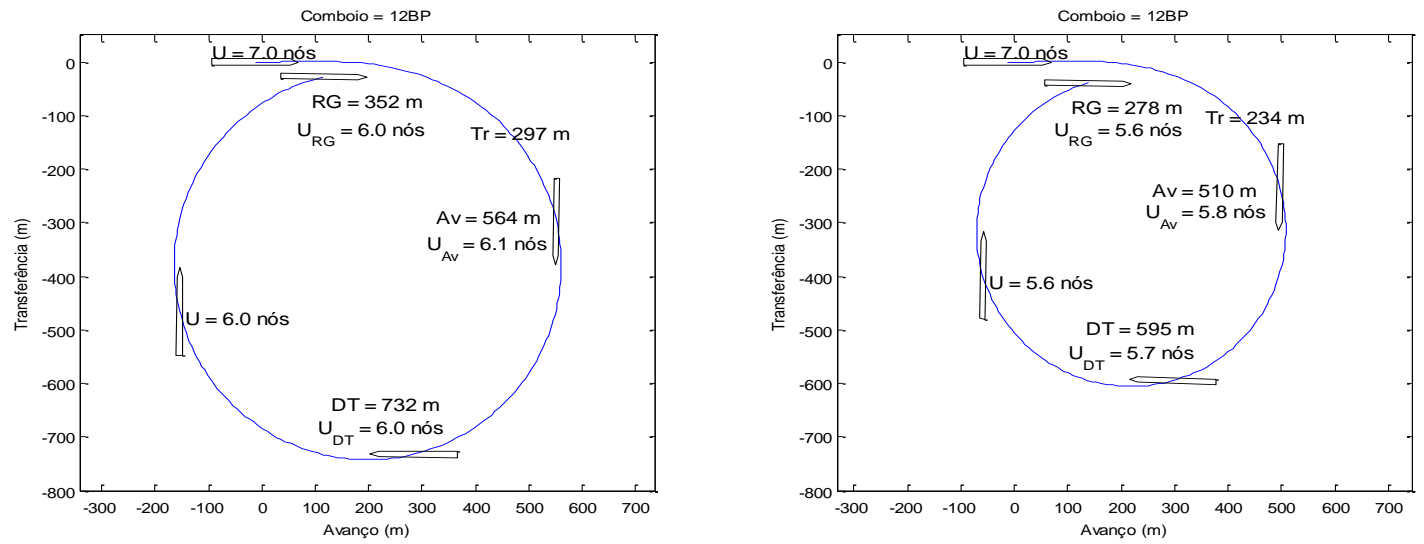

Figura 4-7 - Manobra de giro para sistema C (esq.) e A (dir.) para $U_{0}=7$ nós - comboio 12BP $\left(\delta=\delta_{A}=20^{\circ}\right)$
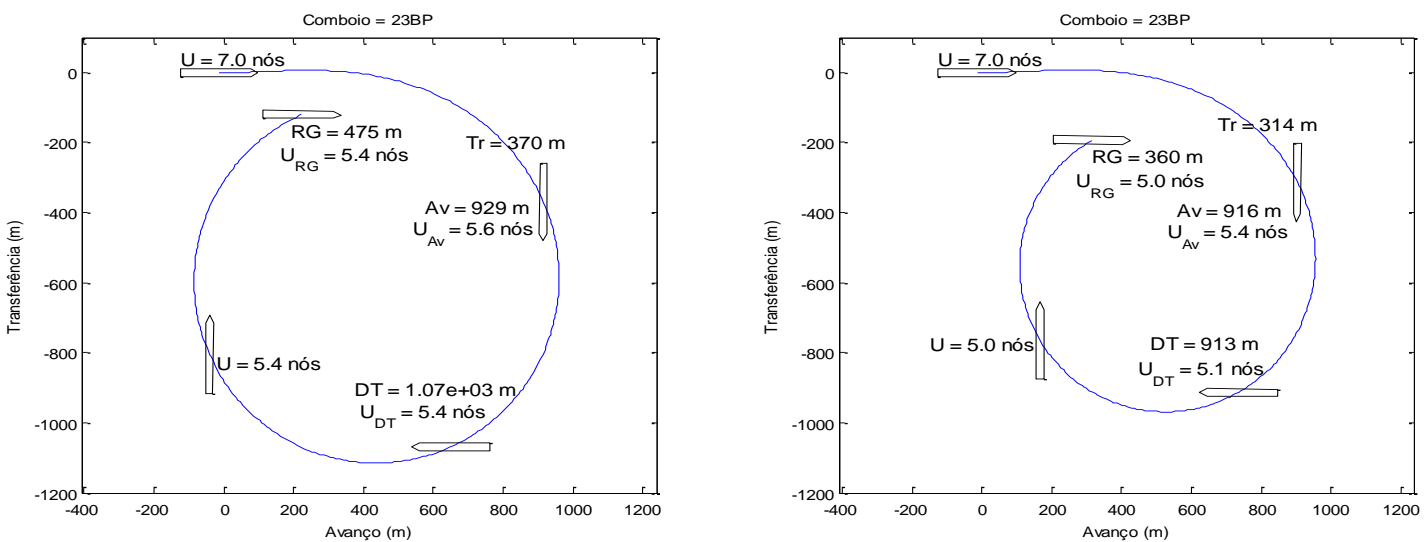

Figura 4-8 - Manobra de giro para sistema C (esq.) e A (dir.) para $U_{0}=7$ nós - comboio 23BP $\left(\delta=\delta_{A}=20^{\circ}\right)$

Observa-se das figuras uma diminuição da velocidade na execução da manobra de giro para o sistema $\mathrm{A}$ em relação a $\mathrm{C}$. 


\subsubsection{Manobra de zig-zag para sistema C e A}

Nesta seção apresentam-se os resultados da manobra de zig-zag 10/10 para os comboios 11BP (Figura 4-9), 12BP (Figura 4-10) e 23BP (Figura 4-11) comparando os sistemas $\mathrm{C}$ e $\mathrm{A}$.

As manobras foram executadas para a velocidade inicial $U_{0}=7$ nós e intervalo de tempo de 800 segundos.

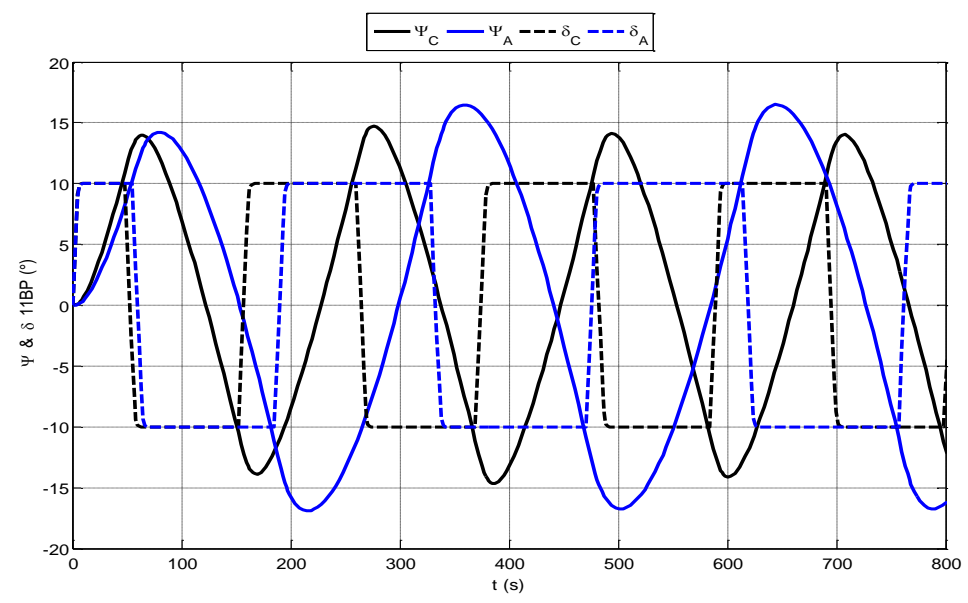

Figura 4-9 - Manobra de zig-zag 10/10 para sistema C e A - comboio 11BP

Apreende-se da Figura 4-9 que o sistema $C$ tem um desempenho melhor na manobra de zig-zag em relação ao sistema $A$, o qual tem o sobressinal menor e tempo de resposta do sobressinal também.

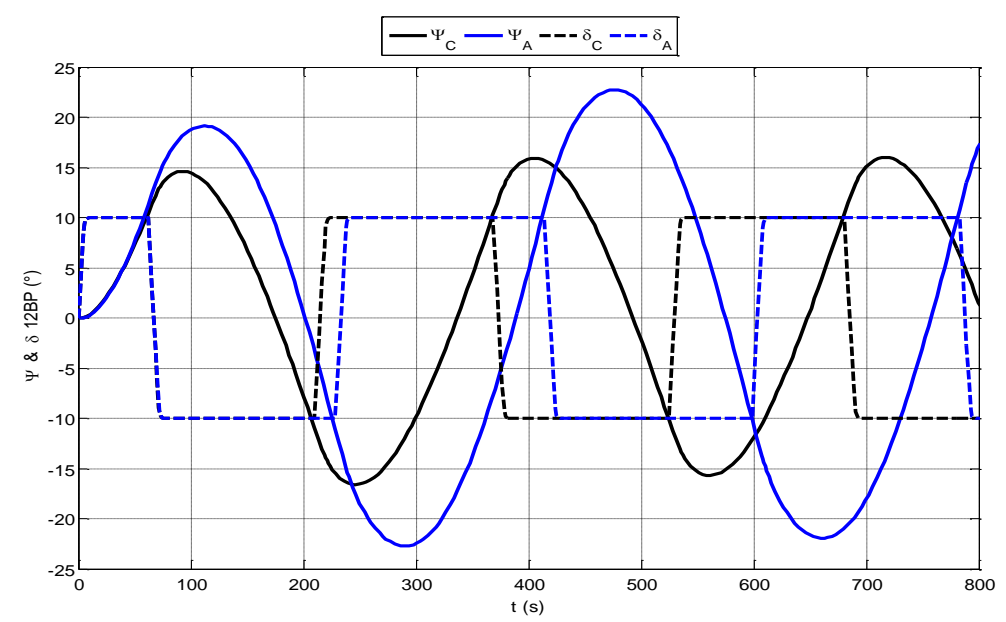

Figura 4-10 - Manobra de zig-zag 10/10 para sistema C e A - comboio 12BP 


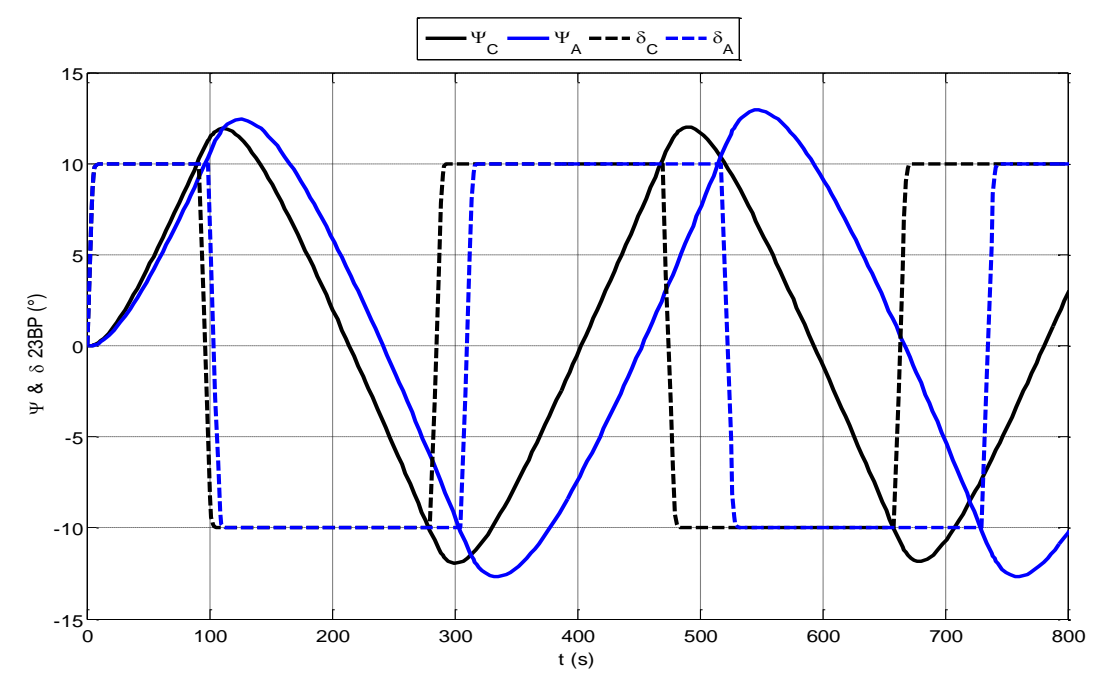

Figura 4-11 - Manobra de zig-zag 10/10 para sistema C e A - comboio 23BP

Observa-se que as embarcações com sistema C apresenta melhores resultados que o sistema $A$ nas manobras de zig-zag 10/10, tanto em relação ao sobressinal, como em relação tempo de inversão de taxa de guinada. Porém, a diferença de desempenho no tempo se reduz à medida há mais barcaças nos comboios, como no caso da configuração 23BP. Em relação ao sobressinal, a maior diferença de desempenho é para o comboio 12BP no qual o sobressinal do sistema C chega a ser até $30 \%$ menor que o sistema $A$.

\subsubsection{Comparação entre sistema C e sistema CA}

Nesta seção é analisado o desempenho do equipamento de proa combinado com o sistema convencional para os comboios 11BP, 12BP e 23BP. Simulouse a manobra de giro para velocidades iniciais entre 6 e 8 nós. Os parâmetros do sistema de manobras utilizados foram ângulo de leme $\delta=20^{\circ}$, e ângulo do equipamento auxiliar $\delta_{a u x}=-20^{\circ}$. Também foram simuladas as manobras de zig-zag 10/10. Ressalta-se que na execução das manobras o empuxo é divido entre o sistema auxiliar e os propulsores traseiros, resultando empuxo total igual em ambos os sistemas de propulsão e manobra, de modo que a comparação entre os sistemas fosse mais coerente. 


\subsubsection{Manobra de giro para sistema C e CA}

Nesta seção mostram-se os resultados das simulações da manobra de giro em função da velocidade para os parâmetros Av e DT para os sistemas C e CA para as configurações 11BP (Figura 4-12), 12BP (Figura 4-13) e 23BP (Figura 4-14).
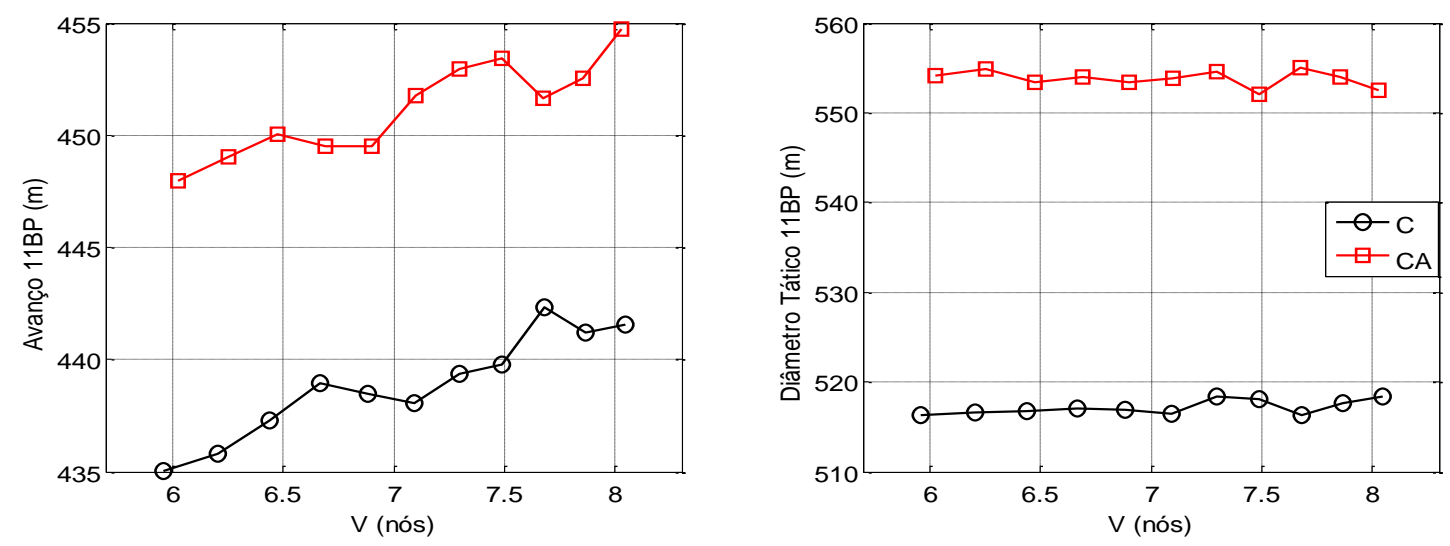

Figura 4-12 - Parâmetros da manobra de giro para sistema C $\left(\delta=20^{\circ}\right)$ e CA $\left(\delta=20^{\circ} / \delta_{a u x}=\right.$ $\left.-20^{\circ}\right)$ - comboio $11 \mathrm{BP}$
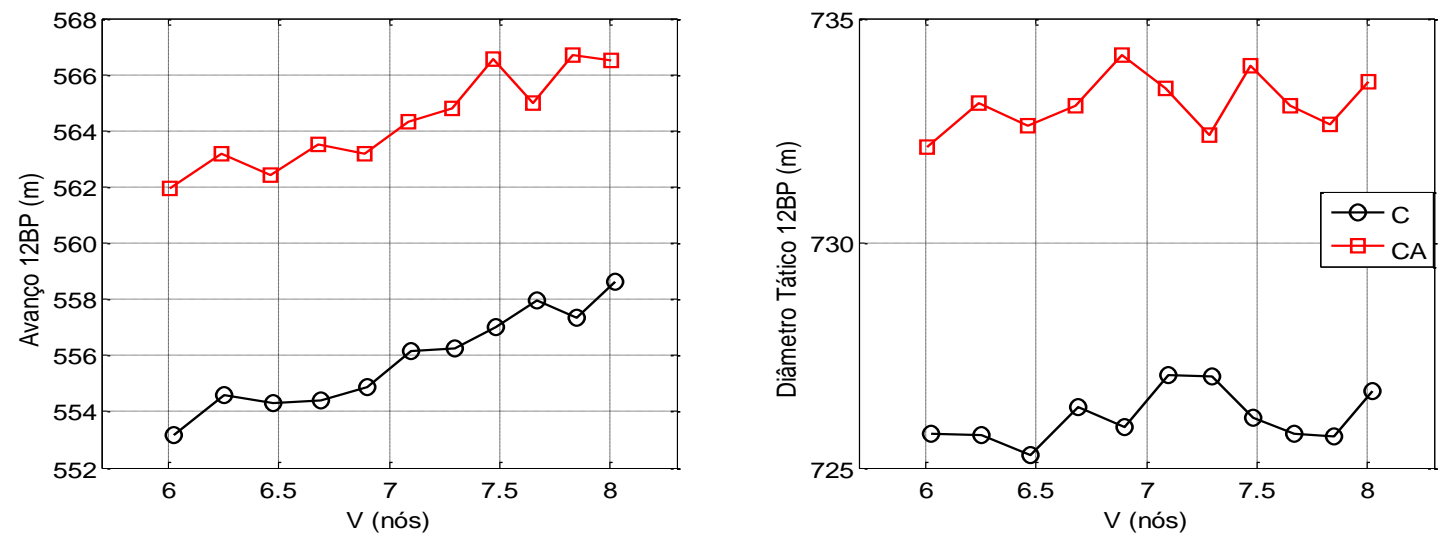

Figura 4-13 - Parâmetros da manobra de giro para sistema C $\left(\delta=20^{\circ}\right)$ e CA $\left(\delta=20^{\circ} / \delta_{\text {aux }}=\right.$ $-20^{\circ}$ ) - comboio $12 \mathrm{BP}$ 

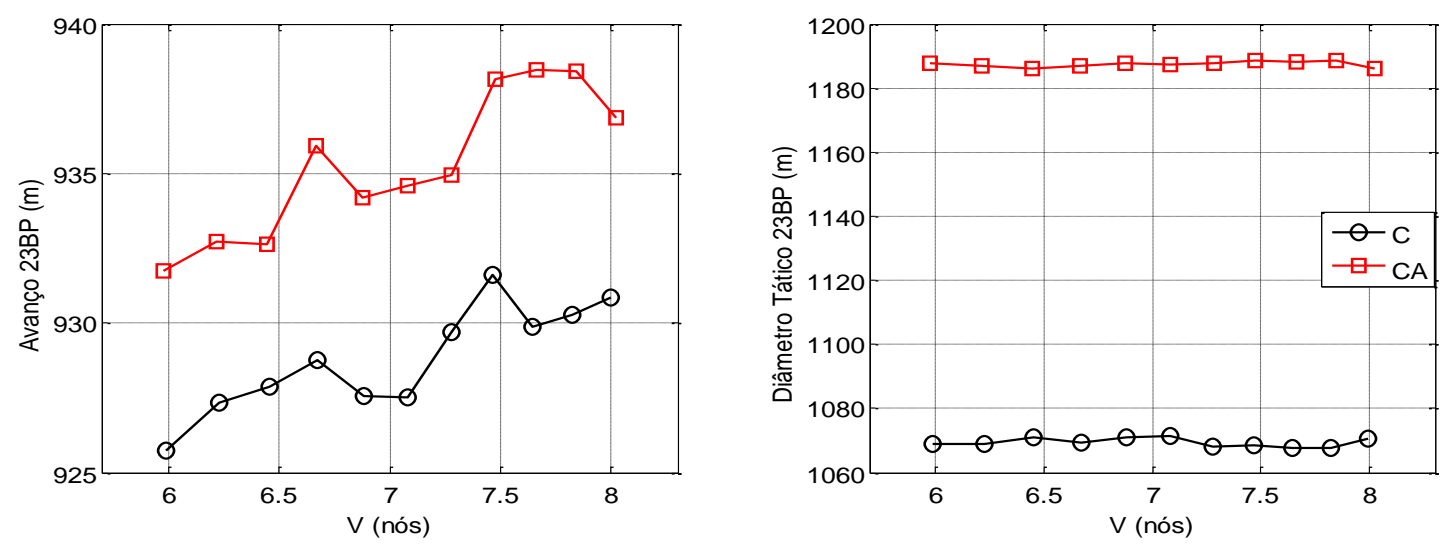

Figura 4-14 - Parâmetros da manobra de giro para sistema C $\left(\delta=20^{\circ}\right)$ e CA $\left(\delta=20^{\circ} / \delta_{\text {aux }}=\right.$ $-20^{\circ}$ ) - comboio 23BP

Observa-se da figura que o desempenho da manobra de giro para o sistema de propulsão convencional associada ao equipamento de proa se mostrou inferior para toda a faixa de velocidade considerada. Nessas manobras o sistema CA apresentou uma piora de aproximadamente $2 \%$ nos parâmetros de Av. No DT, para os comboios 11BP e 23BP o sistema $\mathrm{C}$ teve um desempenho cerca de $10 \%$ melhor em relação ao sistema CA, enquanto que no comboio 12BP a diferença foi de $1 \%$.

A Figura 4-15, Figura 4-16 e Figura 4-17 mostram as manobras de giro para velocidade inicial $U_{0}=7$ nós para ambos os sistemas. Representado os parâmetros Av, Tr, DT, RG e suas respectivas velocidades durante a manobra.
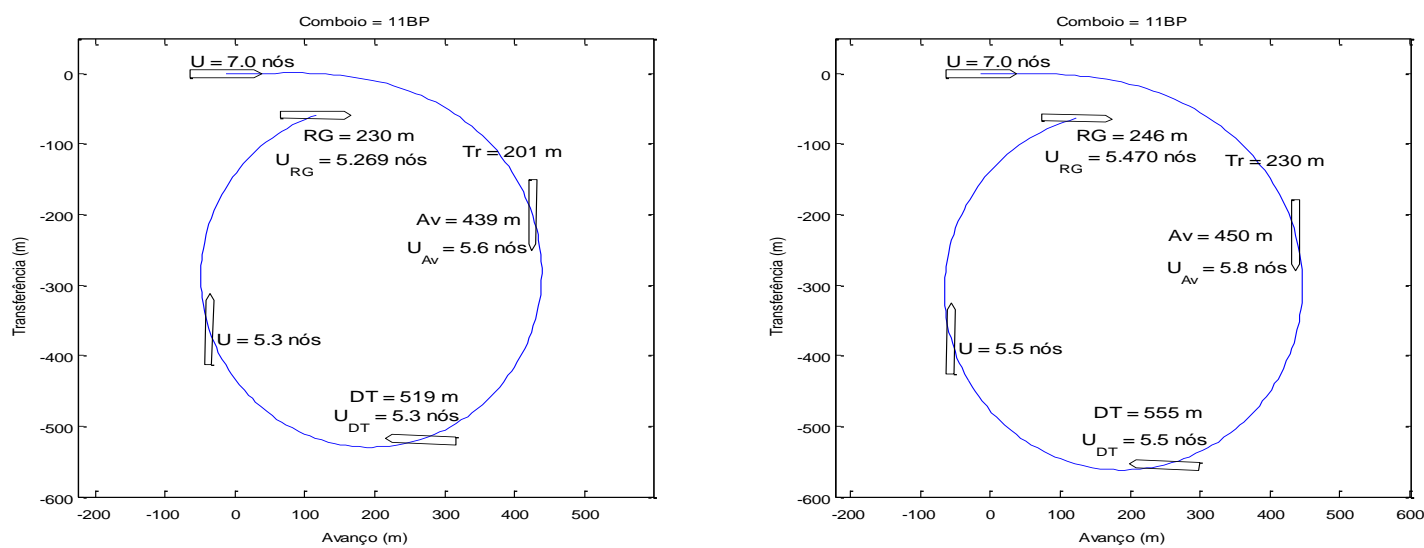

Figura 4-15 - Manobra de giro para sistema C (esq.) e CA (dir.) para $U_{0}=7$ nós - comboio 11BP $\left(\delta=20^{\circ} / \delta_{\text {aux }}=-20^{\circ}\right)$ 

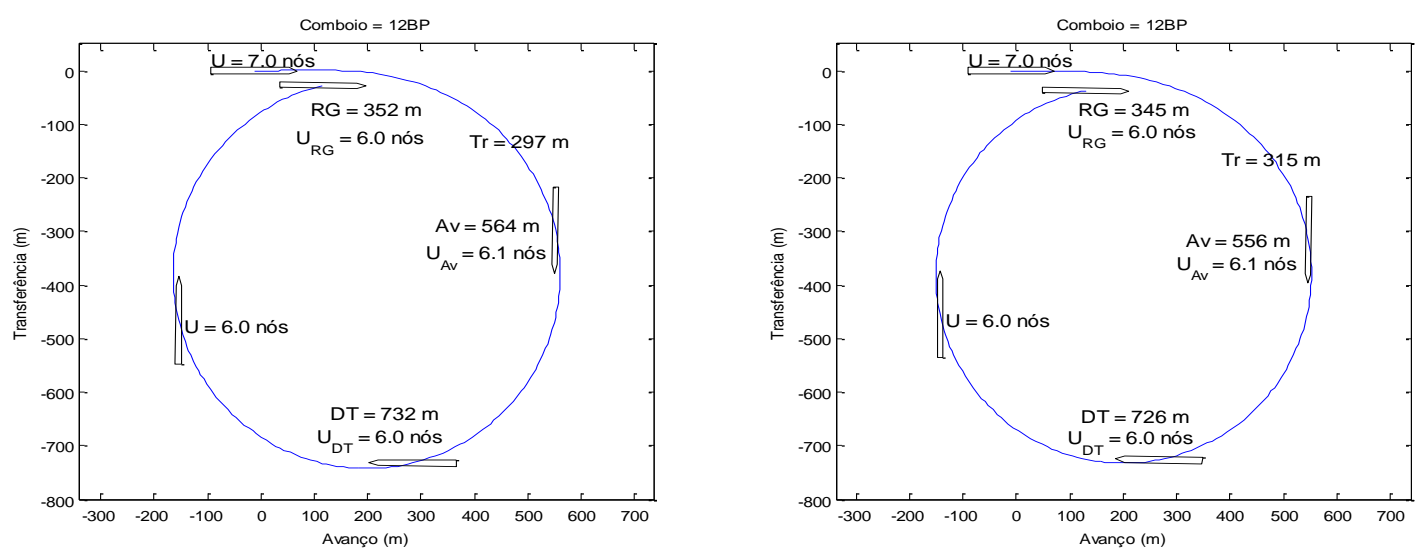

Figura 4-16 - Manobra de giro para sistema C (esq.) e CA (dir.) para $U_{0}=7$ nós - comboio 12BP $\left(\delta=20^{\circ} / \delta_{\text {aux }}=-20^{\circ}\right)$
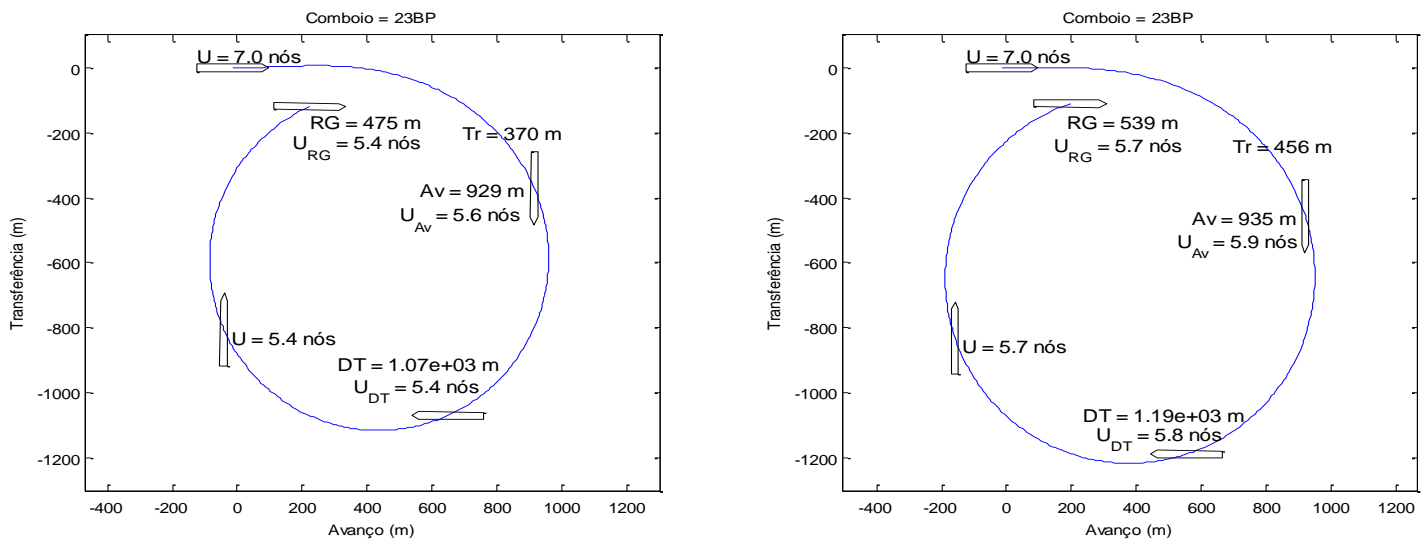

Figura 4-17 - Manobra de giro para sistema C (esq.) e CA (dir.) para $U_{0}=7$ nós - comboio 23BP $\left(\delta=20^{\circ} / \delta_{\text {aux }}=-20^{\circ}\right)$

Observa-se que as velocidades instantâneas são menores para o sistema $C$ durante a execução da manobra de giro, exceto pelo comboio 12BP, no qual a velocidade entre os sistemas se mantiveram iguais durante a manobra. Analisou-se a atuação do sistema de manobra em relação ao ponto de pivotamento da embarcação, o qual se localiza mais próximo da proa. Desse modo o sistema CA proporciona no comboio um menor momento em relação ao ponto de pivotamento, consequentemente tendo uma piora no momento de guinada induzido em relação ao sistema $\mathrm{C}$. 

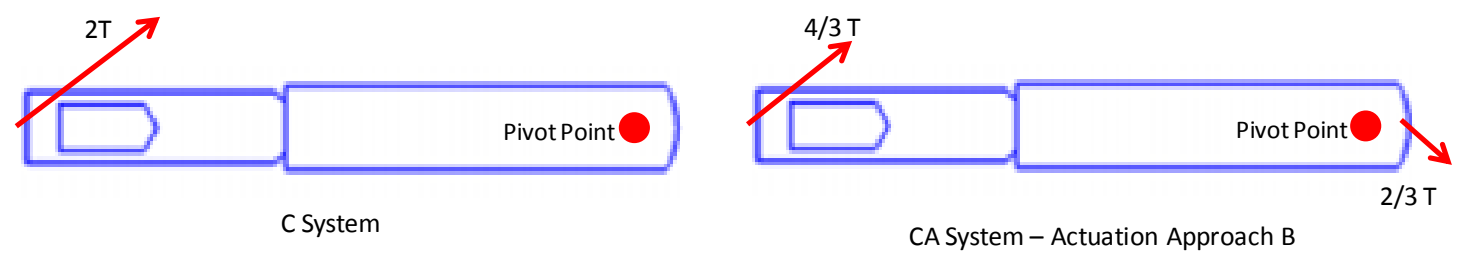

Figura 4-18 - Atuação do sistema de manobra no comboio para sistema C (esq.) e CA (dir.)

\subsubsection{Manobra de zig-zag para sistema C e CA}

Nesta seção, apresentam-se os resultados para a manobra de zig-zag 10/10 para as configurações de comboio 11BP(Figura 4-19), 12BP (Figura 4-20) e 23BP (Figura 4-21) para os sistemas de propulsão C e CA.

As manobras foram simuladas para a velocidade inicial $U_{0}=7$ nós e o tempo de simulação de 800 segundos.

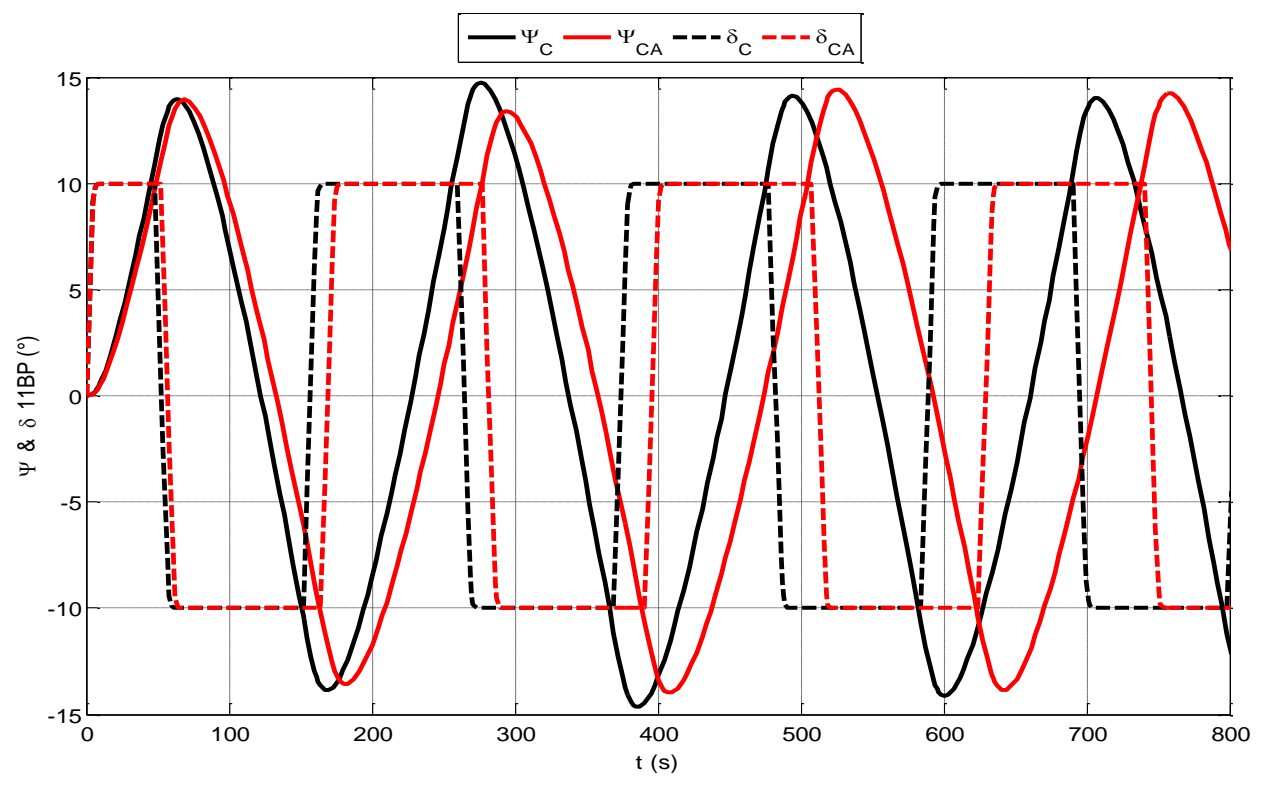

Figura 4-19 - Manobra de zig-zag 10/10 para sistema C e CA - comboio 11BP 


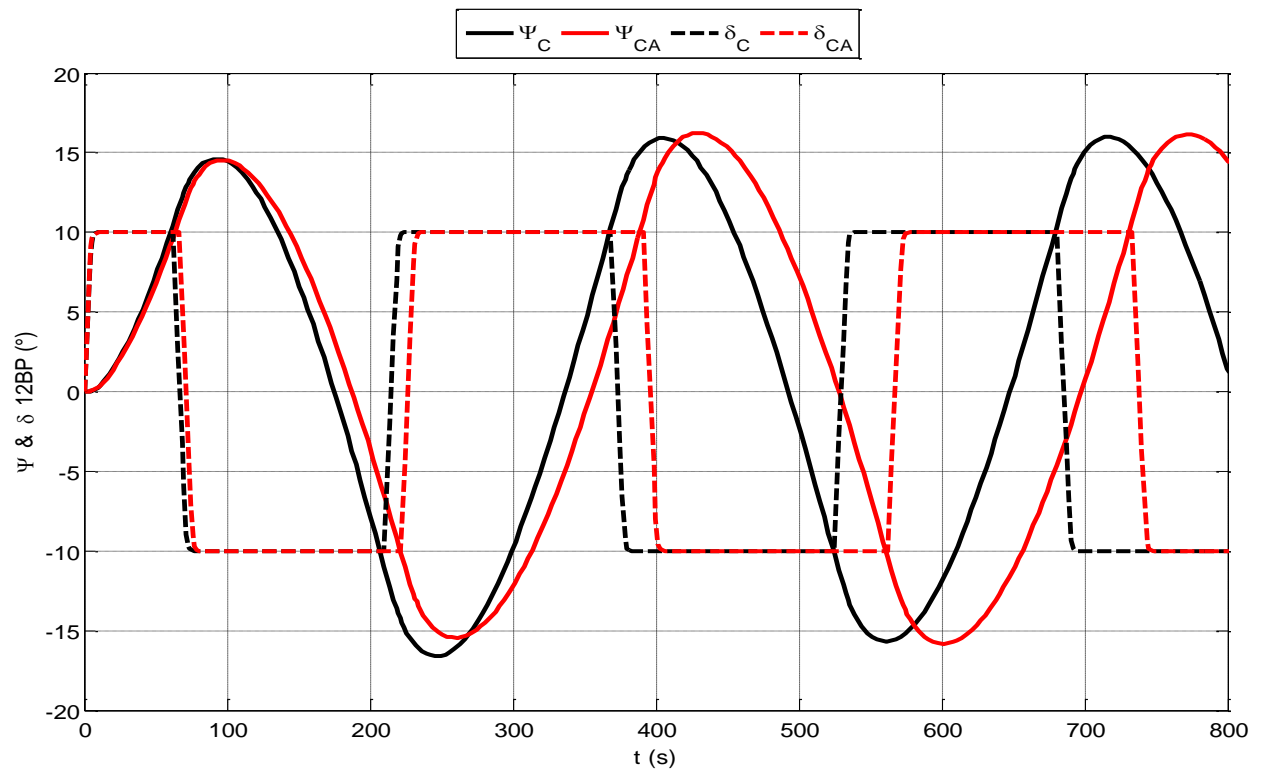

Figura 4-20 - Manobra de zig-zag 10/10 para sistema C e CA - comboio 12BP

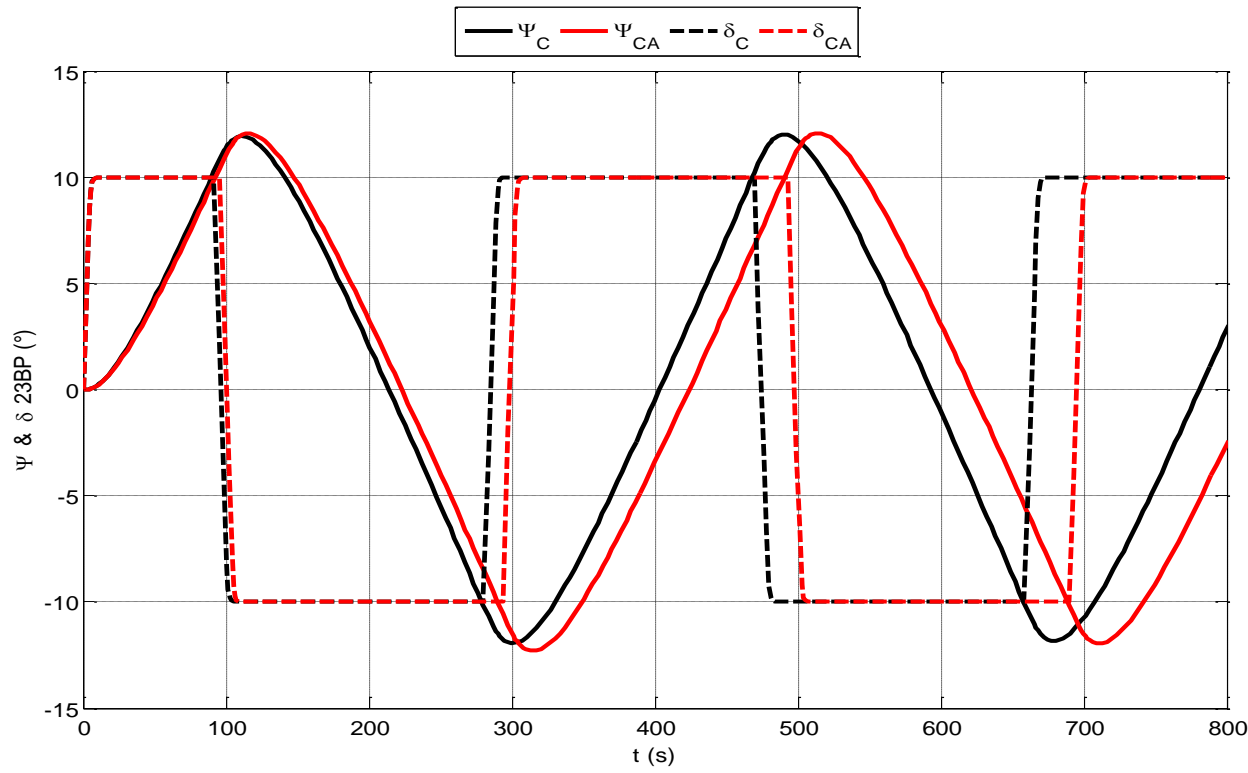

Figura 4-21 - Manobra de zig-zag 10/10 para sistema C e CA - comboio 23BP

Observa-se dos resultados das manobras de zig-zag 10/10 que os sobressinais do sistema CA são melhores que o sistema $C$, exceto para o comboio 23BP, no qual ambos os sistemas obtiveram diferenças desprezíveis. Em relação ao tempo de inversão da taxa de guinada, o sistema $\mathrm{C}$ obteve melhores 
resultados, porém quanto maior o número de barcaças, a diferença no tempo entre os sistemas diminui.

\subsubsection{Comparação entre sistema A e sistema AA}

Neste item, avaliou-se o desempenho do equipamento auxiliar de proa combinado com o sistema de azimutal. Os parâmetros utilizados nessas simulações foram ângulo do azimutal $\delta_{A}=20^{\circ}$ e ângulo do sistema auxiliar $\delta_{a u x}=-20^{\circ}$.

\subsubsection{Manobra de giro para sistema A e AA}

Os parâmetros da manobra de giro para os sistemas A e AA para as configurações de comboio 11BP, 12BP e 23BP são apresentados nas Figura 4-22, Figura 4-23 e Figura 4-24, respectivamente.
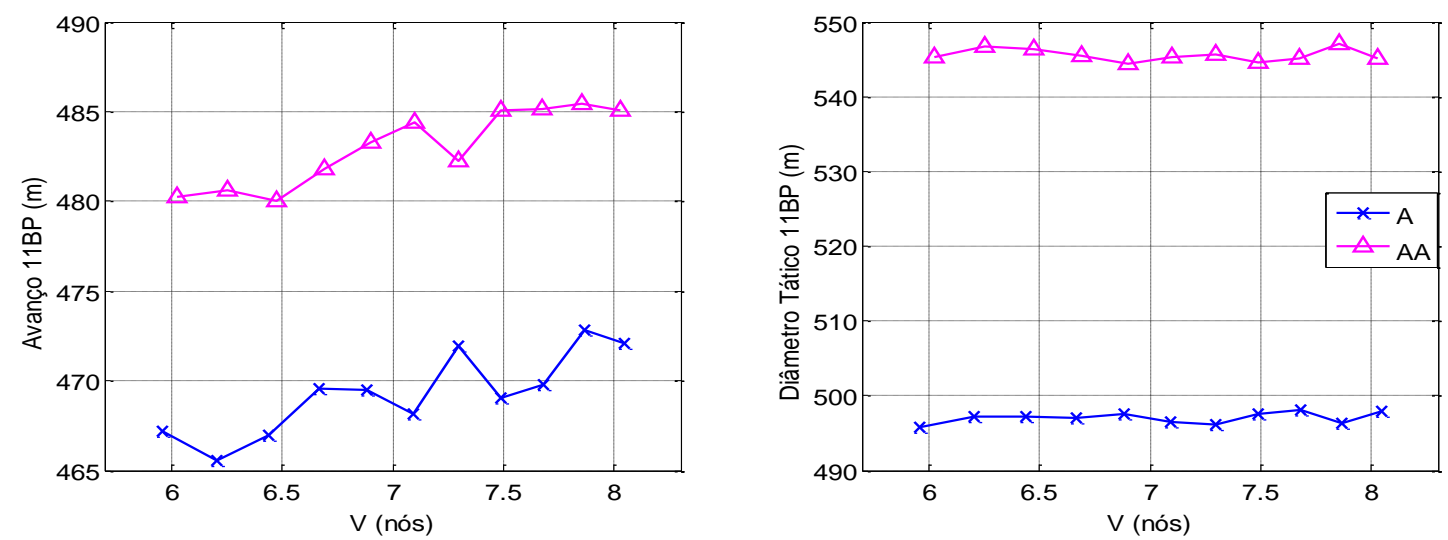

Figura 4-22 - Parâmetros da manobra de giro para sistema $\mathrm{A}\left(\delta_{A}=20^{\circ}\right)$ e $\mathrm{AA}\left(\delta_{A}=20^{\circ} / \delta_{\text {aux }}=\right.$ $-20^{\circ}$ ) - comboio $11 \mathrm{BP}$ 

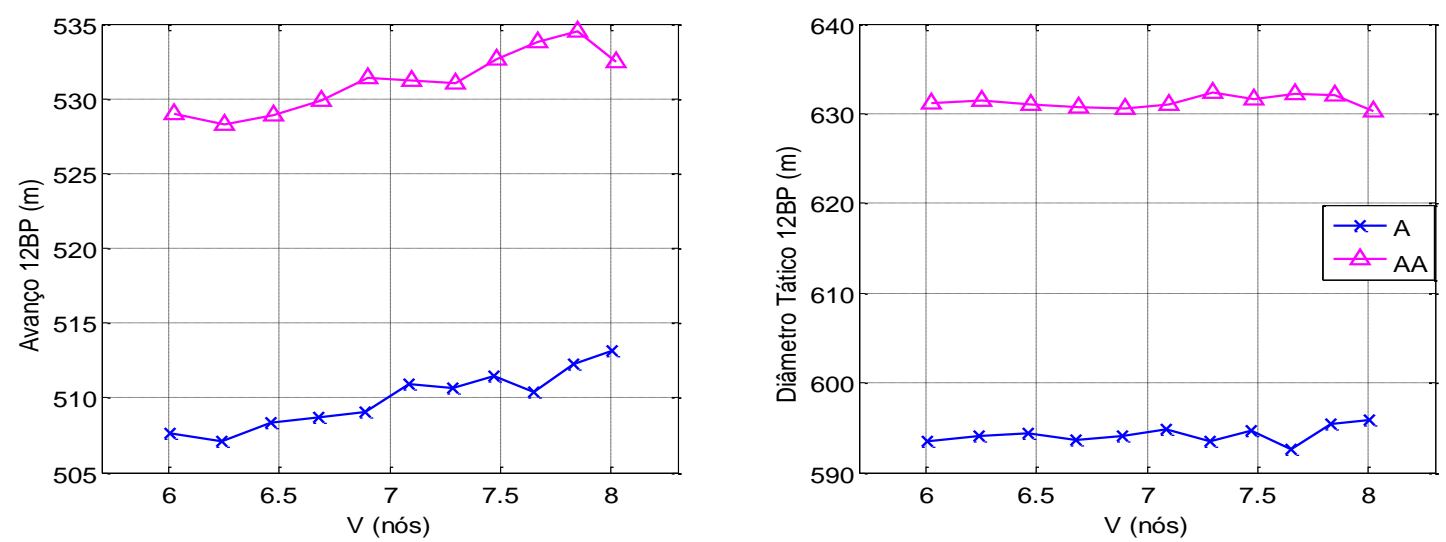

Figura 4-23 - Parâmetros da manobra de giro para sistema $\mathrm{A}\left(\delta_{A}=20^{\circ}\right)$ e $\mathrm{AA}\left(\delta_{A}=20^{\circ} / \delta_{\text {aux }}=\right.$ $-20^{\circ}$ ) - comboio $12 \mathrm{BP}$
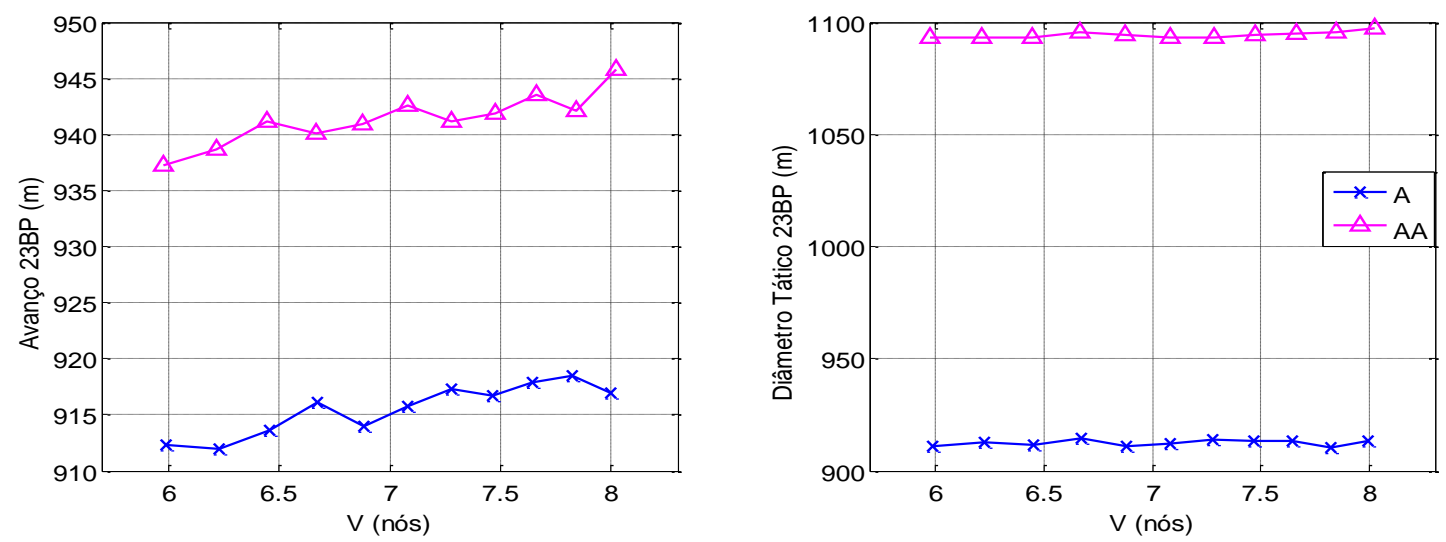

Figura 4-24 - Parâmetros da manobra de giro para sistema $\mathrm{A}\left(\delta_{A}=20^{\circ}\right)$ e $\mathrm{AA}\left(\delta_{A}=20^{\circ} / \delta_{\text {aux }}=\right.$ $-20^{\circ}$ ) - comboio $23 \mathrm{BP}$

No parâmetro $A v$ foi obtido uma piora cerca de $3 \%$ do sistema $A A$ em relação ao sistema A. Em relação ao DT, observa-se uma piora de aproximadamente $10 \%$ no comboio $11 \mathrm{BP}, 5 \%$ para $12 \mathrm{BP}$ e $20 \%$ para $23 \mathrm{BP}$.

A Figura 4-25, Figura 4-26 e Figura 4-27 mostram as manobras de giro para velocidade inicial 7 nós para os sistemas $A$ e AA, em que se apresentam os mesmos parâmetros das simulações das comparações anteriores. 

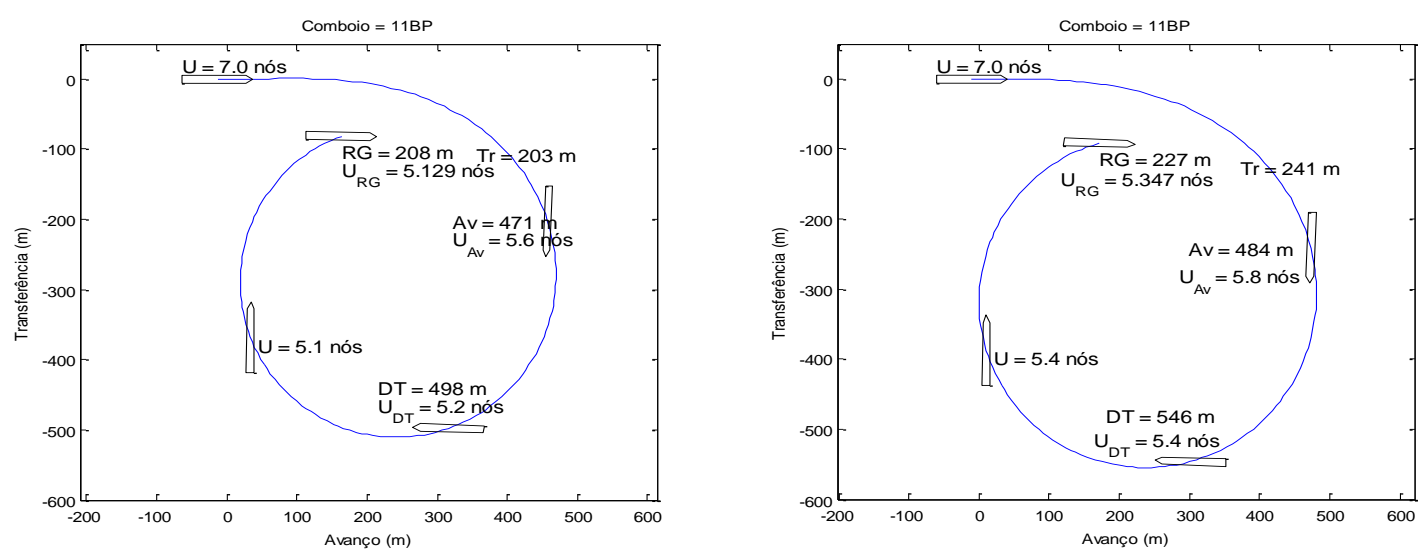

Figura 4-25 - Manobra de giro para sistema A (esq.) e AA (dir.) para $U_{0}=7$ nós - comboio $11 \mathrm{BP}$ $\left(\delta_{A}=20^{\circ} / \delta_{\text {aux }}=-20^{\circ}\right)$
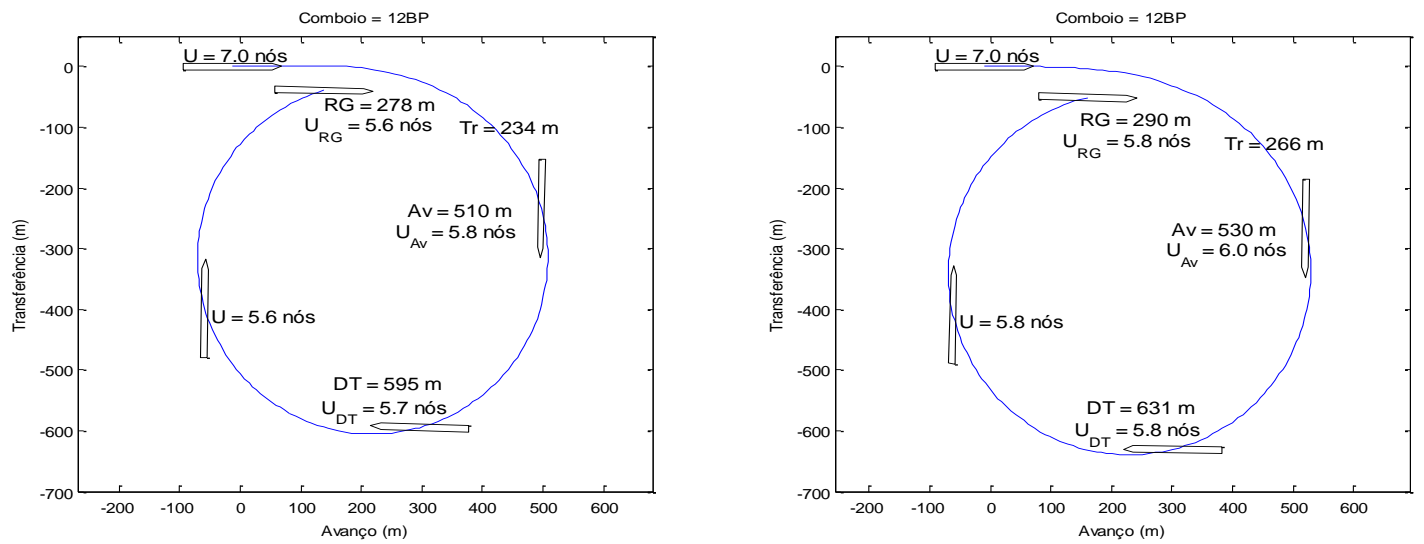

Figura 4-26 - Manobra de giro para sistema A (esq.) e AA (dir.) para $U_{0}=7$ nós - comboio 12BP $\left(\delta_{A}=20^{\circ} / \delta_{\text {aux }}=-20^{\circ}\right)$
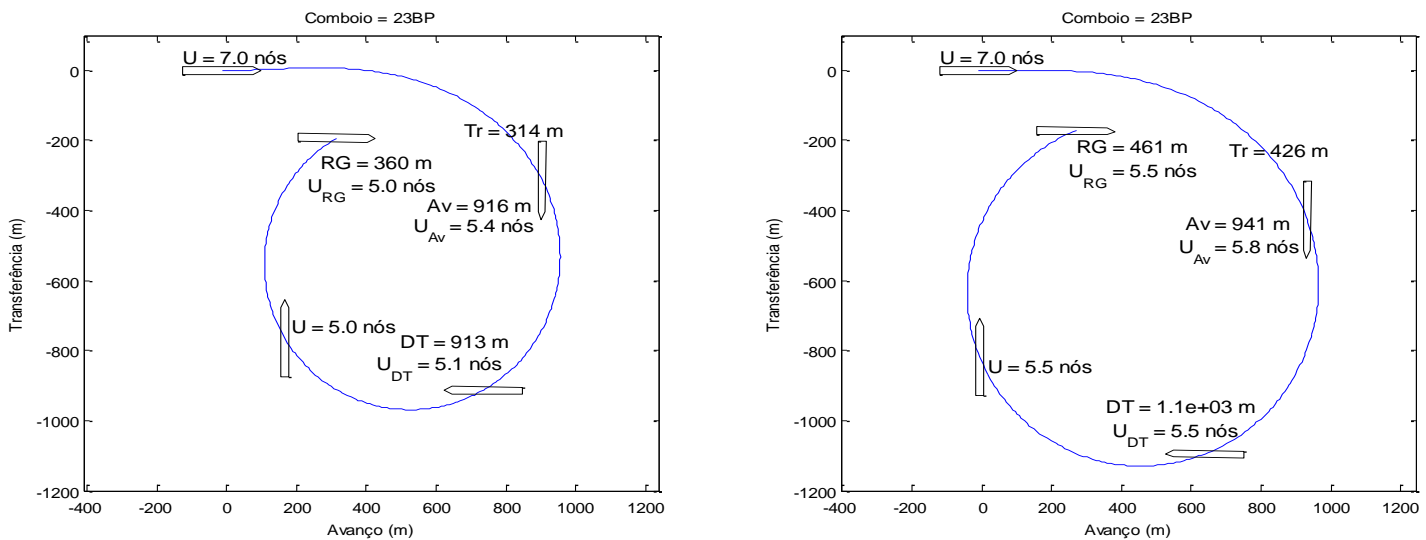

Figura 4-27 - Manobra de giro para sistema A (esq.) e AA (dir.) para $U_{0}=7$ nós - comboio 23BP $\left(\delta_{A}=20^{\circ} / \delta_{\text {aux }}=-20^{\circ}\right)$ 
A explicação para este comportamento é também relacionada ao momento menor no sistema AA em relação ao ponto de pivotamento citado no item 4.1.2.1 de modo a obter uma piora nos parâmetros da manobra de giro.

\subsubsection{Manobra de zig-zag para sistema A e AA}

Nesta seção, apresentam-se os resultados para a manobra de zig-zag 10/10 para os comboios 11BP (Figura 4-28), 12BP (Figura 4-29) e 23BP (Figura 4-30) para os sistemas A e sistema AA. As manobras foram executadas para a velocidade inicial $U_{0}=7$ nós.

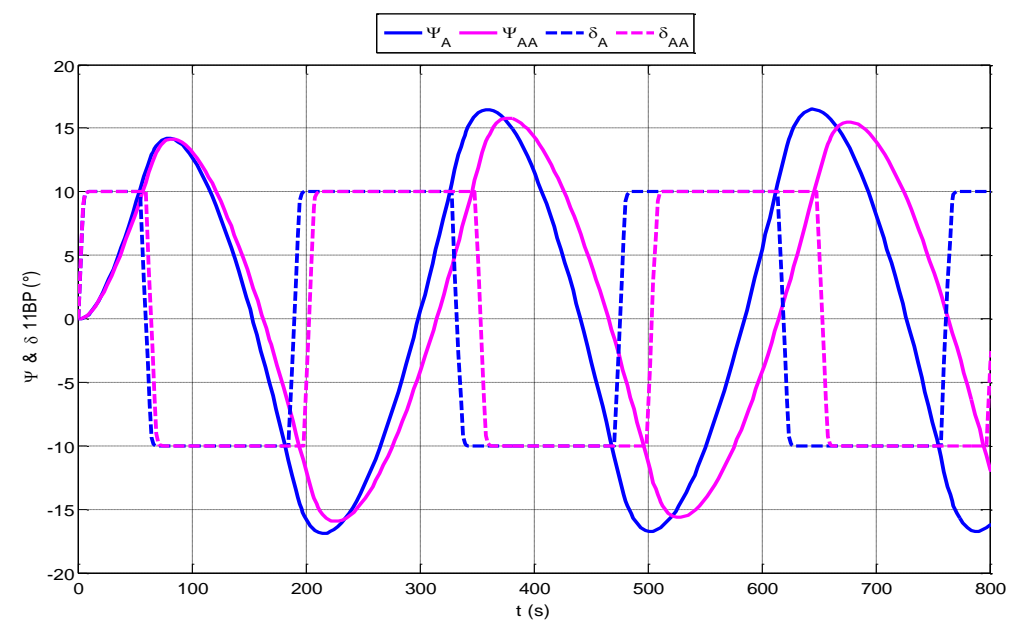

Figura 4-28 - Manobra de zig-zag 10/10 para propulsão A e AA - comboio 11BP

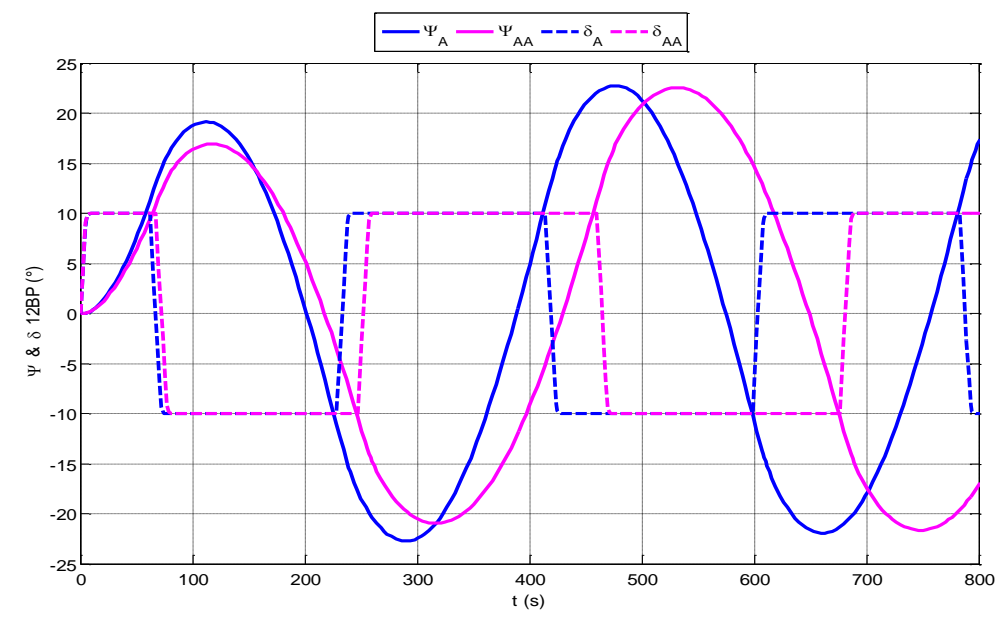

Figura 4-29 - Manobra de zig-zag 10/10 para propulsão A e AA - comboio 12BP 


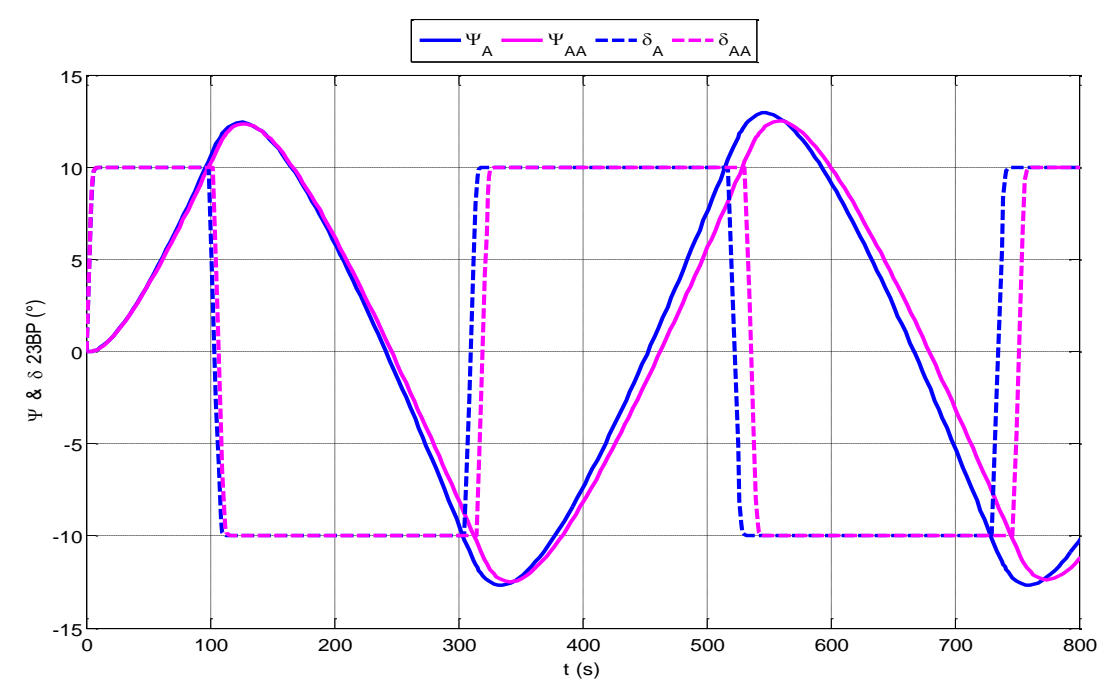

Figura 4-30 - Manobra de zig-zag 10/10 para propulsão A e AA - comboio 23BP

Observa-se uma pequena diminuição dos sobressinais para os sistemas $A A$ em relação ao sistema $A$ nas três configurações de comboio. A explicação para este fato advém de que o sistema $A$ induz uma maior taxa de guinada nos comboios (observar que as curvas do sistema $A$ apresentam maiores inclinações que do sistema $A A)$, entretanto, na inversão, o sistema de manobra tem mais dificuldade de "vencer a inércia" adquirida pelo comboio, explicando-se assim um maior ângulo de sobressinal.

\subsubsection{Variação do ângulo comandado para todos os sistemas}

Neste item foram realizadas as simulações de modo a verificar a eficiência dos diferentes sistemas de propulsão e manobra em função do ângulo comandado. Variou-se o ângulo comandado de $5^{\circ}$ a $35^{\circ}$, ângulos mais comuns durante a execução de manobra. Analisaram-se Av e DT para os comboios 11BP, 12BP e 23BP. Utilizaram-se os mesmos parâmetros das simulações anteriores como velocidade inicial antes do comando de leme $U_{0}=7$ nós, rotação do propulsor de 300 RPM. 


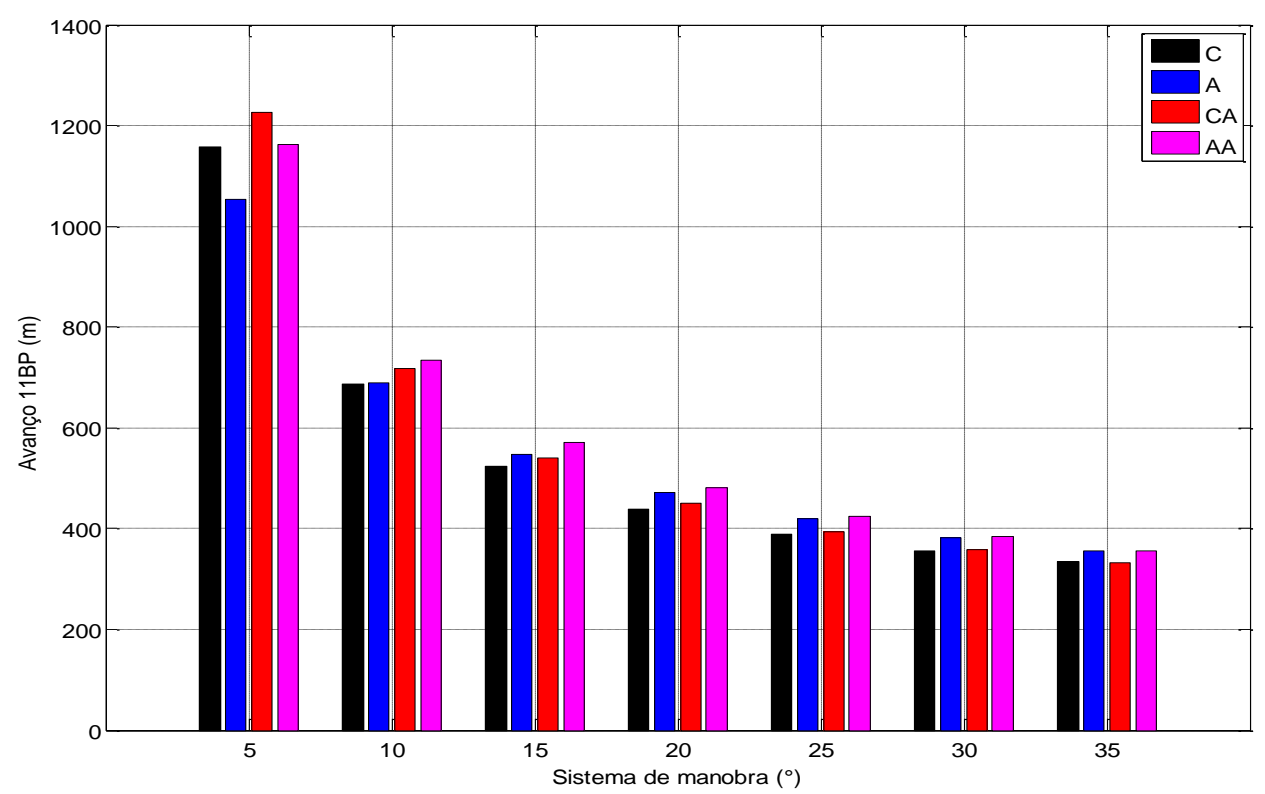

Figura 4-31 - Av para o comboio 11BP em função do ângulo comandando no sistema de manobra

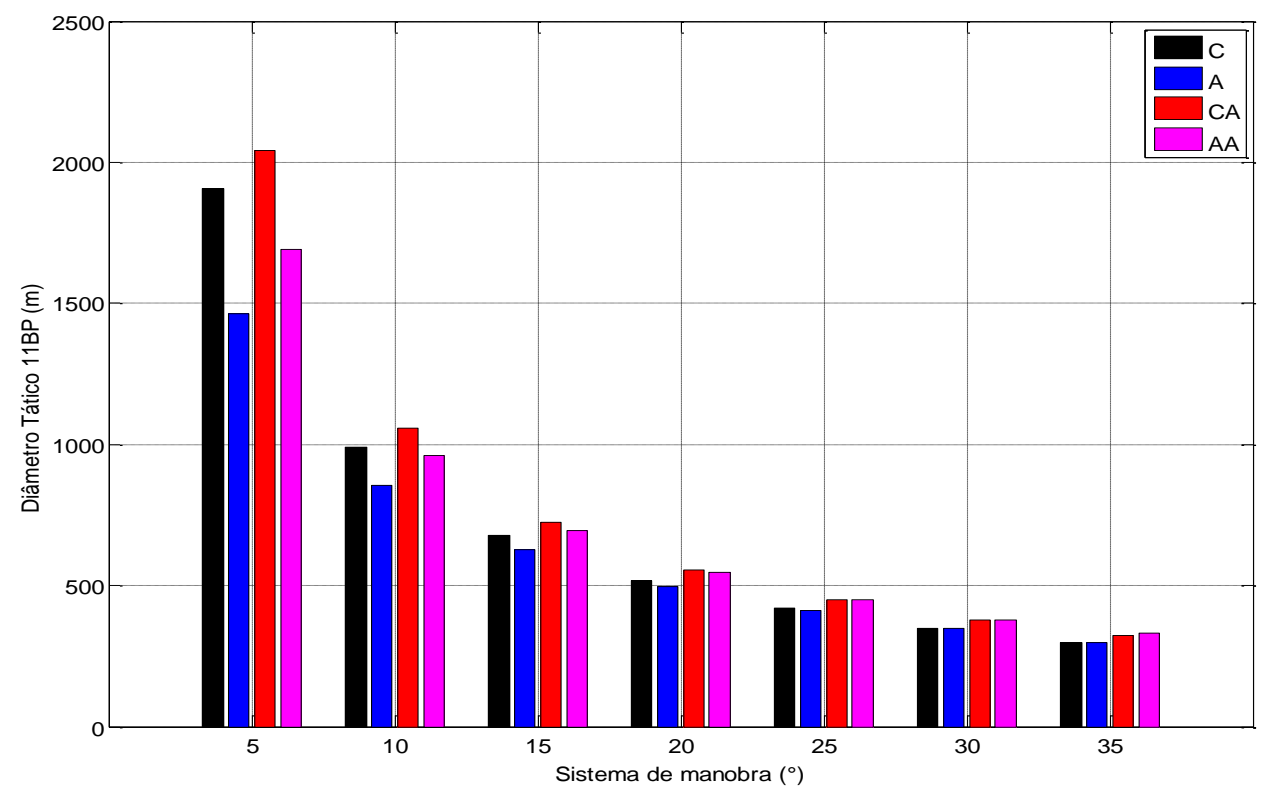

Figura 4-32 - DT para o comboio 11BP em função do ângulo comandando no sistema de manobra 


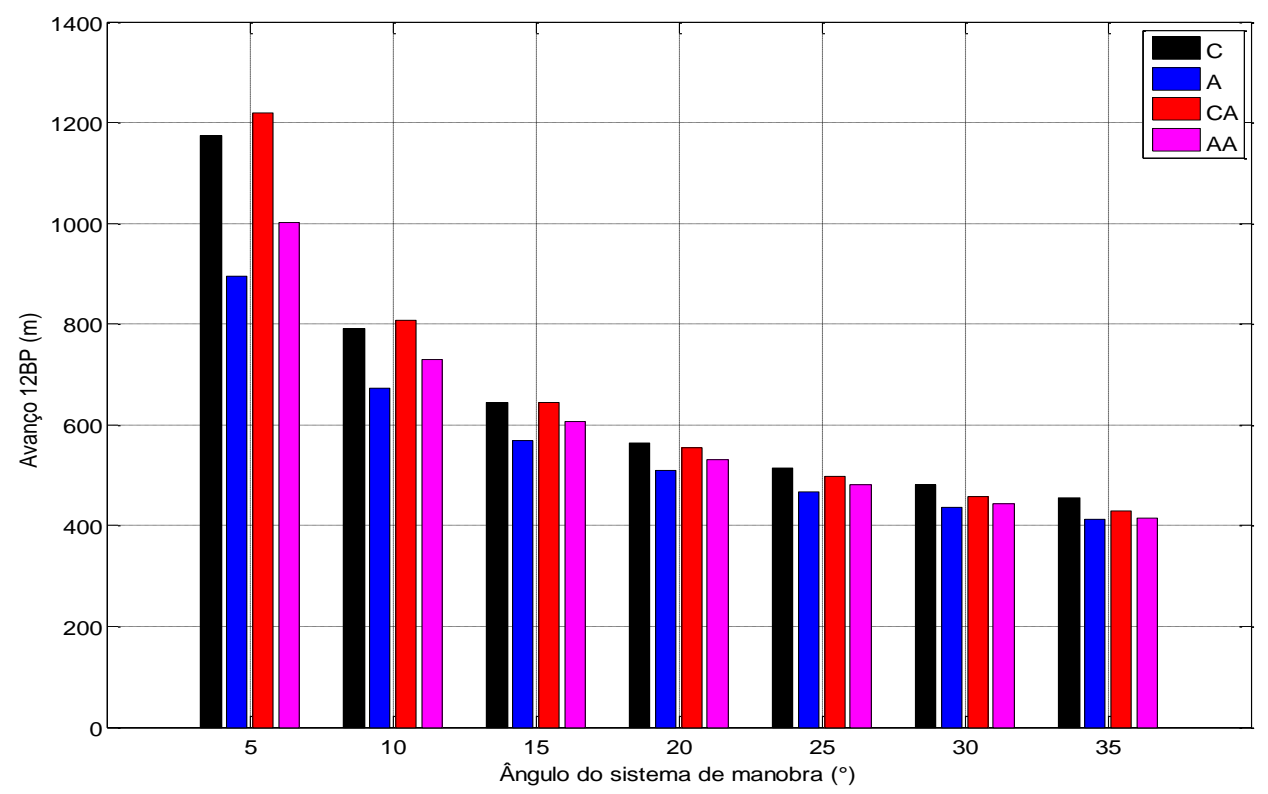

Figura 4-33 - Av para o comboio 12BP em função do ângulo comandando no sistema de manobra

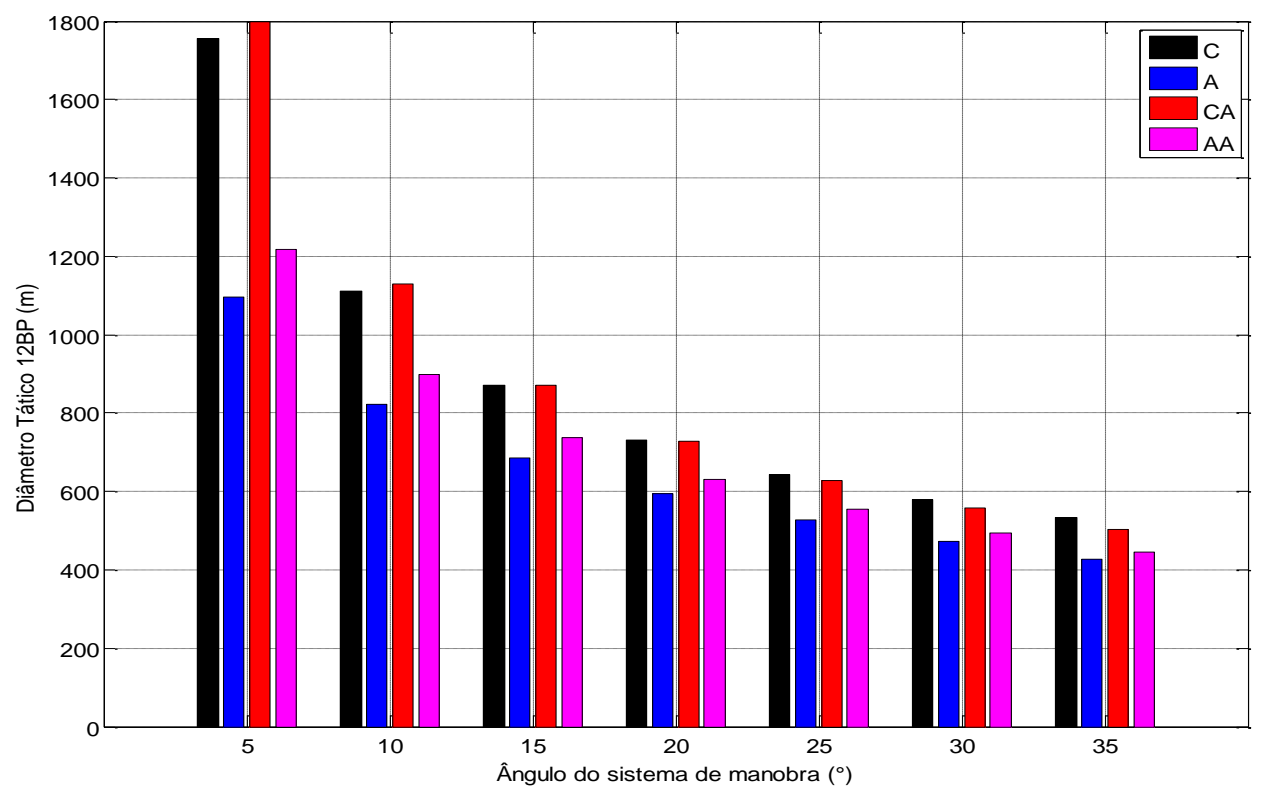

Figura 4-34 - DT para o comboio 12BP em função do ângulo comandando no sistema de manobra 


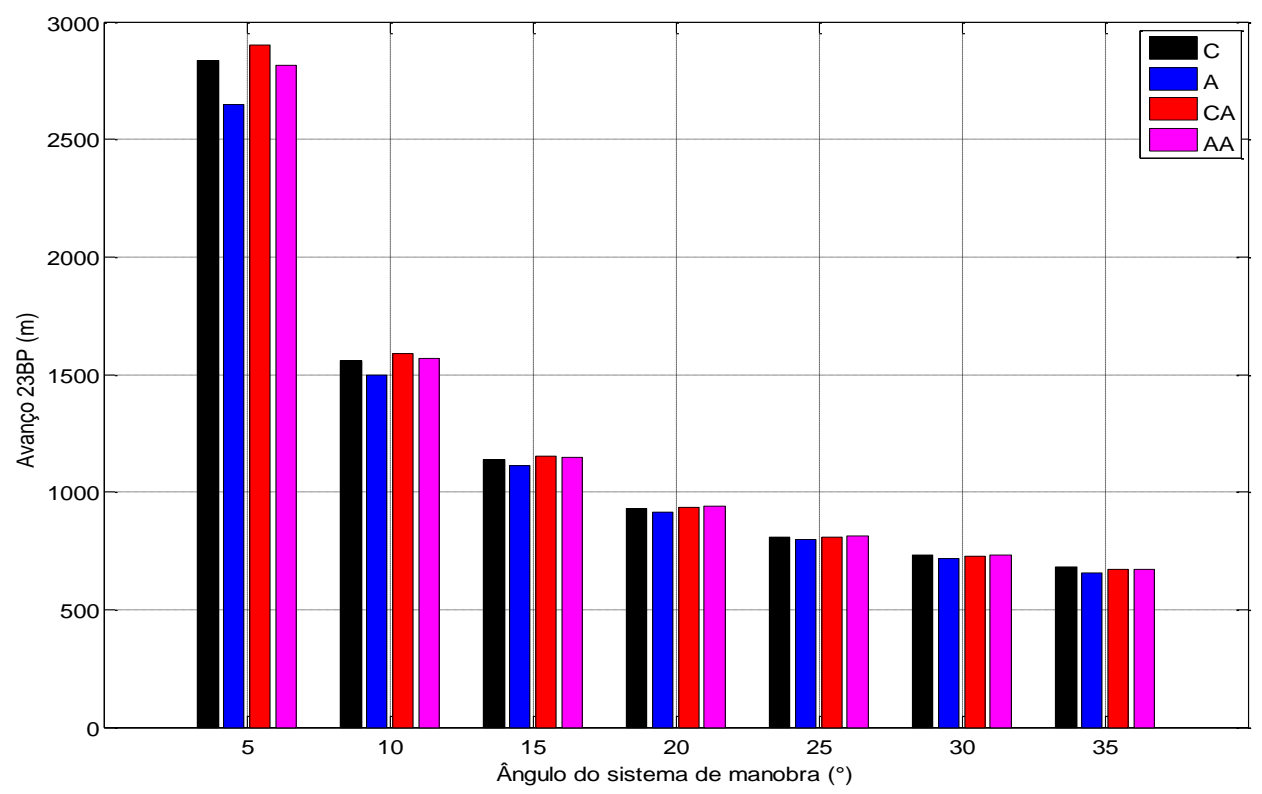

Figura 4-35 - Av para o comboio 23BP em função do ângulo comandando no sistema de manobra

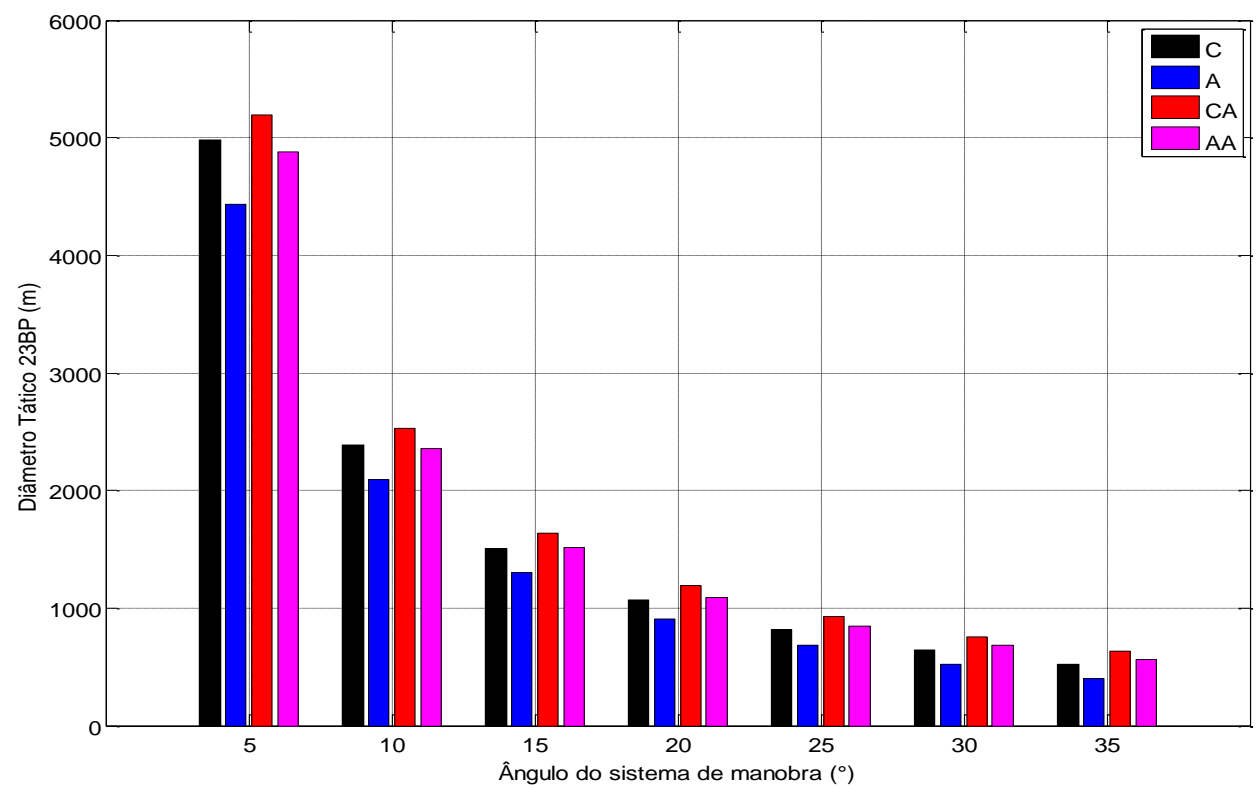

Figura 4-36 - DT para o comboio 23BP em função do ângulo comandando no sistema de manobra

Observa-se dos resultados a mesma tendência dos resultados obtidos nas manobras de giro apresentados anteriormente, em que o sistema A se mostra 
superior ao sistema $\mathrm{C}$, exceto para o comboio $11 \mathrm{BP}$, no qual para os ângulos do sistema de manobra menores que $10^{\circ}$ o Av do sistema $\mathrm{C}$ foi menor em relação ao sistema $A$. Em ambos os sistemas quando equipados com 0 sistema de propulsão auxiliar de proa o desempenho piora devido ao menor momento de guinada em relação ao ponto de pivotamento, que se localiza mais próximo à proa quando a embarcação está em avanço.

\subsection{Simulações com as embarcações em águas rasas}

Simularam-se também os efeitos de águas rasas nos sistemas de propulsão e manobra. Para essas simulações foi necessária a substituição das derivadas hidrodinâmicas calculadas por Yasukawa et al. (2007) pelas derivadas calculadas por Koh e Yasukawa (2012). Foi utilizada a configuração 11BP para uma velocidade de serviço de 5 nós e profundidade em função do calado $(h / T)$ para águas rasas de 1,2. Para realizar essas simulações foram utilizados os mesmos parâmetros de rotação com passo variável das simulações em águas profundas $\left(h / T_{T}>1,9\right)$.
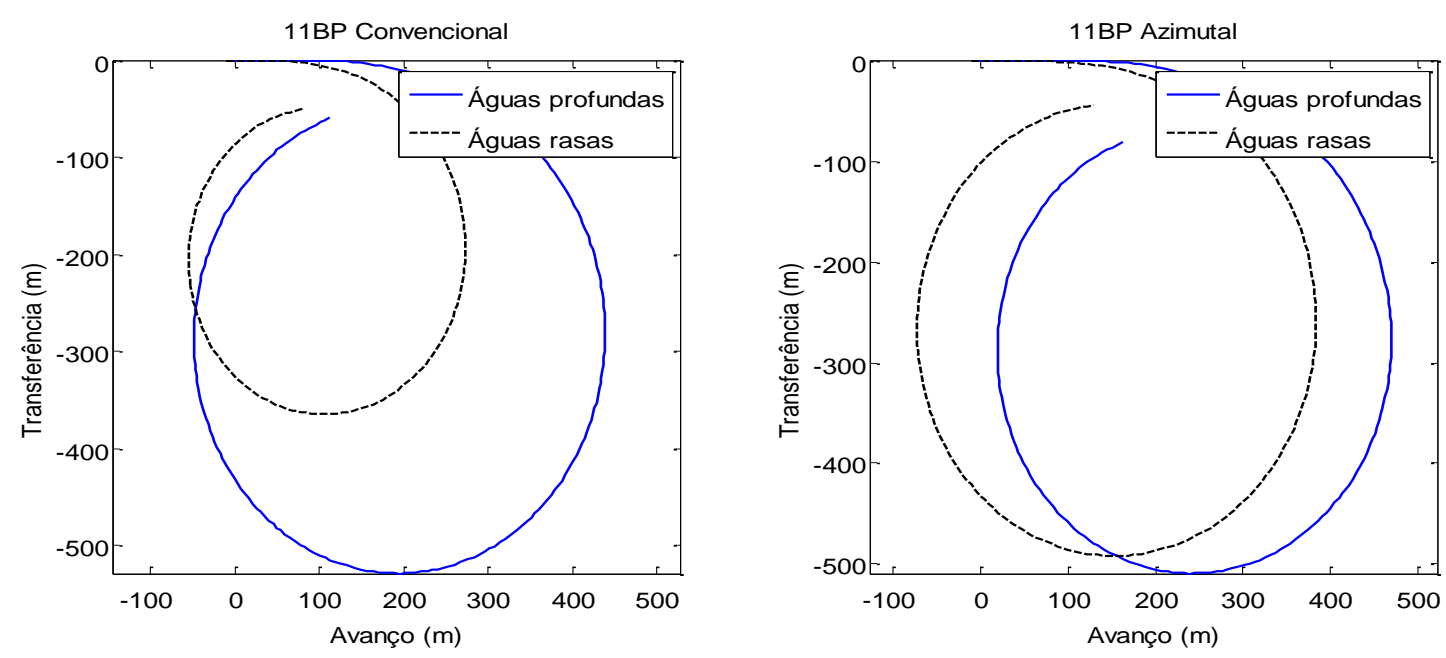

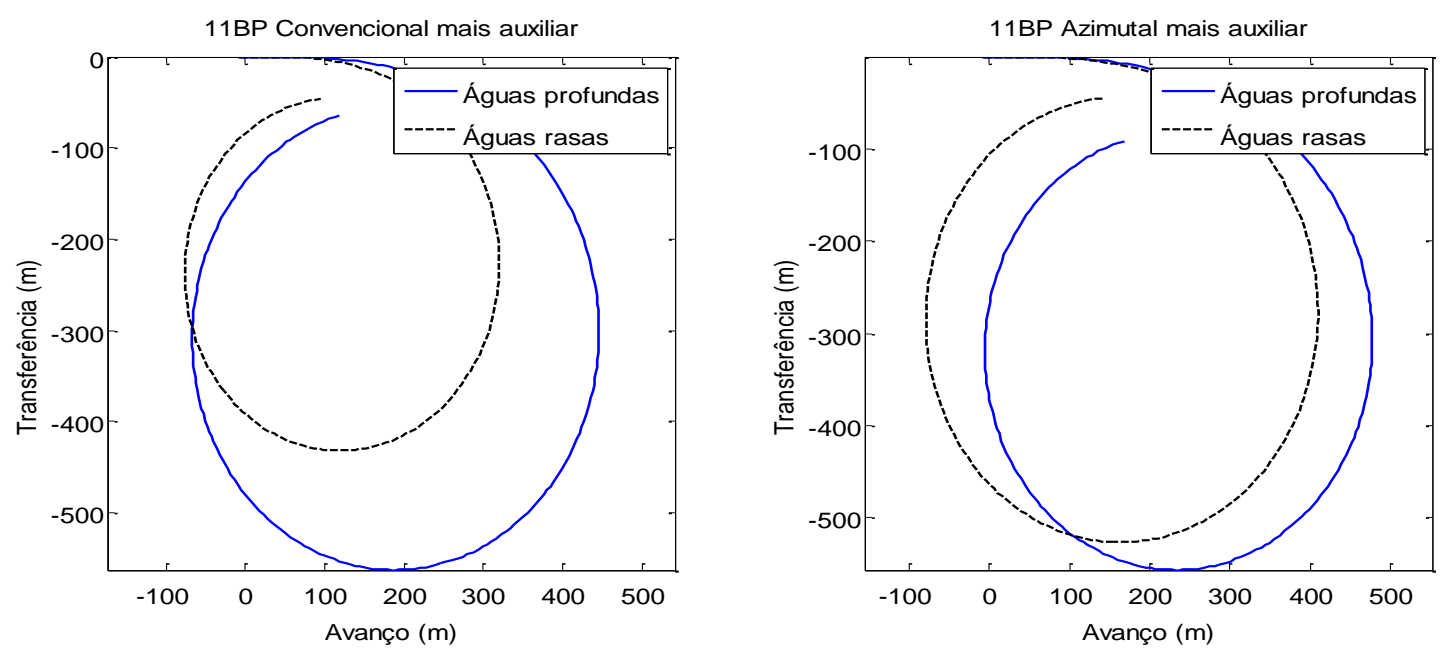

Figura 4-37 - Trajetórias das manobras de giro para os sistemas C (acima, esq.), A (acima, dir.), CA (em baixo, esq.) e AA (em baixo, dir.) em águas rasas e águas profundas - comboio $11 \mathrm{BP}$

Verifica-se pelas trajetórias do comboio que os sistemas com presença de leme são mais eficientes em águas rasas diminuindo consideravelmente os parâmetros nas manobras de giro. Isto difere do que ocorre nas simulações em águas profundas onde o sistema azimutal se mostrou superior. Em ambos os sistemas o equipamento auxiliar de proa piorou o desempenho do comboio.

Uma possível explicação para este fato é o aumento da eficiência do leme em águas rasas. A restrição imposta pelo fundo aumenta a velocidade do fluxo sob a quilha e no leme, o que eleva as forças e manobra produzidas pelo mesmo. Para o propulsor azimutal, esta maior velocidade de fluxo a montante reduz o empuxo gerado por ele. Ressalta-se que há necessidade de um estudo mais aprofundado sobre esse efeito para saber o real motivo em que o desempenho do sistema convencional foi superior ao sistema azimutal, principalmente com realizações de ensaios.

Nas figuras seguintes são apresentadas as manobras de zig-zag 10/10 para os sistemas C e A (Figura 4-38), C e CA (Figura 4-39) e sistemas A e AA (Figura 4-40). 


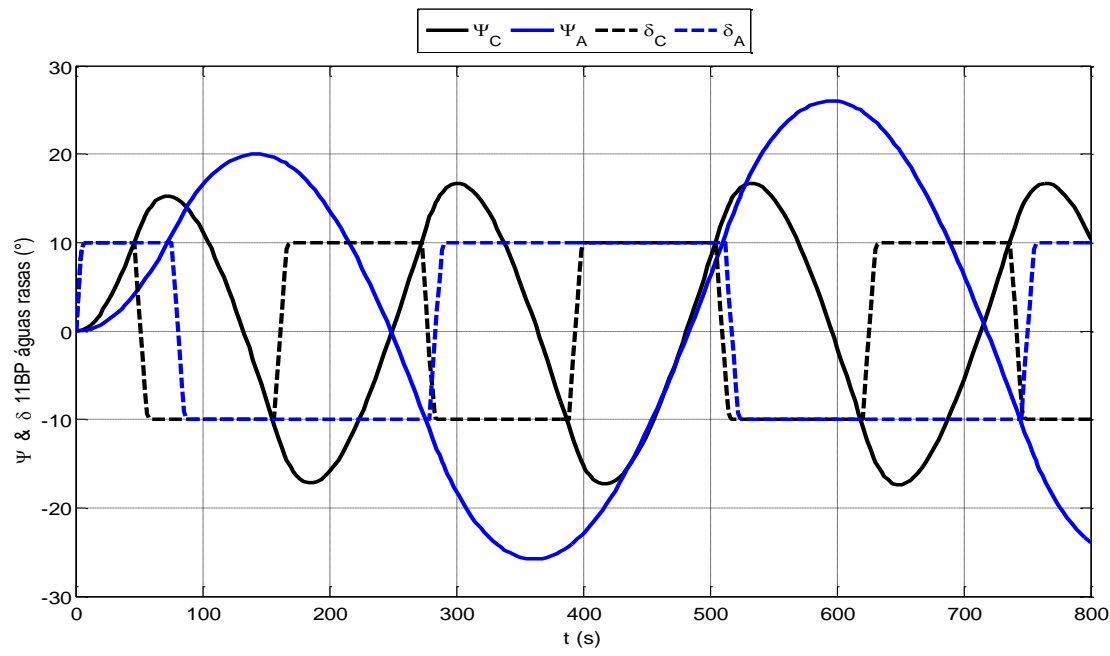

Figura 4-38 - Manobra de zig-zag 10/10 para propulsão C e A - comboio 11BP em águas rasas

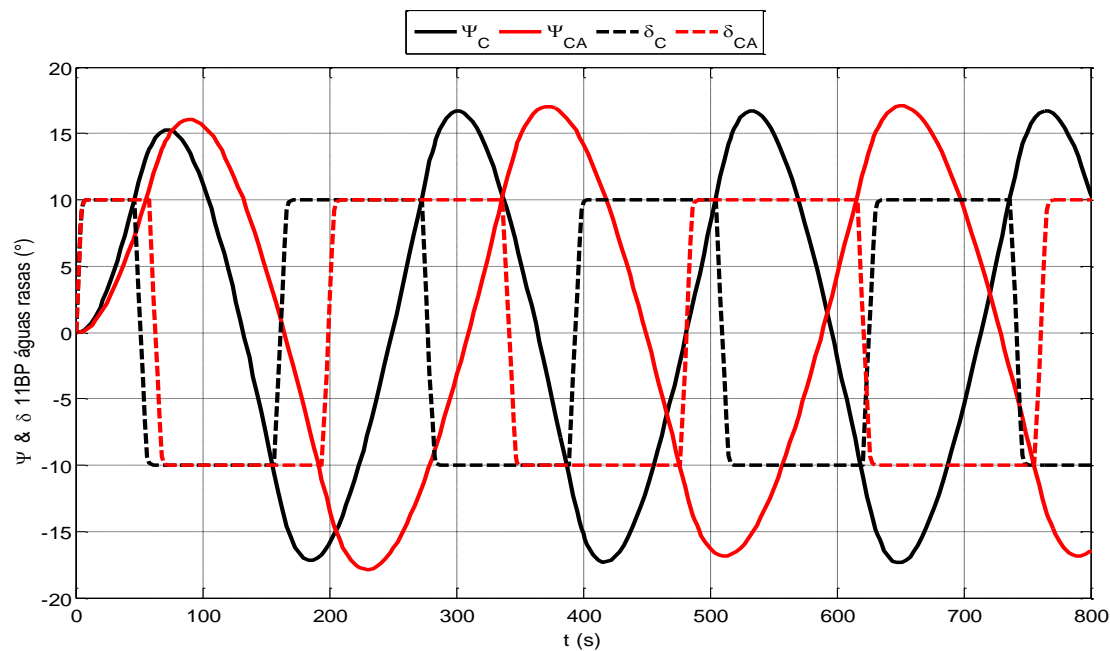

Figura 4-39 - Manobra de zig-zag 10/10 para propulsão C e CA - comboio 11BP em águas rasas 


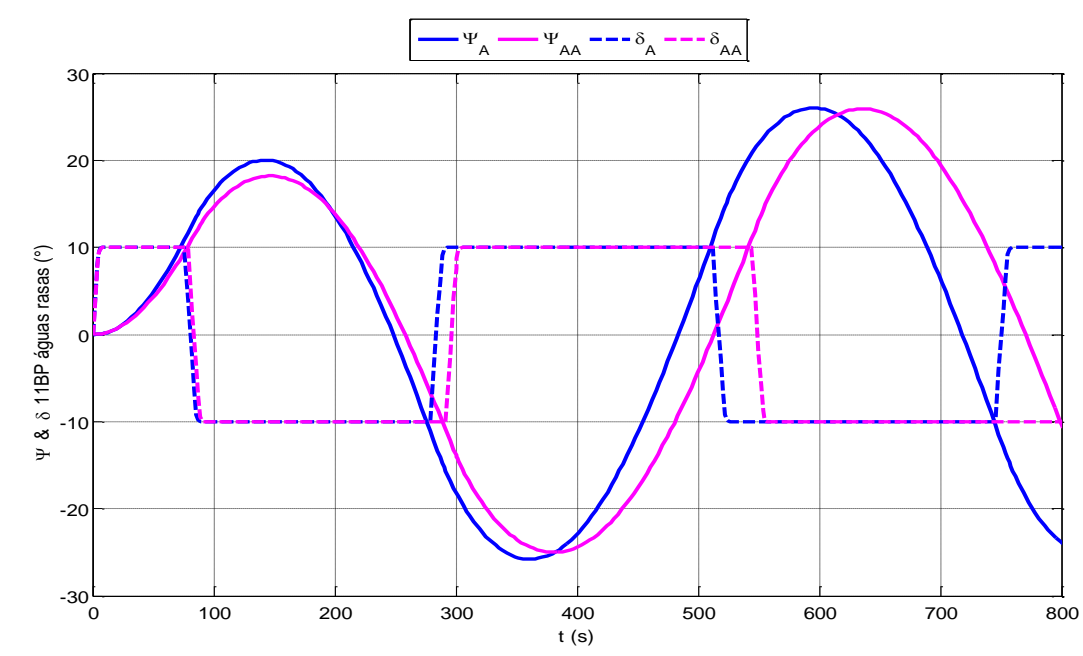

Figura 4-40 - Manobra de zig-zag 10/10 para propulsão A e AA - comboio 11BP em águas rasas

Observa-se dos gráficos de zig-zag a mesma tendência das simulações de águas profundas, em que o desempenho do sistema $\mathrm{C}$ é superior ao sistema $\mathrm{A}$, tanto no sobressinal, quanto no tempo de resposta do mesmo. Em ambos os sistemas o equipamento auxiliar de proa piora o desempenho no tempo de resposta e altera pouco o valor do sobressinal.

Das simulações com a variação do ângulo do sistema de manobra, apreendese a mesma tendência dos resultados da manobra de giro, nos quais o sistema $C$ apresenta um desempenho superior em relação ao sistema $A$, exceto para um ângulo de $5^{\circ}$ no DT. Observa-se também que o sistema auxiliar de proa quando equipado a ambos os sistemas, diminui o desempenho dos dois sistemas. 


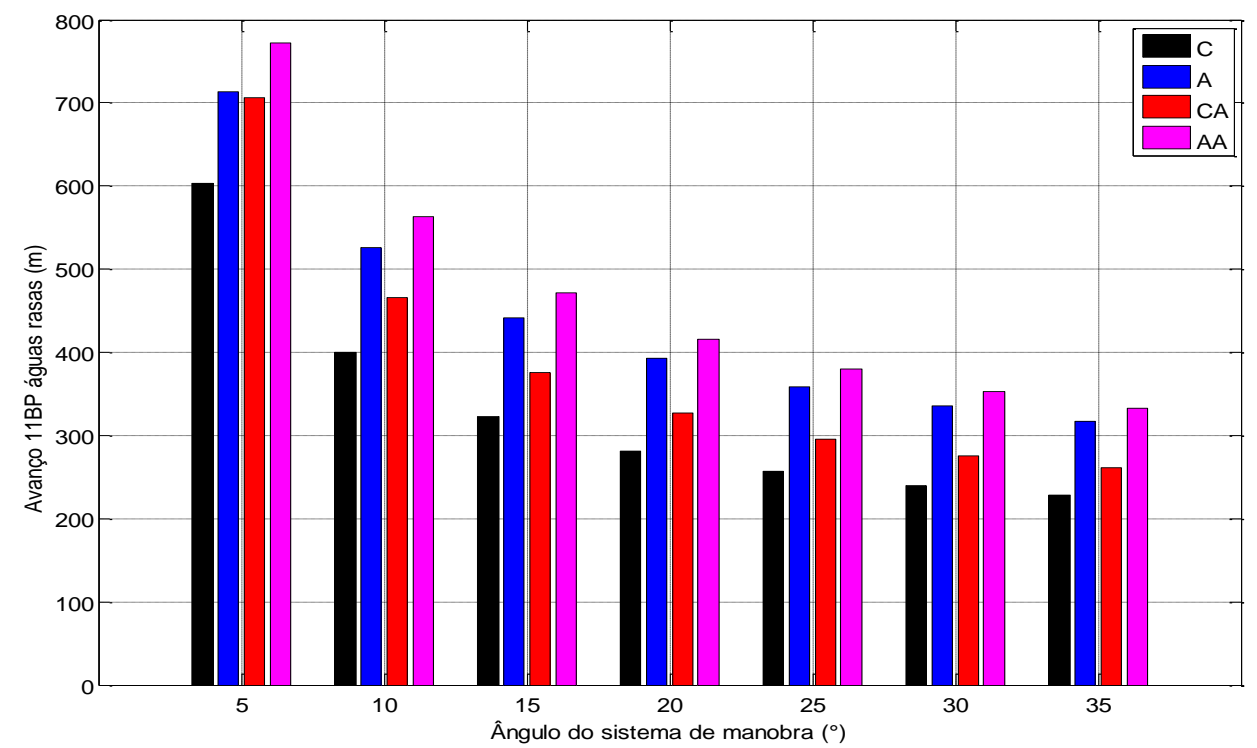

Figura 4-41 - Av para o comboio 11BP para águas rasas em função do ângulo comandando no sistema de manobra

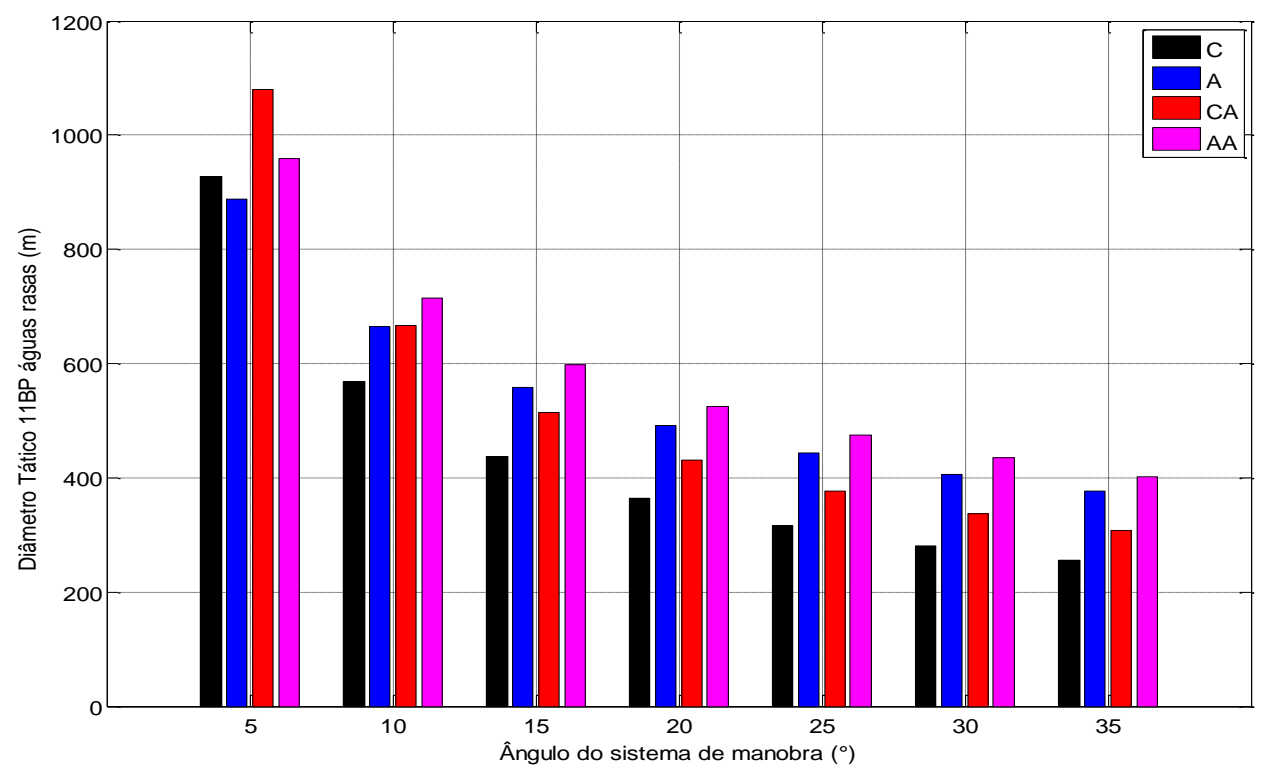

Figura 4-42 - DT para o comboio 11BP para águas rasas em função do ângulo comandando no sistema de manobra 


\subsection{Simulações com embarcações em baixa velocidade}

Neste item são apresentados simulações de baixa velocidade, nos quais as derivadas hidrodinâmicas obtidas por Koh et al.(2008) não são válidas por estarem distante da faixa de velocidade de serviço de 7 nós. Assim foi utilizado o modelo de Obokata (1981) e os coeficientes obtidos através de CFD de Grassi et al. (2013). O comboio utilizado foi do tipo 12BP.

\subsubsection{Manobra com velocidade de 1 nó}

Nesta primeira simulação de baixa velocidade, simula-se a passagem por pontes, por exemplo, em que o comboio necessita estar em baixa velocidade. $\mathrm{Na}$ simulação foi considerada uma velocidade inicial $U_{0}=1$ nó, e a partir desse instante foi dado o comando no sistema de manobra de $20^{\circ}$. Na Figura 4-43 observa-se a trajetória do comboio 12BP. Considerou-se o mesmo intervalo de tempo para as simulações.

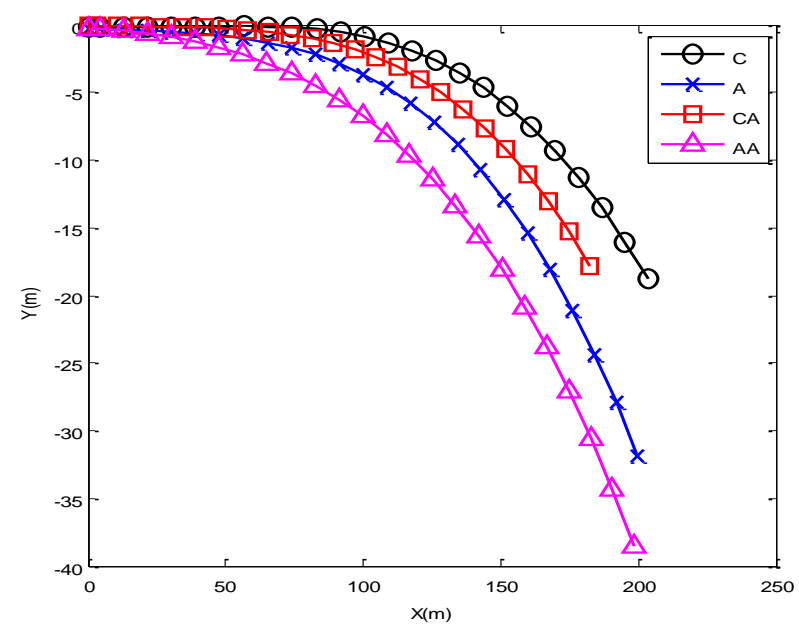

Figura 4-43 - Trajetória do comboio 12BP para os diferentes sistemas de propulsão e manobra para velocidade de 1 nó $\left(\delta=\delta_{A}=20^{\circ} / \delta_{\text {aux }}=-20^{\circ}\right)$

Observa-se dos resultados que o sistema $A$ tem um melhor desempenho em relação ao sistema $\mathrm{C}$. Adicionalmente, o equipamento auxiliar de proa propicia um aumento da manobrabilidade para ambos os sistemas. Desse modo, inverte a tendência das manobras para as embarcações na velocidade de 
serviço, ou seja, o equipamento de proa passa a apresentar considerável vantagem em termos de aumento de manobrabilidade em baixas velocidades.

\subsubsection{Simulações com embarcações inicialmente paradas}

Foram feitas simulações com a configuração 12BP de comboio, de modo a comparar o desempenho dos sistemas de propulsão para manobras nas quais as embarcações iniciam-se paradas. O objetivo destas simulações é avaliar a capacidade de manobra de cada sistema de propulsão em baixas velocidades.

\subsubsection{Sistema C}

$\mathrm{Na}$ simulação com propulsão convencional foi utilizado o ângulo de leme $\delta=35^{\circ}$.

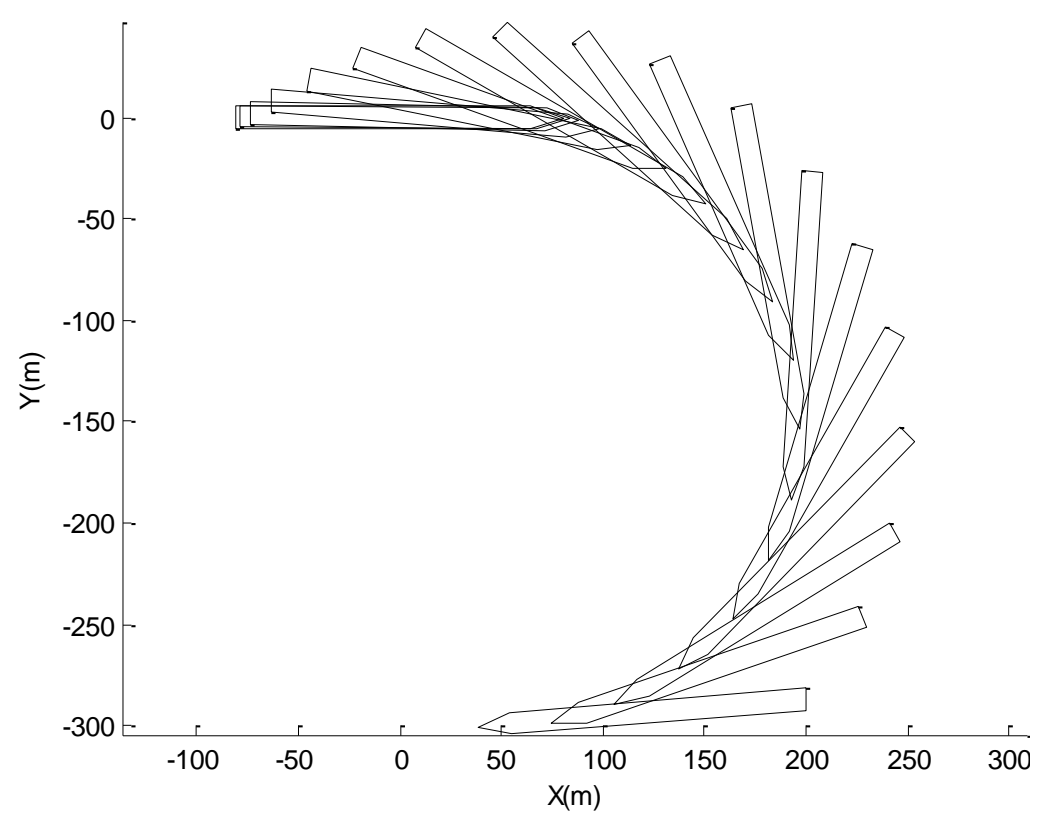

Figura 4-44 - Comportamento em manobra para comboio 12BP inicialmente parada com sistema C

Observa-se que, devido ao comboio se encontrar inicialmente parado, o sistema de propulsão convencional gerou um momento resultante maior se comparada à continuação da manobra, pois o avanço foi de aproximadamente 
200m enquanto que a transferência de $100 \mathrm{~m}$ e diâmetro tático de $300 \mathrm{~m}$. Assim, observa-se que o deslocamento longitudinal até o aproamento de $90^{\circ}$ foi aproximadamente igual ao deslocamento longitudinal do aproamento de $90^{\circ}$ a $180^{\circ}$. A manobra será comparada com o mesmo movimento do sistema de propulsão convencional associado ao equipamento auxiliar de proa no item 4.3.2.3.

\subsubsection{Sistema A}

$\mathrm{Na}$ simulação com propulsão azimutal foi utilizado o ângulo de azimute $\delta_{A}=90^{\circ}$.

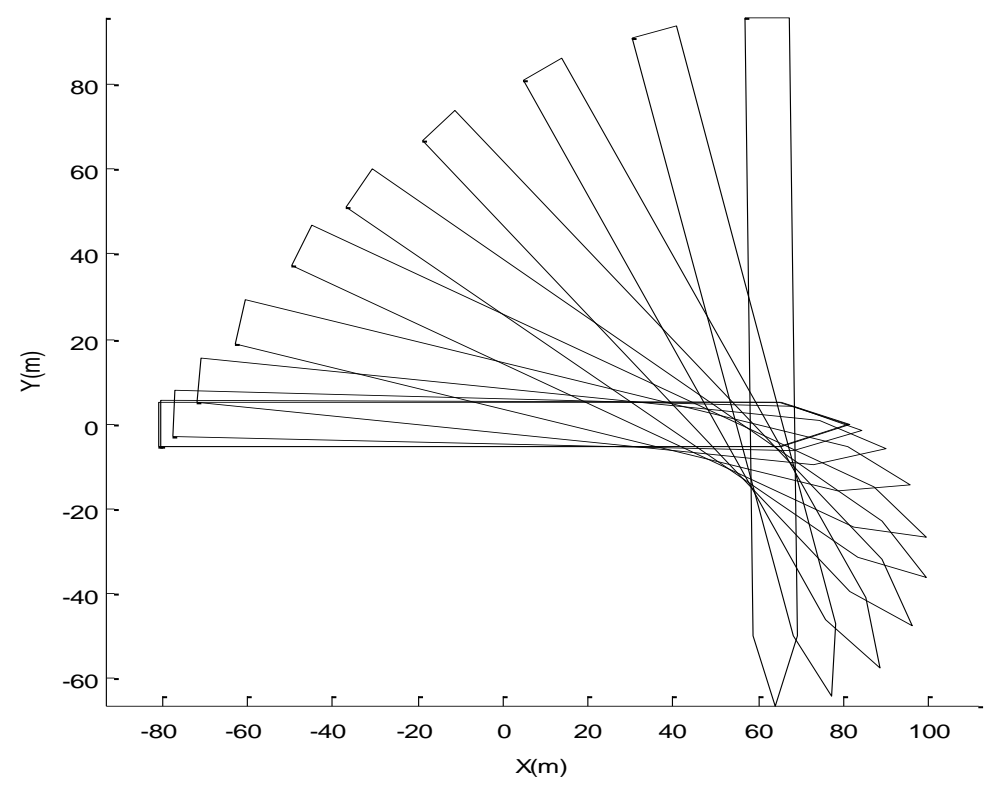

Figura 4-45 - Comportamento em manobra para comboio 12BP inicialmente parada com sistema A

Nota-se da Figura 4-45 que o sistema de propulsão azimutal consegue impor ao um movimento de rotação em torno da sua proa, mostrando que para manobras inicialmente paradas (ou em baixas velocidades) teria uma ótima eficiência em relação ao sistema de propulsão convencional. Observa-se que o ponto de rotação do comboio se encontra entre a seção mestra e a proa da 
embarcação, aumentando consideravelmente a manobrabilidade em relação ao sistema C.

\subsubsection{Sistema CA}

$\mathrm{Na}$ simulação com propulsão convencional associado ao sistema auxiliar de proa, foi utilizado um ângulo do sistema auxiliar de proa $\delta_{a u x}=-90^{\circ}$ e ângulo de leme $\delta=35^{\circ}$.

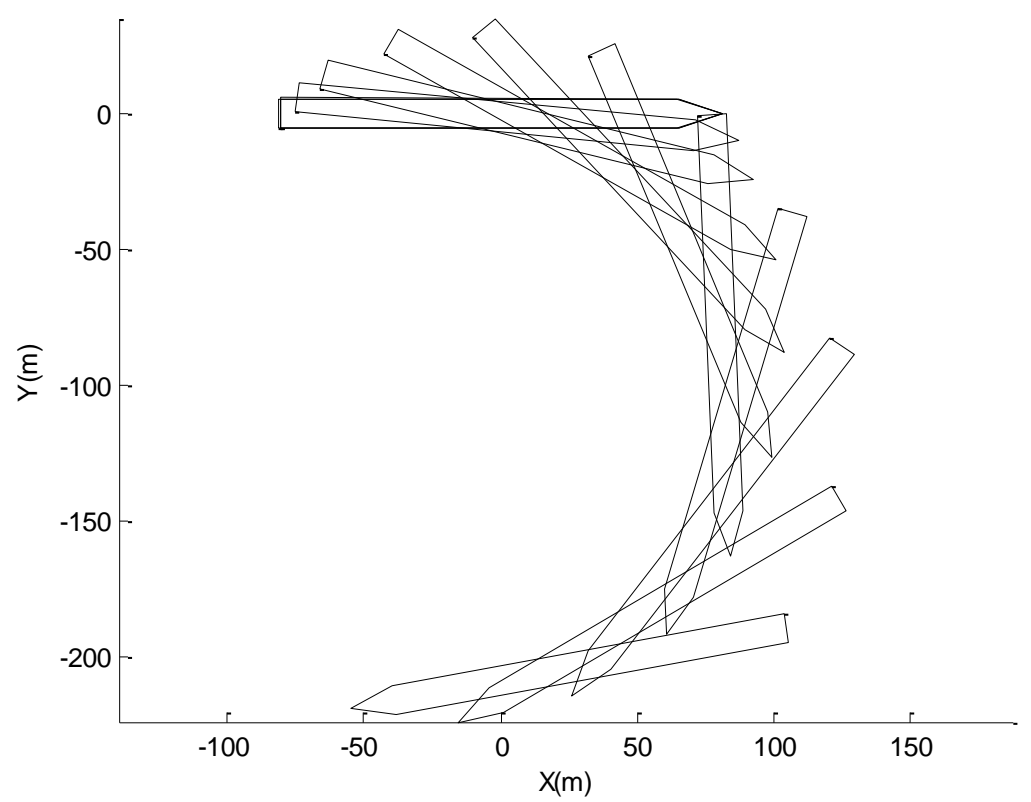

Figura 4-46 - Comportamento em manobra para comboio 12BP inicialmente parada com propulsão CA

Observa-se que o avanço foi de $90 \mathrm{~m}$ e o diâmetro tático de $200 \mathrm{~m}$. Assim, comparando o movimento com o sistema de propulsão convencional (Figura 4-44), com o acréscimo do equipamento auxiliar de proa, percebe-se que o sistema ajuda na movimento de giro da embarcação em relação ao sistema $\mathrm{C}$ diminuindo em aproximadamente 55\% na manobra de avanço e $33 \%$ no diâmetro tático. 


\subsubsection{Sistema AA}

Na simulação com propulsão azimutal associado ao sistema auxiliar de proa, foi utilizado ângulo do sistema auxiliar de proa $\delta_{a u x}=-90^{\circ} \mathrm{e}$ ângulo de azimutal $\delta_{A}=90^{\circ}$.

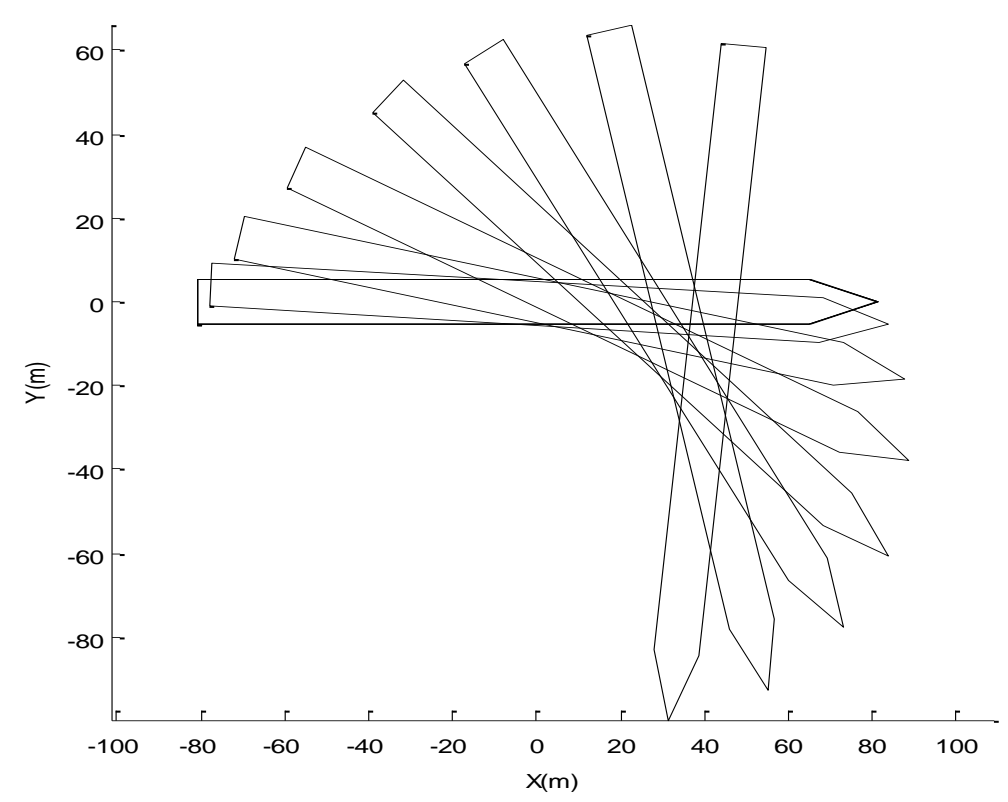

Figura 4-47 - Comportamento em manobra para comboio 12BP inicialmente parada com sistema AA

Observa-se da Figura 4-47 que o sistema de propulsão azimutal combinada com o equipamento de proa faz com que o comboio rotacione sobre um ponto próximo a seção mestra da embarcação. Ou seja, aumenta-se ainda mais a eficiência em manobras em baixas velocidades em relação ao sistema de propulsão auxiliar.

\subsubsection{Análise de sensibilidade do equipamento auxiliar de proa}

Nas análises anteriores considerou-se $1 / 3$ do empuxo total do sistema instalado na proa (Figura 4-2). Porém esse valor pode ser inviável em termos práticos. Assim, neste item realiza-se uma análise de sensibilidade, variandose $1 / 3$ do empuxo total porcentualmente de 0 a $100 \%$ para as manobras 
inicialmente paradas, no qual o equipamento de proa apresentou maior eficiência.

Utilizaram-se nessas simulações os mesmos ângulos dos sistemas de manobra do item 4.3.2 (sistema CA: $\delta_{a u x}=-90^{\circ} / \delta=35^{\circ}$ e sistema AA: $\left.\delta_{\text {aux }}=-90^{\circ} / \delta_{A}=90^{\circ}\right)$

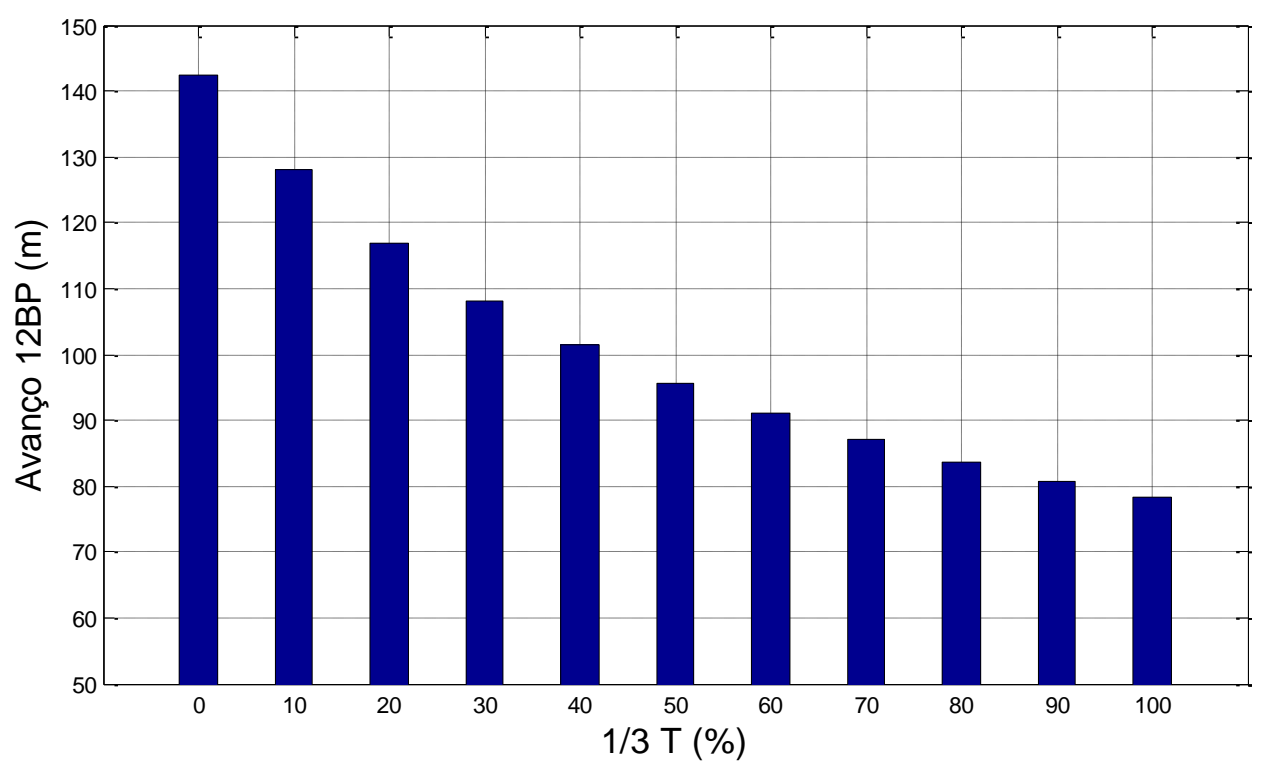

Figura 4-48 - Análise de sensibilidade do avanço para o sistema CA 


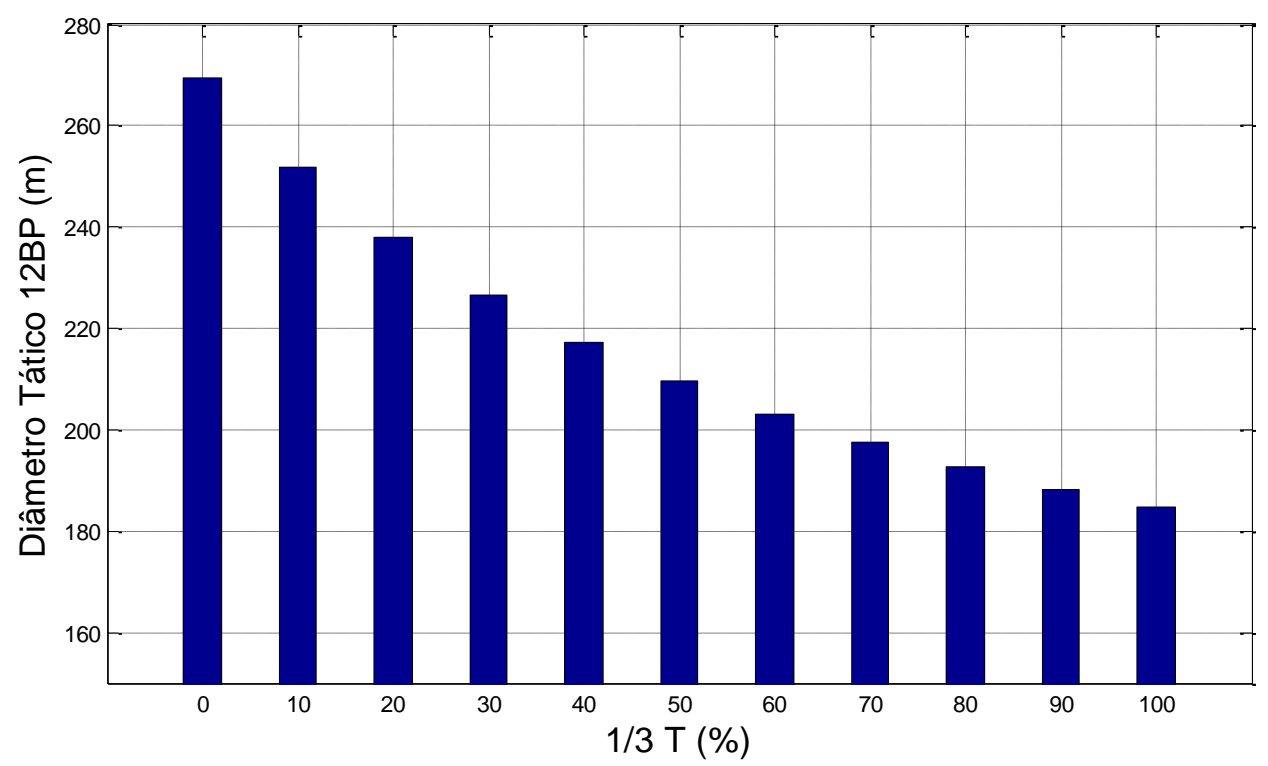

Figura 4-49 - Análise de sensibilidade do diâmetro tático para o sistema CA

Observa-se dos resultados para o sistema CA que há uma maior queda nos parâmetros de $A v$ e DT para um porcentual de até 30\% do empuxo do equipamento auxiliar, pois houve queda de $25 \%$ para o Av e para o DT, uma queda de $15 \%$. Para uma utilização de $60 \%$ de $1 / 3$ T houve uma diminuição de $35 \%$ e $25 \%$ para Av e DT, respectivamente.

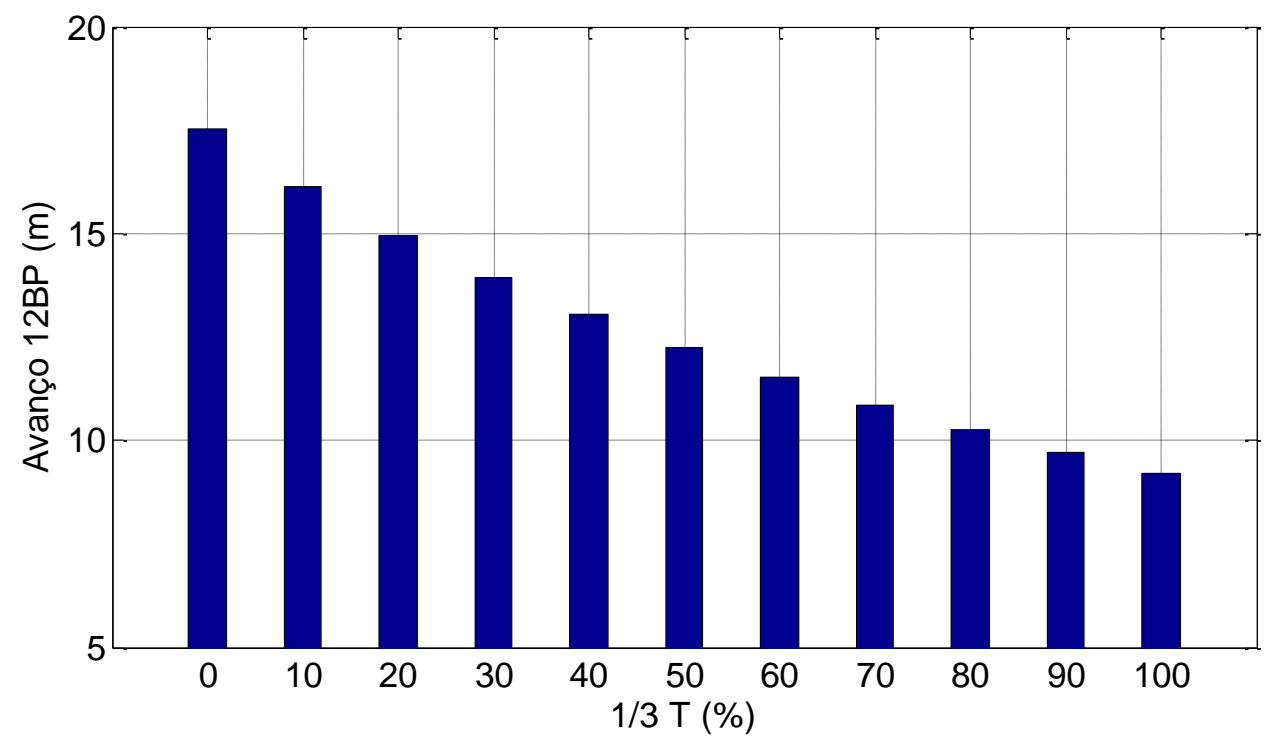

Figura 4-50 - Análise de sensibilidade do avanço para o sistema AA 


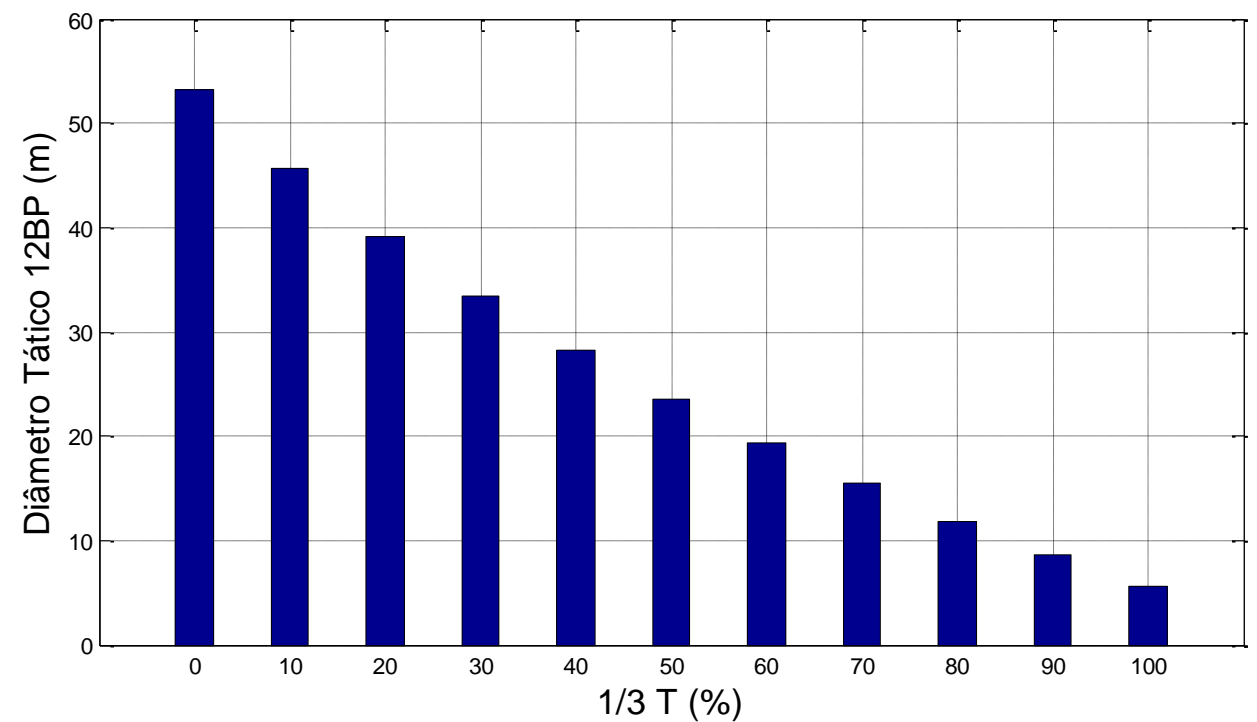

Figura 4-51 - Análise de sensibilidade do diâmetro tático para o sistema AA

O sistema $A A$, utilizando $30 \%$ de $1 / 3$ de T houve uma redução de $20 \%$ para Av e $38 \%$ para DT. Ao utilizar $60 \%$ de $1 / 3$ T houve uma redução de $36 \%$ e $62 \%$ para Av e DT, respectivamente.

Tanto para o sistema CA quanto o sistema AA há uma queda mais acentuada utilizando porcentuais mais baixos do empuxo gerado pelo equipamento auxiliar de proa. O que tornaria um porcentual viável de ser aplicado no comboio. 


\section{Considerações finais}

O trabalho apresentou a modelagem e análises de sistemas de propulsão e manobra alternativos com o objetivo de obter melhores desempenhos de manobras para embarcações fluviais.

Apreende-se dos resultados que os sistemas de propulsão alternativos localizados na proa não propiciam melhora na manobrabilidade dos comboios fluviais para manobras em velocidade de serviço. Porém para manobras em baixas velocidades, o equipamento se mostrou eficaz, aumentando a manobrabilidade do comboio de forma significativa.

Verificou-se também que o sistema de propulsão azimutal de maneira geral é superior ao sistema convencional para as simulações em águas profundas. Porém, em águas rasas, uma análise preliminar de manobras mostrou que essa vantagem pode não ser verificada, pois a eficiência do leme é aumentada neste caso. Necessitam-se maiores estudos sobre o motivo, sendo uma possível explicação o aumento da velocidade do fluxo sobre o leme.

Assim o equipamento poderia ser um propulsor azimutal retrátil ou um sistema tunnel, visto que o ganho é mais significativo com ângulo do sistema auxiliar de $90^{\circ}$. Desse modo os dois sistemas seriam utilizados apenas nas manobras em baixa velocidade, mantendo-se retraído durante a velocidade de serviço, ou desligado no caso do sistema tunnel. Também se verificou que um porcentual de $30 \%$ sobre $1 / 3$ do empuxo total da embarcação proporcionaria ganhos expressivos em manobrabilidade, sendo, também, um porcentual de empuxo viável de ser instalado na proa.

O trabalho focou principalmente nas manobras de giro e zig-zag das embarcações, utilizando modelos de derivadas hidrodinâmicas para as simulações próximas a velocidade de serviço e o modelo de cross-flow para as modelagens em baixa velocidade e inicialmente paradas. 


\section{Referências bibliográficas}

ADMINISTRAÇÃO DA HIDROVIA TIETÊ-PARANÁ - AHRANA, Hidrovia do Rio Paraná. Dados e informações gerais. São Paulo. 2010. Disponível em: <http://www.ahrana.gov.br> Acesso em: 15/02/2011

ABKOWITZ, M. Lectures on ship hydrodynamics, steering and manoeuvrability. Hydro-Og Aerodynamisk Laboratorium, Report Hy-5, Lyngby, Denmark, pp113, 1964.

BERNITSAS, M.M.; GARZA-RIOS, L.O., KIM, B.K. Mooring Design Based on Catastrophes of Slow Dynamics. Proceedingsof $8^{\text {th }}$ Offshore Station Keeping Symposium, SNAME, Houston, Texas, February 25-26, pps. 76-123.

CRANE, C. L. Maneuvering safety of large tankers: Stopping, turning and speed selection, Transactions SNAME, v.181, p.213-42, 1973.

EDA, $H$. Digital simulation analysis of maneuvering performance. Proc. $10^{\text {th }}$ ONR Symposium in Naval Hydrodynamics, Cambridge MA/USA, p.181-205, 1974.

GRASSI, A.G.F., LAVIERI, R.S., PEREIRA, A.A.P., TANNURI, E.A., CFD and Experimental Analysis of Current Forces and Maneuvering Derivatives of Pusher-Barge Systems, submitted to OMAE 2013.

HOOFT, J.P.; PIEFFERS, J.B.M. Maneuverability of frigates in waves, Marine Technology, Vol. 25, No.4., 1988.

IPT-SP, "Avaliação do desempenho de comboios com seis chatas na hidrovia Tietê-Paraná", Relatório Técnico No 74.236-205, IPT-SP, Dezembro, 2004.

IPT-SP, "Manobrabilidade de Comboios Fluviais", Relatório Técnico No 99.937205, IPT-SP, Junho, 2008.

JAKE HAULK, C. Inland Waterways as Vital National Infraestructure: Refuting "Corporate Welfare" Attacks, Allegheny Institute for Public Policy, 1998 
KAT, J.O., WICHERS, J.E.W. Behavior of a Moored Ship in Unsteady Current, Wind and Waves, Marine Technology, Setembro, pp.251-264, 1991.

KIJIMA, K.,NAKIRI,Y.,TSUSUI,Y.,MATSUNAGA,M. Prediction method of ship manoeuvrability in deep and shallow waters. MARSIM and ICSM,vol.90, Tokyo, Japan,1990.

KOBAYASHI, E., KAGEMOTO, H., FURUKAWA, Y., 1995. Research on ship manoeuvrability and its application to ship design. Chapter 2: mathematical models of manoeuvring motions. In: The 12th Marine Dynamic Symposium, pp. 23-90.

KOH, K.K., YASUKAWA, H., HIRATA, N., KOSE, K. Maneuvering simulations of pusher-barge systems. J. Mar. Sci. Technol. 13, 117-126, 2008a.

KOH, K.K., YASUKAWA, H., HIRATA, N., KOSE, K. Hydrodynamic derivatives investigation on unconventionally arranged pusher-barge systems. J. Mar. Sci. Technol. 13, 256-268, 2008b.

$\mathrm{KOH}$, K.K.; YASUKAWA, H. Comparison study of a pusher-barge system in shallow water, medium shallow water and deep water conditions, Ocean Engineering, Volume 46, Pages 9-17, ISSN 0029-8018, 10.1016/j.oceaneng.2012.03.002, 2012.

KOSE, K., YUMURO, A. AND YOSHIMURA, Y. "Concrete of Mathematical model for ship manoeuvrability", 3rd Symposium on ship manoeuvrability, SNAJ, pp.27-80, 1981. (em japonês)

LEITE, A.J.P.; ARANHA, J.A.P.; UMEDA, C.; de CONTI, M.B. Current forces in tankers and bifurcation of equilibrium of turret systems: hydrodynamic model and experiments. Applied Ocean Research, no. 20, p.145-56, 1998. 
MAIMUN, A.; PRIYANTO, A.; MUHAMMAD, A.H.; SCULLY, C.C.; AWAL, Z.I.; Manoeuvring prediction of pusher barge in deep and shallow water, Ocean Engineering, Volume 38, Issues 11-12, Pages 1291-1299, ISSN 0029-8018, 10.1016/j.oceaneng.2011.05.011, 2011.

MARIN, 2013, Minutes of Meetings - TRUST JIP, Setembro, 2013, Documento Interno.

MOBERG, S.; HELLSTRÔM, S.A. Dynamic Positioning of a four-collum semisubmersible. Model tests of interaction forces and a philosophy about optimum strategy when operating thrusters, In: Proceedings of Second Intenational Symposium on Ocean Engineering and Ship Handling, Swedish Maritime Research Centre SSPA, pp, 443-480, 1983.

MOLLAND, A.F.; TURNOCK, S.R. Marine rudders and control surfaces: principles, data, design and applications, Elsevier, 2007.

MOOLGARD A.PMM tank tests with a Model of a $258 \mathrm{~m}$ Suez-max Tanker in Loaded Condition, DMI 2002189, report No.3, 2003.

OBOKATA, J.; SASAKI, N.; NAGASHIMA, J., On the estimation of current force induced on a ship hull by some model tests. Association of Naval Arch.of Western Japan, vol.180, pp.47-57,1981. (em japonês)

OGAWA, A., KASAI, H. "On the Mathematical Model of Manoeuvring Motion of Ship”, ISP, 25, 292, pp.306-319, 1978.

PADOVEZI, C.D. Conceito de embarcações adaptadas à via aplicado a navegação fluvial no Brasil. Tese (Doutorado) - Escola Politécnica da Universidade de São Paulo. Departamento de Engenharia Naval e Oceânica. São Paulo, 2003.

PEREIRA, N. N., Um estudo sobre instalações propulsoras para empurradores fluviais. Tese (Mestrado) - Escola Politécnica da Universidade de São Paulo. Departamento de Engenharia Naval e Oceânica. São Paulo, 2007. 
SAAD, K.A.B.M. Manoeuvring control for pusher barge in inland waterway, Dissertação de Mestrado, Universidade de Tecnologia da Malásia, Faculdade de Engenharia Mecânica, 2007.

TAKASHINA, J. Ship maneuvering motion due to tugboats and its mathematical model. Journal of the Society of Naval Architects of Japan, v.160, p. 93$104,1986$.

TANNURI, E. A. ; ARACENA, J.G.N. ; MADUREIRA, R. M. L. ; OSHIRO, A.T. ; YUBA, D. G. T. . Análise comparativa da manobrabilidade de empurradores com propulsão azimutal ou convencional. In: 7 Seminário de Transporte e Desenvolvimento Hidroviário Interior SOBENA HIDROVIÁRIO 2011, 2011, Porto Alegre. Anais do 7 Seminário de Transporte e Desenvolvimento Hidroviário Interior SOBENA HIDROVIÁRIO 2011, 2011.

TANNURI, E. A. ; Mendes, M.A.P.G. ; OSHIRO, A.T. ; PADOVEZI, C.D. ; CORREA, L.R. . Dimensionamento de comboios para Hidrovia Tietê-Paraná por meio de ensaios experimentais e simulações numéricas. In: 6 Seminário de Transporte e Desenvolvimento Hidroviário Interior, 2009, Rio de Janeiro. Anais do 6온 Seminário de Transporte e Desenvolvimento Hidroviário Interior, 2009.

YASUKAWA, H., HIRATA, N., KOH, K.K., PUNAYANGKOOL, K., KOSE, K., 2007. Hydrodynamic force characteristics on maneuvering of pusher-barge systems. J. Jpn. Soc. Nav. Archit. Ocean Eng. 5, 133-142, 2007. (em japonês)

YOON, H.K.; RHEE, K.P. Identification of hydrodynamic coefficients in ship maneuvering equations of motion by Estimation-Before-Modeling technique, Ocean Engineering, Volume 30, Issue 18, Pages 2379-2404, 2003.

YOON, H.K. Phase-Averaged Stereo-PIV Flow Field and Force / Moment / Motion Measurements for Surface Combatant in PMM Maneuvers, Tese de Doutorado, The University of lowa, EUA, 2009. 